\title{
Phosphine Oxides from a Medicinal Chemist's Perspective: Physicochemical and in vitro Parameters Relevant for Drug Discovery
}

\author{
Peter Finkbeiner, ${ }^{\S, \dagger}$ Jörg P. Hehn ${ }^{\S}$ and Christian Gnamm $^{\S *}$
}

\section{Supporting Information}

\author{
Author information \\ $\S$ Boehringer Ingelheim Pharma GmbH \& Co. KG, Birkendorfer Straße 65, 88397 Biberach \\ an der Riß, Germany \\ † Syngenta Crop Protection AG, Schaffhauserstrasse, 4332 Stein, Switzerland
}

\section{Corresponding Author}

*E-Mail: christian.gnamm@boehringer-ingelheim.com. Phone: (+49)7351-98297. Fax: $(+49) 7351-545181$. 


\section{Table of Contents:}

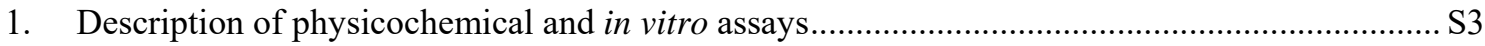

1.1. Determination of dissociation constants ( $\mathrm{pK}_{\mathrm{a}}$ values) ........................................................ $\mathrm{S} 3$

1.2. Determination of partition coefficients ( $\log \mathrm{D}$ values) ........................................................ $\mathrm{S} 4$

1.3. Determination of metabolic stability with human liver microsomes................................... S4

1.4. Determination of the drug transport across human Caco-2 cells........................................ S4

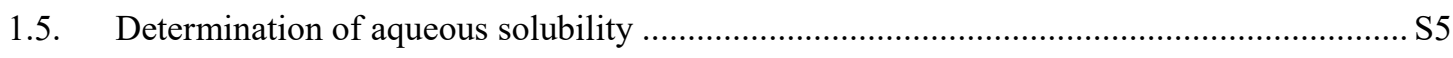

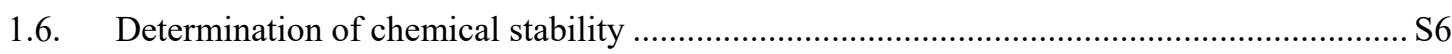

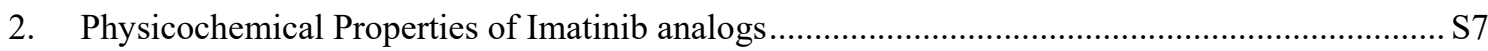

3. Biological activity of Imatinib analogs in selected kinase assays ................................................ S9

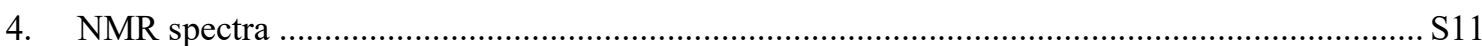




\section{Description of physicochemical and in vitro assays}

\subsection{Determination of dissociation constants $\left(\mathbf{p} \mathrm{K}_{\mathrm{a}}\right.$ values)}

Depending on the nature of the molecule, two alternative approaches are typically used to determine the pK-values of a compound. For both approaches the Sirius GLpKa and/or DPAS equipment are used. Dissociation constants could only be detected between $\mathrm{pH} 2$ and $\mathrm{pH} 12$.

\section{Potentiometric titration:}

In this approach, an automated potentiometric titration technique using the Sirius T3 system is applied. Due to the poor solubility of many compounds in pure aqueous media, the addition of an organic solvent (typically methanol, acetonitrile, DMF or DMSO) is necessary. Typically, three titration experiments are performed with a varying mixture of aqueous and organic media (typical mixtures contain approx. $20 \%, 30 \%$ and $40 \%$ of organic solvent). As the amount of organic solvent affects the measured pKvalues, only so called apparent $\mathrm{pK}_{\mathrm{a}}$-values $\left(\mathrm{p}_{\mathrm{s}} \mathrm{K}_{\mathrm{a}}\right)$ are obtained. The pure aqueous $\mathrm{pK}_{\mathrm{a}}$ can be deduced by extrapolation of the $\mathrm{p}_{\mathrm{s}} \mathrm{K}_{\mathrm{a}}$ values to zero percent organic solvent using the so-called Yasuda \& Shedlovsky extrapolation. ${ }^{1,2,3}$

\section{pH-dependent UV-profile:}

In this approach the DPAS (= Dip Probe Absorption Spectroscopy) technique is used. A fiber optics dip probe, a UV light source and a photodiode array detector (PDA) are used in conjunction with the Sirius T3 instrument to automatically capture the absorption spectra of the sample in solution in the course of a $\mathrm{pH}$-metric titration. Target factor analysis can be applied to deduce the $\mathrm{pK}_{\mathrm{a}}$ values of the sample from the pH-dependent UV-profile. Again, organic co-solvents can be used if the compound shows poor solubility in pure aqueous media. However, using an organic co-solvent makes a multiset titration with extrapolation to zero percent co-solvent mandatory in order to get the pure aqueous $\mathrm{pK}_{\mathrm{a}}$ value(s). This approach can certainly only be used if the UV-spectra are affected by the ionization behavior of the compound, thus, if the ionizable group is too far away from the UV-active chromophore, no $\mathrm{pH}-$ dependent changes can be expected in the respective UV-spectra.

\footnotetext{
${ }^{1}$ Shedlovsky, T. The behaviour of carboxylic acids in mixed solvents. In Electrolytes; Pesce, B. Ed.; Pergamon Press: New York, 1962; pp. 146-151.

2 Avdeef, A.; Box, K. J.; Comer, J. E. A.; Gilges, M.; Hadley, M.; Hibbert, C.; Patterson, W.; Tam, K. Y. PHmetric $\log \mathrm{P} 11$. pKa determination of water-insoluble drugs in organic solvent-water mixtures. J. Pharm. Biomed. Anal. 1999, 20, 631-641.

${ }^{3}$ Motoo, Y. Dissociation Constants of Some Carboxylic Acids in Mixed Aqueous Solvents. Bull. Chem. Soc. Jpn. 1959, 32, 429-432.
} 


\subsection{Determination of partition coefficients (logD values)}

\section{Determination of $\operatorname{logD}$ by HPLC at pH 2 \& pH 11}

The logarithm of the octanol-water partition coefficient at $\mathrm{pH} 2[\log \mathrm{D}(2)]$ and $\mathrm{pH} 11[\log \mathrm{D}(11)]$ is determined employing a water-acetonitrile gradient HPLC technique using a C18 column (e.g. Waters SunFire ${ }^{\mathrm{TM}} \mathrm{C}_{18}$ or Waters $\mathrm{XBridge}{ }^{\mathrm{TM}} \mathrm{C}_{18}$ ). Since the correlation between $\log \mathrm{D}$ and retention time is linear the unknown $\log \mathrm{D}$ can be determined using the $\log \mathrm{D}$ and the retention time of the two standards and the retention time of the sample.

\subsection{Determination of metabolic stability with human liver microsomes}

The metabolic degradation of the test compound is assayed at $37{ }^{\circ} \mathrm{C}$ with pooled human liver microsomes. The final incubation volume of $100 \mu \mathrm{L}$ per time point contains TRIS buffer $\mathrm{pH} 7.6(0.1 \mathrm{M})$, magnesium chloride $(5 \mathrm{mM})$, microsomal protein $(1 \mathrm{mg} / \mathrm{mL})$ and the test compound at a final concentration of $1 \mu \mathrm{M}$. Following a short preincubation period at $37^{\circ} \mathrm{C}$, the reactions are initiated by addition of beta-nicotinamide adenine dinucleotide phosphate, reduced form (NADPH, $1 \mathrm{mM}$ ) and terminated by transferring an aliquot into acetonitrile after different time points. Additionally, the $\mathrm{NADPH}$-independent degradation is monitored in incubations without NADPH, terminated at the last time point. The [\%] remaining test compound after NADPH independent incubation is reflected by the parameter c(control) (metabolic stability). The quenched incubations are pelleted by centrifugation $\left(1 \cdot 10^{4} \mathrm{~g}, 5 \mathrm{~min}\right)$. An aliquot of the supernatant is assayed by LC-MS/MS for the amount of parent compound.

The half-life $\left(t_{1 / 2}\right)$ is determined by the slope of the semilogarithmic plot of the concentration-time profile. The intrinsic clearance $\left(\mathrm{CL}_{\text {int }}\right)$ is calculated by considering the amount of protein in the incubation:

$\mathrm{CL}_{\text {int }}[\mu \mathrm{l} / \mathrm{min} / \mathrm{mg}$ protein $]=(\ln 2 /($ half-life $[\mathrm{min}] \cdot \operatorname{protein}$ content $[\mathrm{mg} / \mathrm{ml}])) \cdot 10^{3}$.

\subsection{Determination of the drug transport across human Caco-2 cells}

The assay provides information on the potential of a compound to pass the cell membrane, on the extent of oral absorption as well as on whether the compound is actively transported by uptake and/or efflux transporters. For the measurement of permeability across polarized, confluent human cancer colon carcinoma cells 2 (Caco-2), cell monolayers grown on permeable filter supports are used as the in vitro absorption model.

Apparent permeability coefficients (PE) of the compounds across the Caco-2 monolayers are measured $\left(\mathrm{pH} 7.2,37^{\circ} \mathrm{C}\right)$ in apical-to-basal (AB) (absorptive) and basal-to-apical (BA) (secretory) transport 
direction. $\mathrm{AB}$ permeability (PEAB) represents drug absorption from the intestine into the blood and $\mathrm{BA}$ permeability (PEBA) drug secretion from the blood back into the intestine by both passive permeability as well as active transport mechanisms mediated by efflux and uptake transporters that are expressed on the Caco-2 cells. The compounds are assigned to permeability/absorption classes by comparison of the $\mathrm{AB}$ permeabilities with the $\mathrm{AB}$ permeabilities of reference compounds with known in vitro permeability and oral absorption in the human. Identical or similar permeabilities in both transport directions indicate passive permeation, vectorial permeability points to additional active transport mechanisms. Higher PEBA than PEAB suggests the involvement of an apical efflux transporter (like P-gp) and/or basolateral uptake transporter; higher PEAB than PEBA permeability suggests involvement of an apical uptake transporter (like PepT1) and/or basolateral efflux transporter (like MRP3). Active transport is concentration-dependently saturable.

Caco-2 cells $\left(1-2 \cdot 10^{5}\right.$ cells $/ \mathrm{cm}^{2}$ area) are seeded on filter inserts (Costar transwell polycarbonate or PET filters, $0.4 \mu \mathrm{m}$ pore size) and cultured (DMEM) for 10-25 days.

Compounds are dissolved in appropriate solvent (like DMSO, 1-20 mM stock solutions). Stock solutions are diluted with HTP-4 buffer $\left(128.13 \mathrm{mM} \mathrm{NaCl}, 5.36 \mathrm{mM} \mathrm{KCl}, 1 \mathrm{mM} \mathrm{MgSO} 4,1.8 \mathrm{mM} \mathrm{CaCl}_{2}, 4.17\right.$ $\mathrm{mM} \mathrm{NaHCO} 3,1.19 \mathrm{mM} \mathrm{Na}_{2} \mathrm{HPO}_{4} \cdot 7 \mathrm{H}_{2} \mathrm{O}, 0.41 \mathrm{mM} \mathrm{NaH}_{2} \mathrm{PO}_{4} \cdot \mathrm{H}_{2} \mathrm{O}, 15 \mathrm{mM}$ HEPES, $20 \mathrm{mM}$ glucose, $\mathrm{pH}$ 7.2) to prepare the transport solutions (typically $10 \mu \mathrm{M}$ compound, final DMSO $<=0.5 \%$ ). The transport solution (TL) is applied to the apical or basolateral donor side for measuring A-B or B-A permeability (3 filter replicates), respectively. The receiver side contains HTP-4 buffer supplemented with $0.25 \%$ BSA. Samples are collected at the start and end of experiment from the donor and at various time intervals for up to 2 hours also from the receiver side for concentration measurement by LC-MS/MS or scintillation counting. Sampled receiver volumes are replaced with fresh receiver solution.

\subsection{Determination of aqueous solubility}

\section{Determination of aqueous solubility from DMSO stock solution (high-throughput assay)}

The aqueous solubility of the test compound is determined by comparing the amount dissolved in buffer to the amount in an acetonitrile/water (1:1) solution. Starting from a $10 \mathrm{mM}$ DMSO stock solution aliquots are diluted with acetonitrile/water (1:1) or buffer, respectively. After $24 \mathrm{~h}$ of shaking, the solutions are filtrated and analyzed by LC-UV. The amount dissolved in buffer is compared to the amount in the acetonitrile solution. Solubility will usually be measured from 0.001 to $0.125 \mathrm{mg} / \mathrm{mL}$ at a DMSO concentration of $2.5 \%$. If more than $90 \%$ of the compound is dissolved in buffer, the value is marked with ">". 


\section{Determination of equilibrium thermodynamic aqueous solubility from solid material (shake flask solubility)}

This method describes the general procedure for the determination of equilibrium solubility in aqueous media.

Saturated solutions are prepared by addition of a defined volume of $\mathrm{pH} 6.8$ buffer solution $(0.1 \mathrm{M}$; $1.00 \mathrm{~mL})$ to a known quantity of solid drug substance $(0.5-30.0 \mathrm{mg})$. The resulting mixtures are shaken for a predefined period of time (typically $24 \mathrm{~h}$ ) and then filtered using appropriate filter membranes (typically PTFE-filters with $0.45 \mu \mathrm{m}$ pore size). Filter absorption is avoided by discarding the first few drops of filtrate. The amount of dissolved drug substance is determined by UV spectroscopy. In addition, the $\mathrm{pH}$ of the aqueous saturated solution is measured using a glass-electrode $\mathrm{pH}$ meter.

\subsection{Determination of chemical stability}

This method describes the chemical stability assessment of test compounds in neutral, acidic or basic methanolic media.

Defined aliquots of test compound solution $(1 \mathrm{mg} / \mathrm{mL}$ in $\mathrm{MeOH} ; 300 \mu \mathrm{L})$ are mixed with $20 \mu \mathrm{L}$ of water [solution A], concentrated aqueous $\mathrm{HCl}(37 \%)$ [solution B] or concentrated aqueous $\mathrm{NH}_{4} \mathrm{OH}(25 \%)$ [solution $\mathrm{C}$ ], and the corresponding solutions are stored at room temperature for 7 days. The stability of the test compound in the corresponding media is determined as follows:

Aliquots of solution A/B/C $(100 \mu \mathrm{l})$ are taken after defined periods of time and mixed with a solution of 1-ethyl-2-phenylindole $(16.7 \mathrm{mM}$ in $\mathrm{MeOH} ; 600 \mu \mathrm{L})$ as an internal standard. The resulting samples are analyzed by RP-HPLC with UV-detection $(\lambda=305 \mathrm{~nm})$. The stability of the test compound is estimated in comparison to the internal standard signal.

Solution A is analyzed immediately after preparation and after 7 days whereas solution $\mathrm{B}$ and $\mathrm{C}$ are analyzed after 1 day and 7 days. 


\section{Physicochemical Properties of Imatinib analogs}

While imatinib (36) and the P-containing analogs 43-45 where tested as free base or free acid, the analogs 37-42 where employed as their TFA salts as obtained after purification by preparative reversedphase HPLC. This salt form differences however do not affect the data obtained in assays starting from DMSO stock solutions using buffered conditions, such as the assay for $\log \mathrm{D}$, stability in human liver microsomes or Caco-2 permeability. For solubility it does affect data from the shake-flask assay, but not data from the HPLC-based high-throughput assay. In the shake flask assay, imatinib as free base (36) showed poor solubility of only $2 \mu \mathrm{g} / \mathrm{mL}$, however, this strong discrepancy in comparison to the HPLC assay is likely due to the high crystallinity of the material used.

Table S1: Physicochemical and in vitro parameters of different salt forms of imatinib (36) and imatinib analogs 37-45.

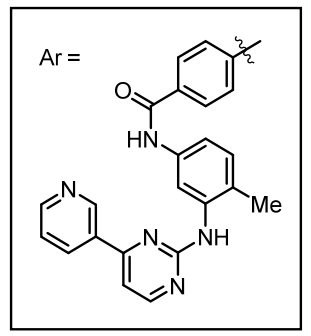

\begin{tabular}{|c|c|c|c|c|c|c|c|c|c|}
\hline \multirow{2}{*}{ Compound } & \multirow{2}{*}{ Structure } & \multicolumn{2}{|c|}{$\begin{array}{c}\log D \\
(H P L C \text { assay) }\end{array}$} & \multicolumn{2}{|c|}{$\begin{array}{c}\text { Stability in human } \\
\text { liver microsomes }\end{array}$} & \multicolumn{2}{|c|}{$\begin{array}{c}\text { Aqueous solubility } \\
\text { (pH 6.8) }[\mu \mathrm{g} / \mathrm{mL}]\end{array}$} & \multicolumn{2}{|c|}{$\begin{array}{c}\text { Caco-2 } \\
\text { permeability }\end{array}$} \\
\hline & & pH 2 & pH 11 & $T_{1 / 2}[\mathrm{~min}]$ & $\% Q_{H}$ & $\begin{array}{r}\text { HPLC } \\
\text { assay }\end{array}$ & $\begin{array}{c}\text { Shake flask } \\
\text { assay }\end{array}$ & $\begin{array}{c}P_{A \rightarrow B} \\
{\left[10^{-6} \mathrm{~cm} / \mathrm{s}\right]}\end{array}$ & $\begin{array}{c}\text { Efflux } \\
\text { ratio }\end{array}$ \\
\hline $36 \cdot \mathrm{Ms}$ & & -0.1 & 2.7 & 26 & 59 & 103 & 400 & 19.0 & 1.8 \\
\hline $36 \cdot \mathrm{Cl}$ & & -0.1 & 2.3 & 30 & 57 & 65 & n.d. & 19.9 & 1.5 \\
\hline 36 & & -0.1 & 2.4 & 38 & 50 & $>122$ & 2 & 15 & 1.9 \\
\hline 37a $\cdot$ TFA & & 0.8 & -0.1 & $>130$ & $<23$ & $>135$ & n.v. & 0.1 & 54.0 \\
\hline 37b $\cdot$ TFA & & 1.0 & 3.5 & $<5$ & $>88$ & $<1$ & n.d. & n.v. & - \\
\hline $38 \mathrm{a} \cdot \mathrm{TFA}$ & & 0.4 & 1.5 & 117 & 25 & $<1$ & n.d. & 3 & 8.1 \\
\hline 38b $\cdot$ TFA & & 0.5 & 1.7 & $>130$ & $<23$ & $<1$ & n.d. & 8 & 4.9 \\
\hline $38 \mathrm{c} \cdot$ TFA & & 0.7 & 2.0 & 67 & 37 & $<1$ & n.d. & 19 & 2.2 \\
\hline
\end{tabular}




\begin{tabular}{|c|c|c|c|c|c|c|c|c|c|}
\hline \multirow{2}{*}{ Compound } & \multirow{2}{*}{ Structure } & \multicolumn{2}{|c|}{$\begin{array}{c}\log D \\
(H P L C \text { assay) }\end{array}$} & \multicolumn{2}{|c|}{$\begin{array}{c}\text { Stability in human } \\
\text { liver microsomes }\end{array}$} & \multicolumn{2}{|c|}{$\begin{array}{c}\text { Aqueous solubility } \\
\text { (pH 6.8) [mg/mL] }\end{array}$} & \multicolumn{2}{|c|}{$\begin{array}{c}\text { Caco-2 } \\
\text { permeability }\end{array}$} \\
\hline & & pH 2 & pH 11 & $T_{1 / 2}[\min ]$ & $\% Q_{H}$ & $\begin{array}{l}\text { HPLC } \\
\text { assay }\end{array}$ & $\begin{array}{c}\text { Shake flask } \\
\text { assay }\end{array}$ & $\begin{array}{c}P_{A \rightarrow B} \\
{\left[10^{-6} \mathrm{~cm} / \mathrm{s}\right]}\end{array}$ & $\begin{array}{c}\text { Efflux } \\
\text { ratio }\end{array}$ \\
\hline $39 \cdot$ TFA & & 0.4 & 1.7 & 97 & 29 & $<1$ & n.d. & 7 & 5.3 \\
\hline $40 \cdot$ TFA & & 0.8 & 2.2 & 78 & 33 & $<1$ & n.d. & 18 & 1.1 \\
\hline $41 a$ & & 0.2 & 1.5 & $>130$ & $<23$ & 1 & n.d. & $<5$ & - \\
\hline $41 b$ & & 0.2 & 1.8 & 26 & 60 & $<1$ & n.d. & 17 & 2.4 \\
\hline $42 a \cdot$ TFA & $\mathrm{Ar}^{\text {ONs }}$ & 0.5 & 1.3 & 46 & 46 & $<1$ & n.d. & $<2$ & - \\
\hline $42 \mathrm{~b} \cdot$ TFA & $\mathrm{Ar}^{\mathrm{O}-\mathrm{S}}$ & 0.9 & 2.2 & 6 & 87 & $<1$ & n.d. & 7 & 4.9 \\
\hline $42 c$ & & 1.4 & 2.8 & $<5$ & $>89$ & $<1$ & n.d. & 42 & 0.5 \\
\hline $43 \cdot$ TFA & & 0.3 & 1.4 & $>130$ & $<23$ & 50 & 2,200 & $<0.4$ & - \\
\hline 43 & & 0.4 & 1.5 & $>130$ & $<23$ & 77 & 20 & 0.1 & 16 \\
\hline $44 a \cdot$ TFA & $\begin{array}{c}\text { O } \\
\text { An-P-Me } \\
\text { Ar- } \\
\text { OEt }\end{array}$ & 0.9 & 2.2 & 48 & 45 & 51 & n.v. & 5 & 9.9 \\
\hline 44b $\cdot$ TFA & & 0.3 & -0.2 & $>130$ & $<23$ & $>123$ & $>10,000$ & 3 & 1.3 \\
\hline $44 b$ & & 0.6 & -0.6 & $>130$ & $<23$ & $>115$ & $>10,000$ & $<0.1$ & - \\
\hline $45 a \cdot$ TFA & & 1.5 & 2.8 & 23 & 63 & $<1$ & $<1$ & 13 & 2.3 \\
\hline $45 a$ & & 1.5 & 2.8 & 17 & 70 & 1 & n.d. & 18 & 1.6 \\
\hline $45 b \cdot$ TFA & & 0.7 & 0.0 & $>130$ & $<23$ & 92 & 8,500 & $<0.1$ & - \\
\hline $45 b$ & & 1.0 & -0.6 & $>130$ & $<23$ & $>122$ & 1,100 & $<0.1$ & - \\
\hline $45 c$ & 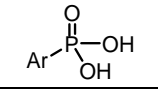 & 0.44 & -1.0 & $>130$ & $<23$ & $>115$ & 700 & $<0.3$ & - \\
\hline
\end{tabular}

a Ms: methanesulfonate salt; $\mathrm{Cl}$ : hydrochloride salt; TFA: trifluoracetate salt; N.d.: not determined; n.v.: no valid data; color-coding: green: desirable, yellow: acceptable, red: undesirable. 


\section{Biological activity of Imatinib analogs in selected kinase assays}

Table S2: Biological activity of imatinib analogs in selected kinase assays.

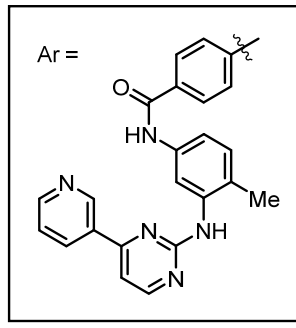

\begin{tabular}{|c|c|c|c|c|c|}
\hline Compound & Structure & $\begin{array}{c}\text { PDGFRß } \\
\text { IC }_{50}[\mu \mathrm{M}]^{\mathrm{a}}\end{array}$ & $\begin{array}{c}\text { ABL1 } \\
\mathrm{IC}_{50}[\mu \mathrm{M}]^{\mathrm{a}}\end{array}$ & $\begin{array}{c}\text { LCK } \\
\text { IC }_{50}[\mu \mathrm{M}]^{\mathrm{a}}\end{array}$ & $\begin{array}{c}\text { KIT } \\
\text { IC }_{50}[\mu \mathrm{M}]^{\mathrm{a}}\end{array}$ \\
\hline 36 & & 0.37 & 0.09 & 0.09 & 1.5 \\
\hline $37 a$ & & $>1$ & $>1$ & $>1$ & $>1$ \\
\hline $37 b$ & & $>1$ & 0.24 & $>1$ & $>1$ \\
\hline $38 \mathrm{a}$ & & $>1$ & $>1$ & $>1$ & $>1$ \\
\hline $38 \mathrm{~b}$ & & $>1$ & $>1$ & $>1$ & $>1$ \\
\hline $38 \mathrm{c}$ & & $>1$ & $>1$ & $>1$ & $>1$ \\
\hline 39 & & $>1$ & $>1$ & $>1$ & $>1$ \\
\hline 40 & & $>1$ & $>1$ & $>1$ & $>1$ \\
\hline $41 a$ & & 0.99 & $>1$ & $>1$ & $>1$ \\
\hline $41 b$ & & $>1$ & $>1$ & $>1$ & $>1$ \\
\hline $42 a$ & & 0.88 & $>1$ & $>1$ & $>1$ \\
\hline $42 b$ & & 1.0 & 0.35 & $>1$ & $>1$ \\
\hline $42 c$ & & $>1$ & $>1$ & $>1$ & $>1$ \\
\hline 43 & & $>1$ & $>1$ & $>1$ & $>1$ \\
\hline $44 a$ & & $>1$ & $>1$ & $>1$ & $>1$ \\
\hline
\end{tabular}




\begin{tabular}{|c|c|c|c|c|c|}
\hline 44b & $\mathrm{Ar}^{-} \stackrel{\stackrel{\mathrm{N}}{\|}-\mathrm{Me}}{\mathrm{OH}}$ & $>1$ & $>1$ & $>1$ & $>1$ \\
\hline $45 a$ & 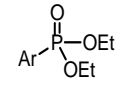 & $>1$ & $>1$ & $>1$ & $>1$ \\
\hline $45 b$ & $\mathrm{Ar}^{-} \stackrel{\substack{\mathrm{O} \\
\mathrm{P}}}{\mathrm{OH}}$ & $>1$ & $>1$ & $>1$ & $>1$ \\
\hline $45 c$ & $\mathrm{Ar}^{-} \stackrel{\substack{\mathrm{O} \\
\mathrm{P}}}{\mathrm{OH}}$ & $>1$ & $>1$ & $>1$ & $>1$ \\
\hline
\end{tabular}

a Determined by SelectScreen Kinase Profiling Service from ThermoFisher. 


\section{NMR spectra}

Dimethyl(4-(trifluormethyl)phenyl)phosphine oxide (21a)

${ }^{1} \mathrm{H}-\mathrm{NMR}$<smiles>CS(=O)(=O)c1ccc(C(F)(F)F)cc1</smiles>

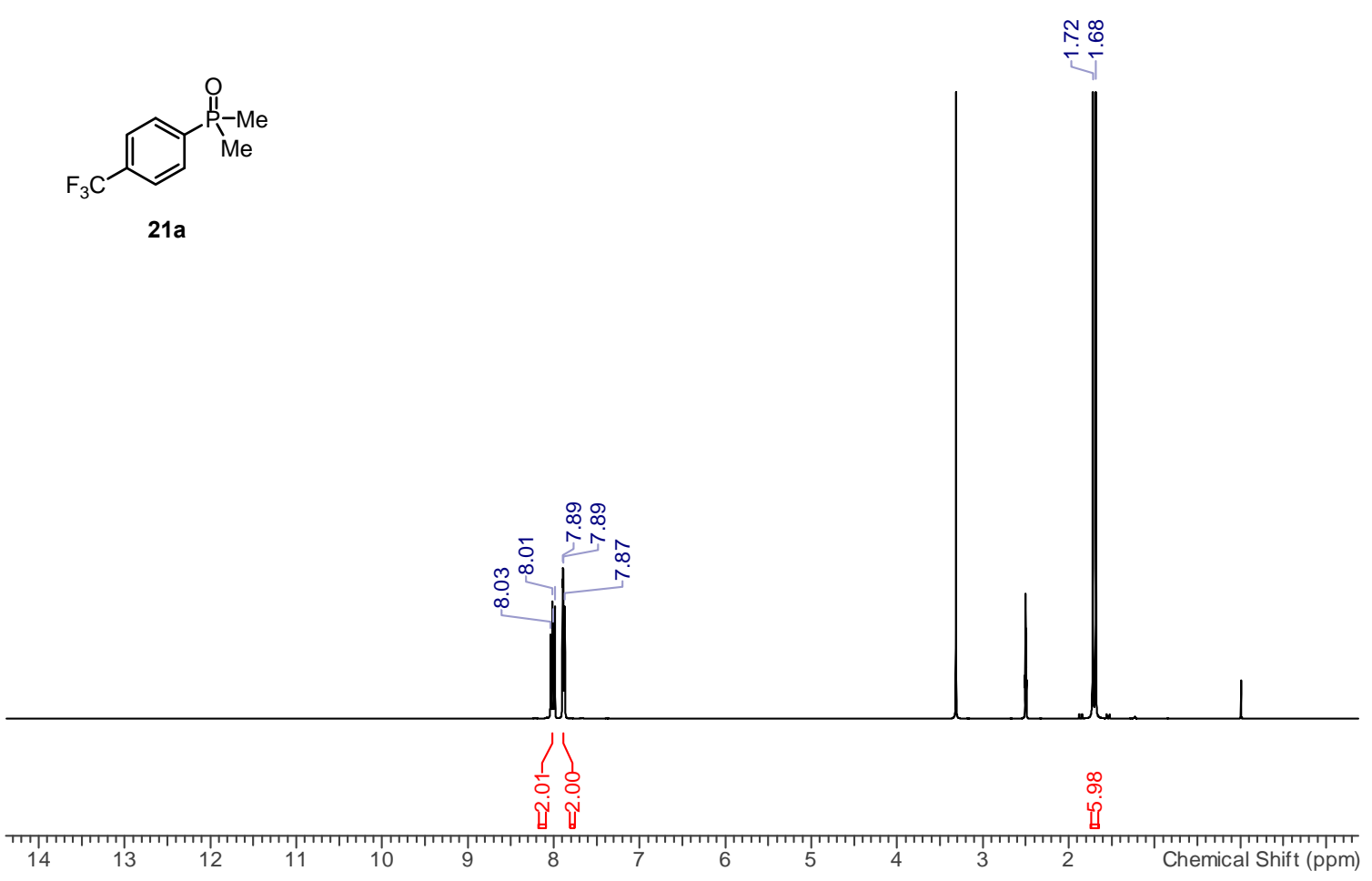

${ }^{13} \mathrm{C}-\mathrm{NMR}$
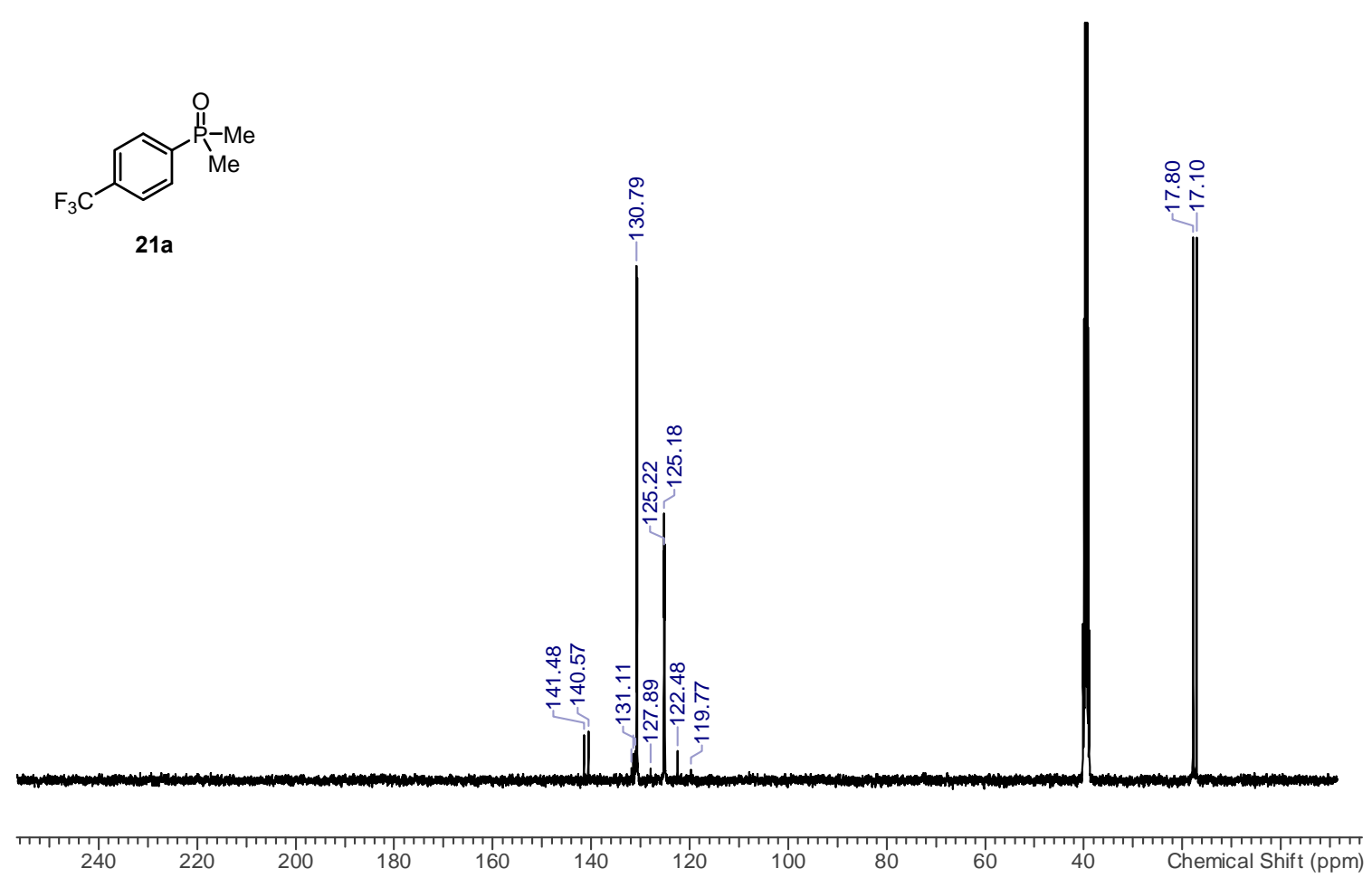
${ }^{19}$ F-NMR

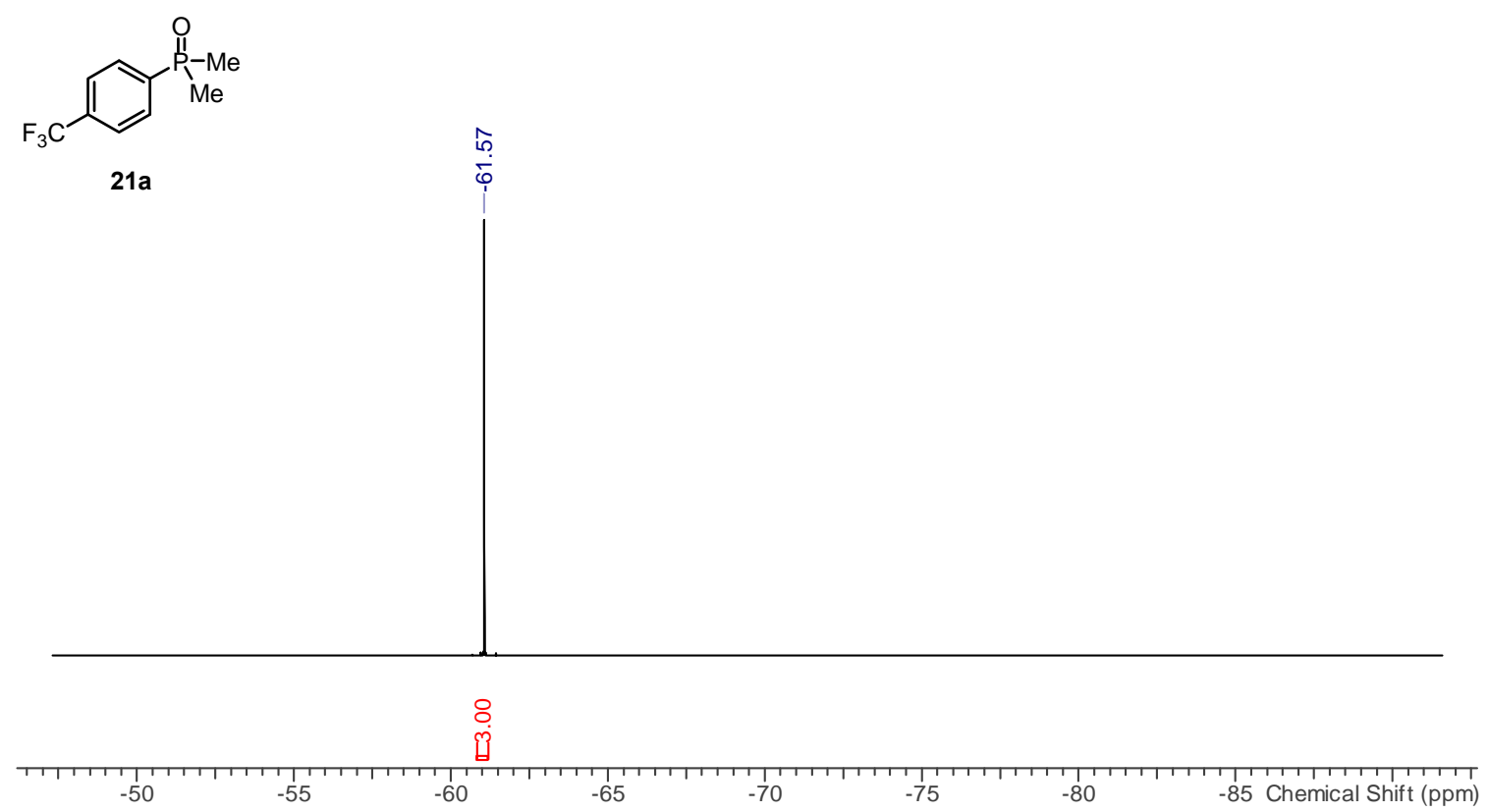

${ }^{31}$ P-NMR

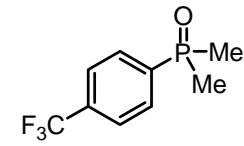

21a

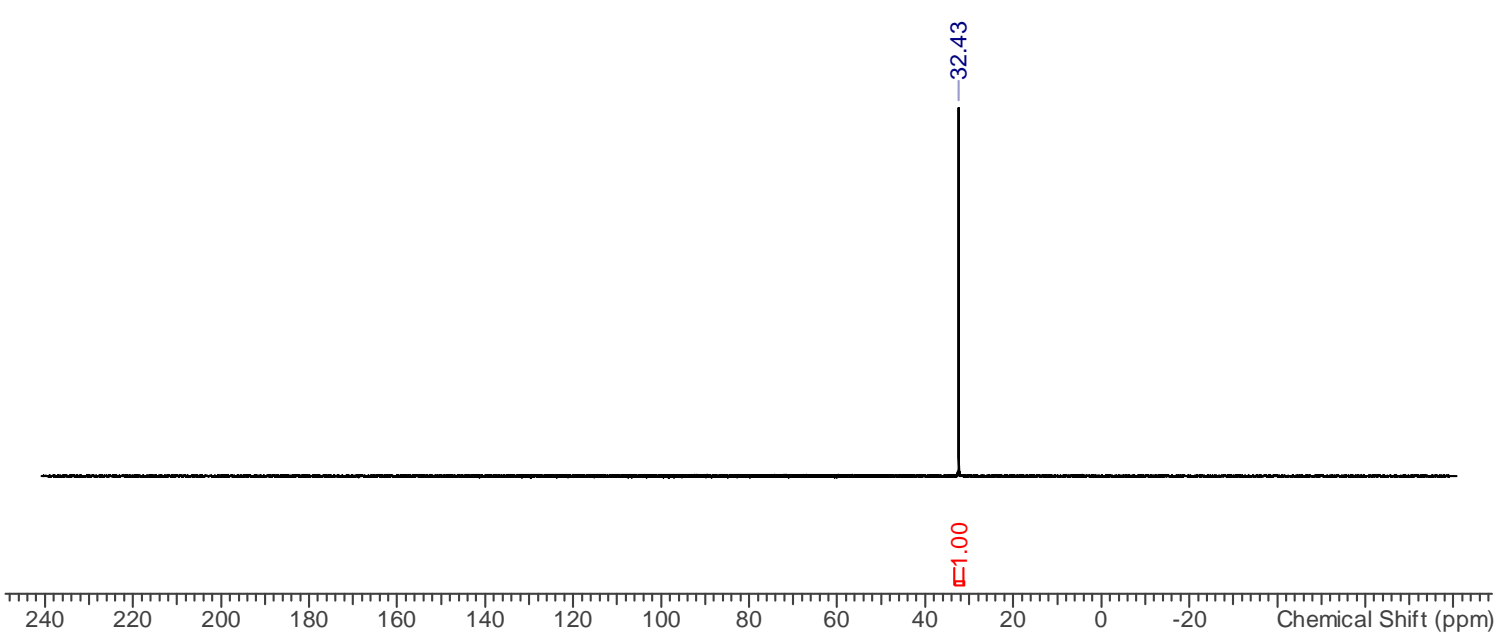




\section{Diethyl(4-(trifluormethyl)phenyl)phosphine oxide (21b)}

${ }^{1} \mathrm{H}-\mathrm{NMR}$<smiles>CCP(=O)(c1ccccc1)c1ccc(F)cc1</smiles>

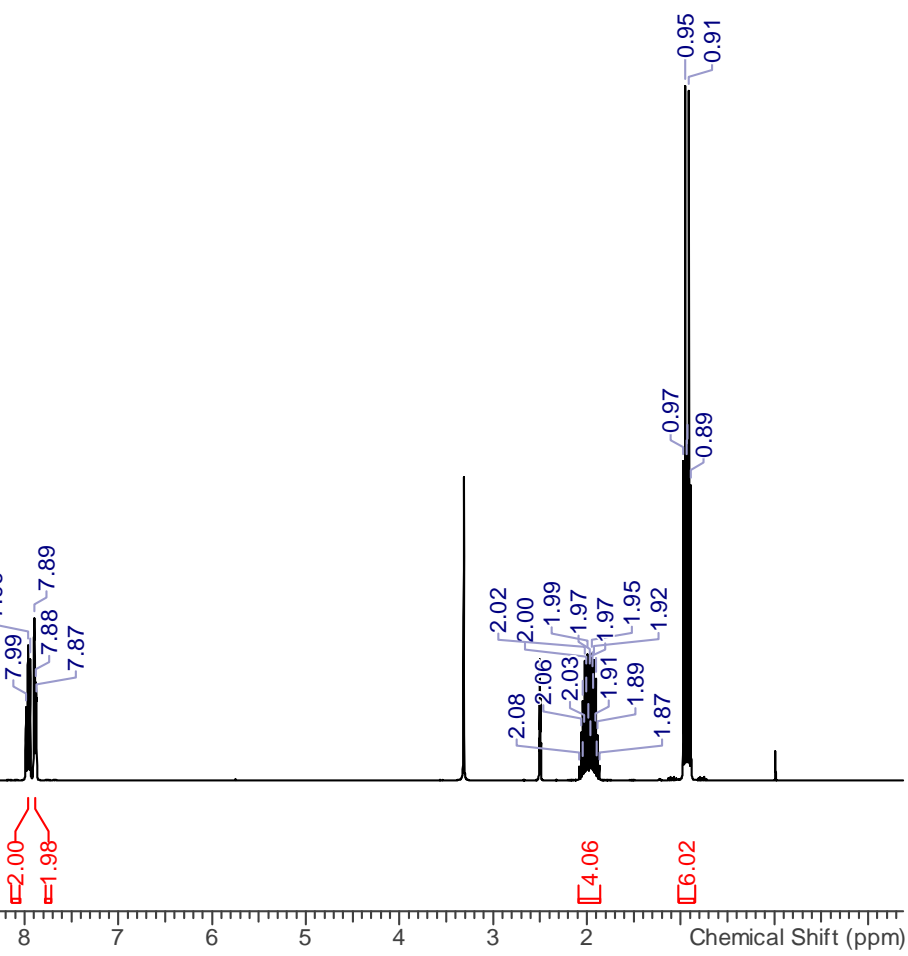

${ }^{13} \mathrm{C}-\mathrm{NMR}$<smiles>CCP(=O)(c1ccccc1)c1ccc(C(F)(F)F)cc1</smiles>

21b
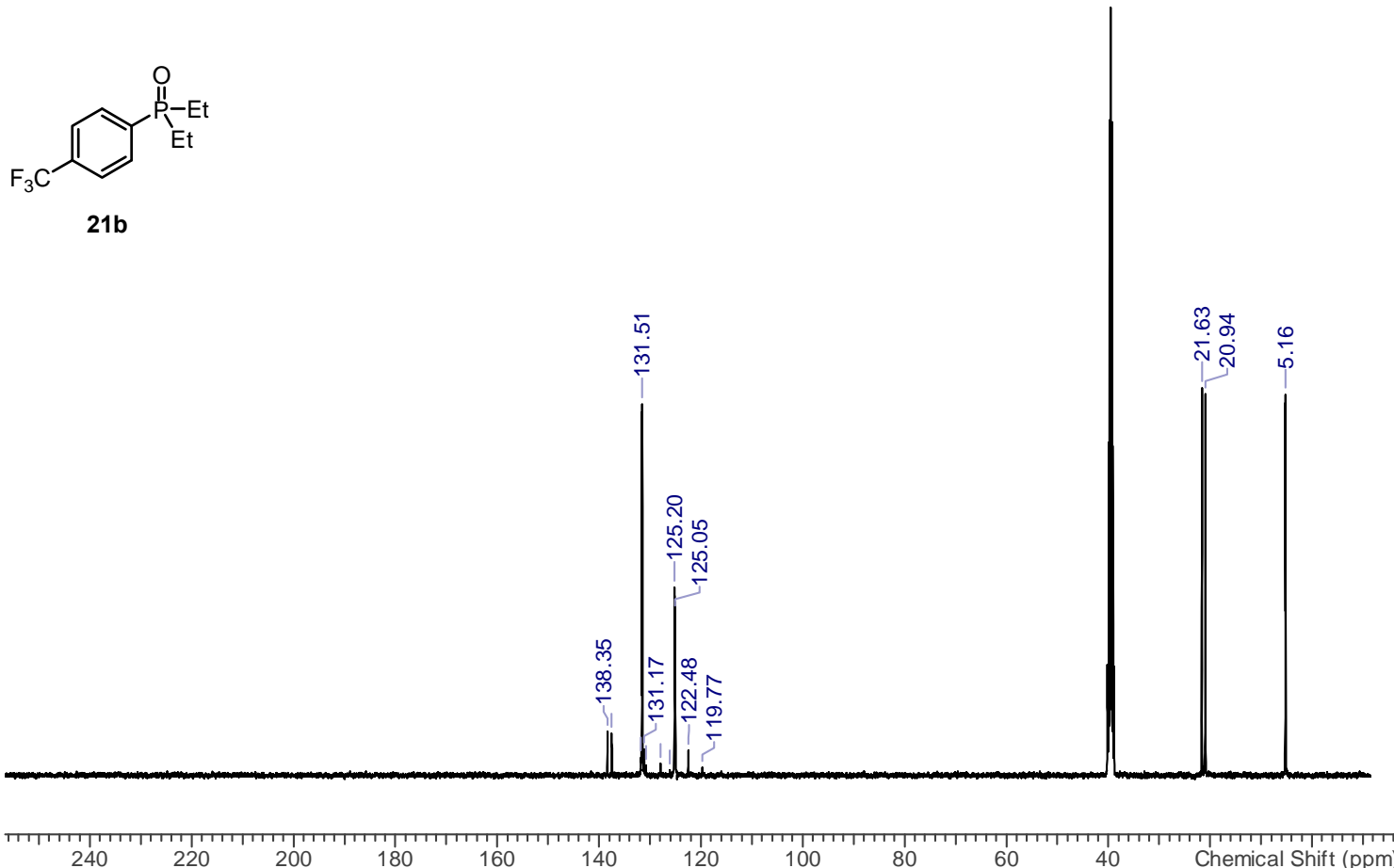


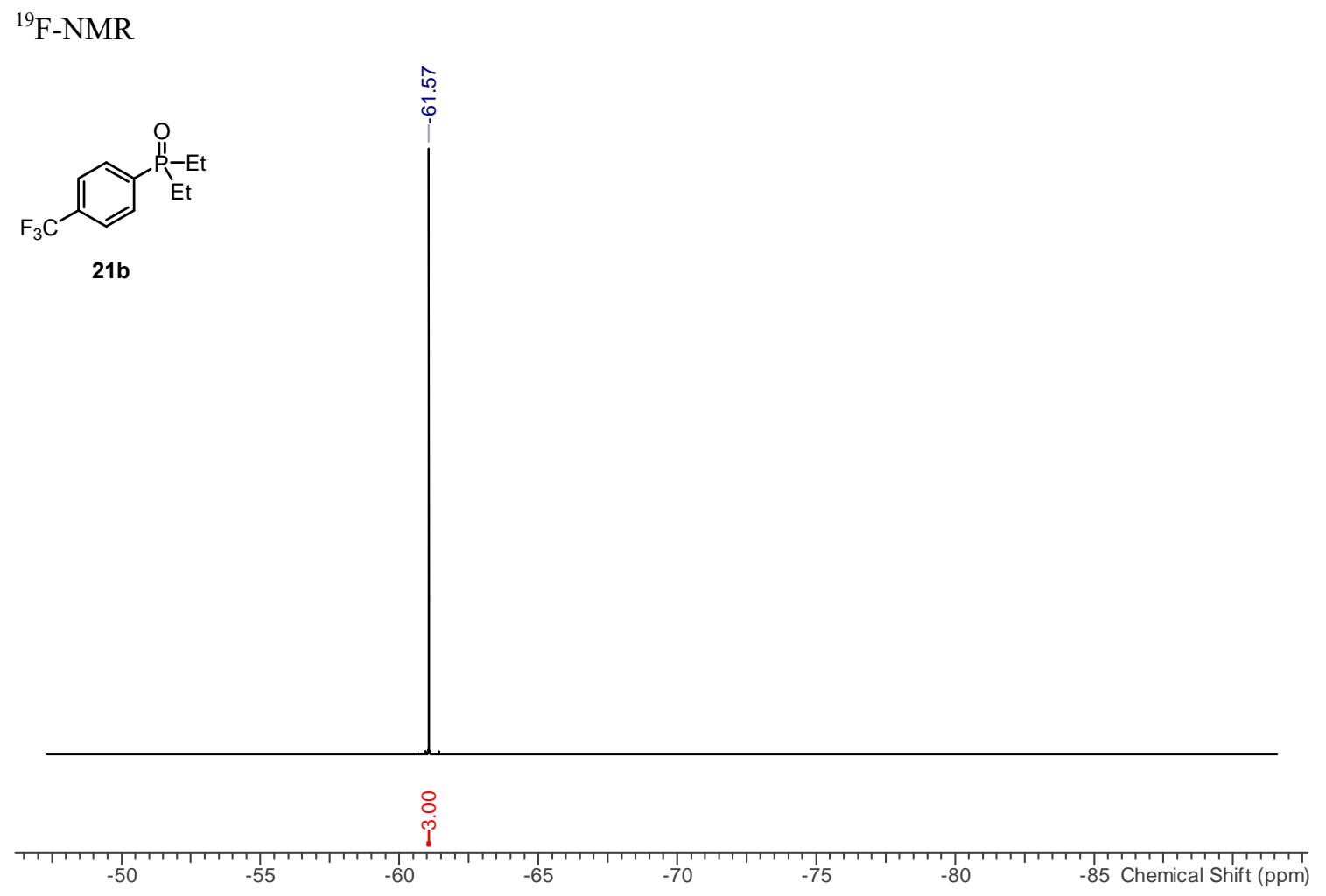

${ }^{31} \mathrm{P}-\mathrm{NMR}$

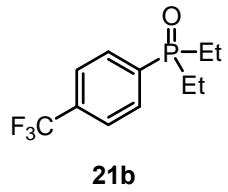

ํํำ

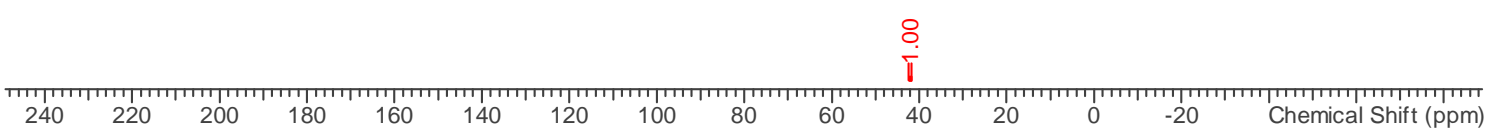


Diisopropyl(4-(trifluormethyl)phenyl)phosphine oxide (21c)

${ }^{1} \mathrm{H}-\mathrm{NMR}$<smiles>CCCP(=O)(CC(C)C)c1ccc(C(F)(F)F)cc1</smiles>

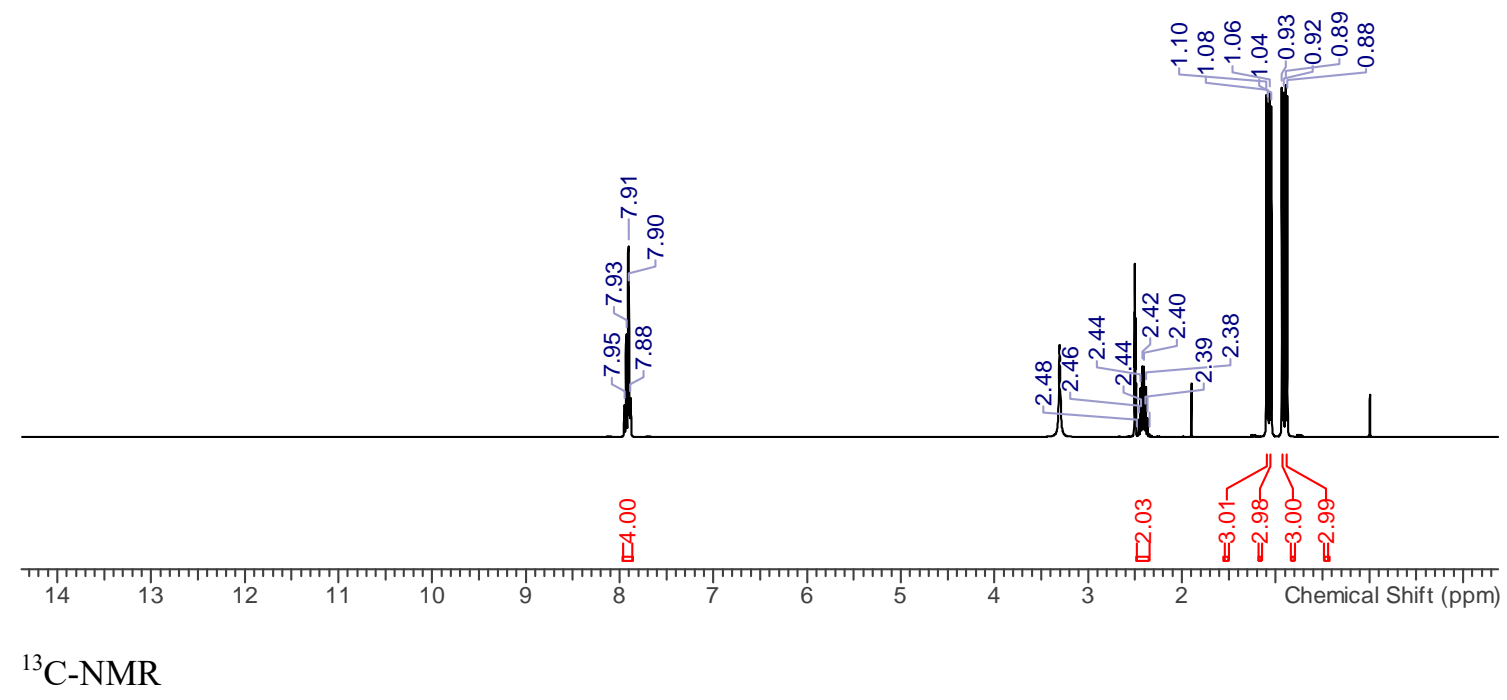<smiles>CC(C)CP(=O)(c1ccc(C(F)(F)F)cc1)C(C)C</smiles>

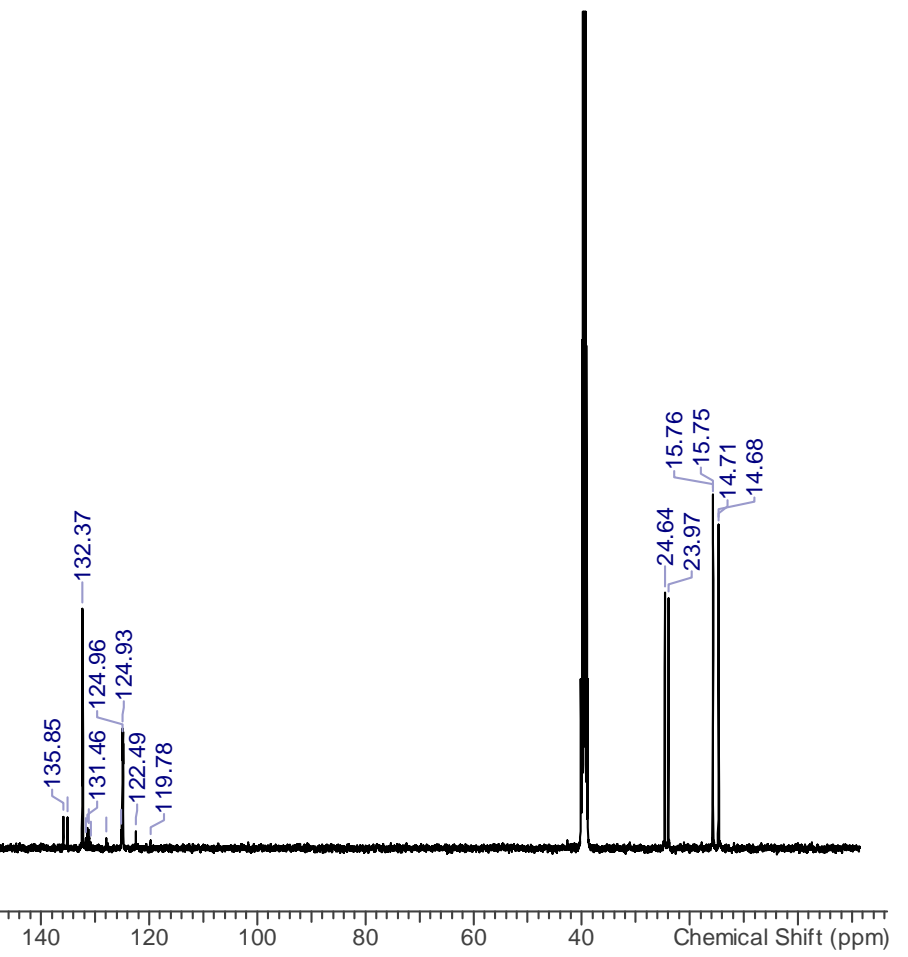


${ }^{19}$ F-NMR

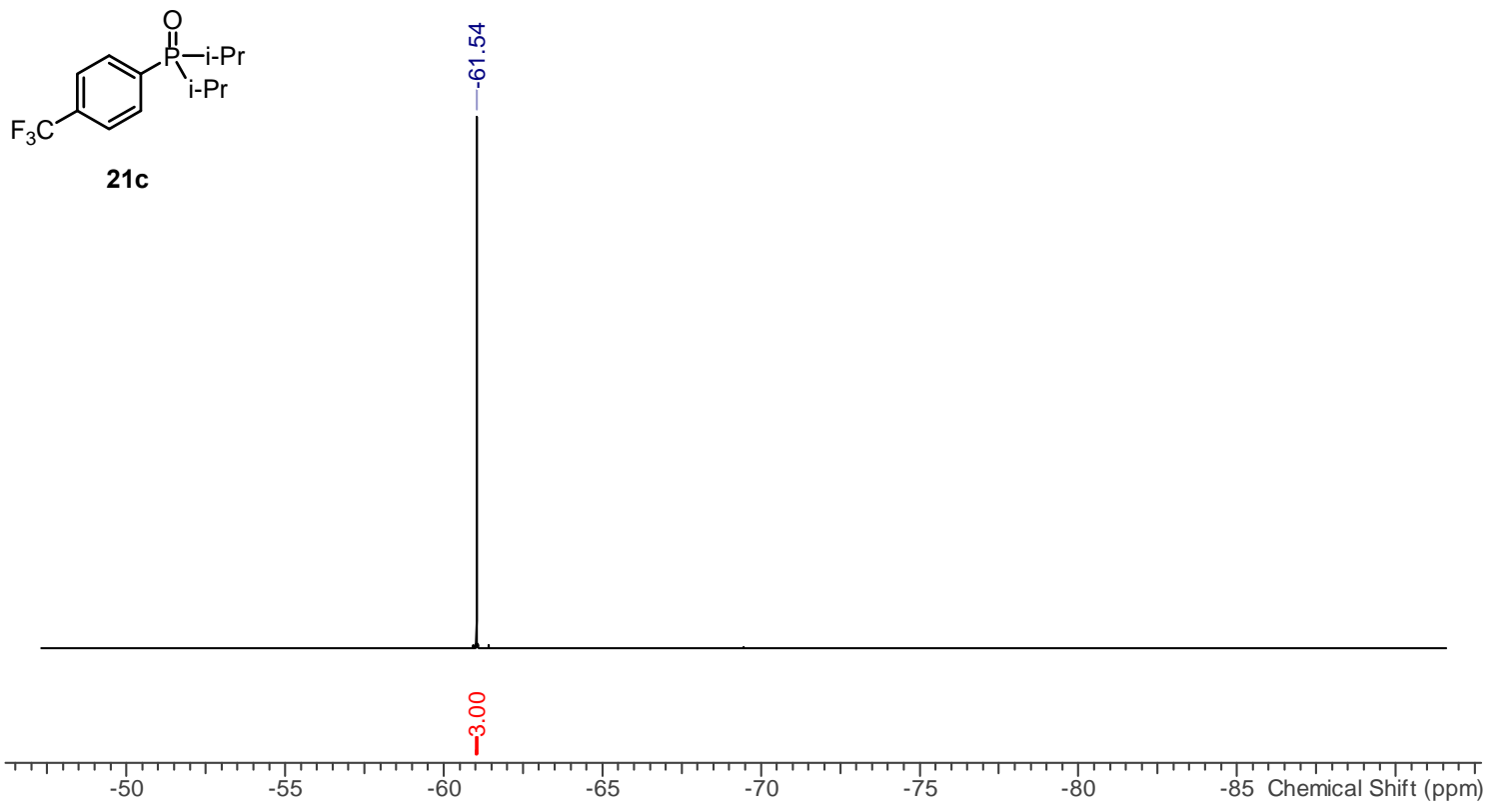

${ }^{31} \mathrm{P}-\mathrm{NMR}$

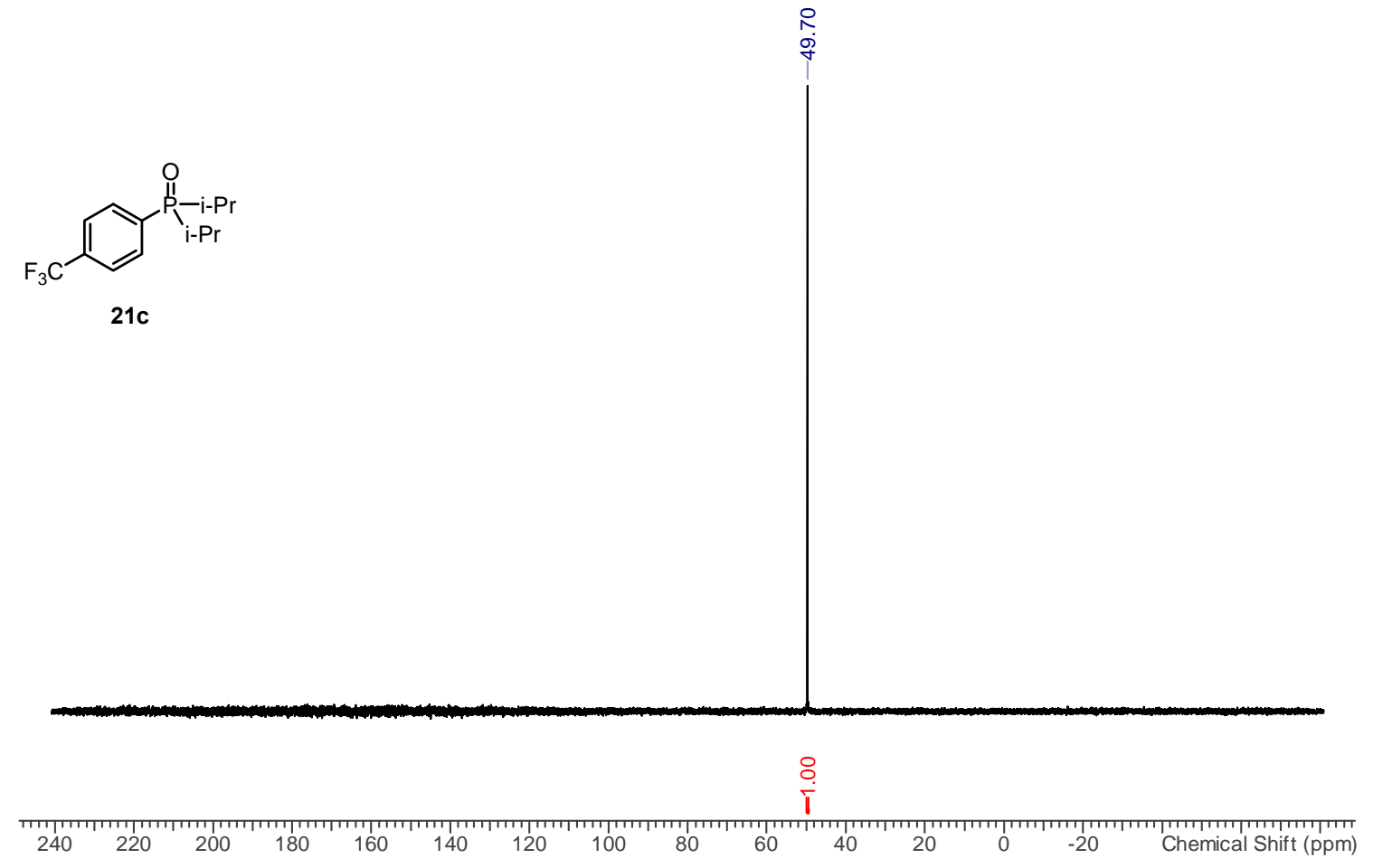

กิ 
1-[4-(Trifluoromethyl)phenyl]-1 $\lambda^{5}$-phosphetan-1-one (22a)

${ }^{1} \mathrm{H}-\mathrm{NMR}$
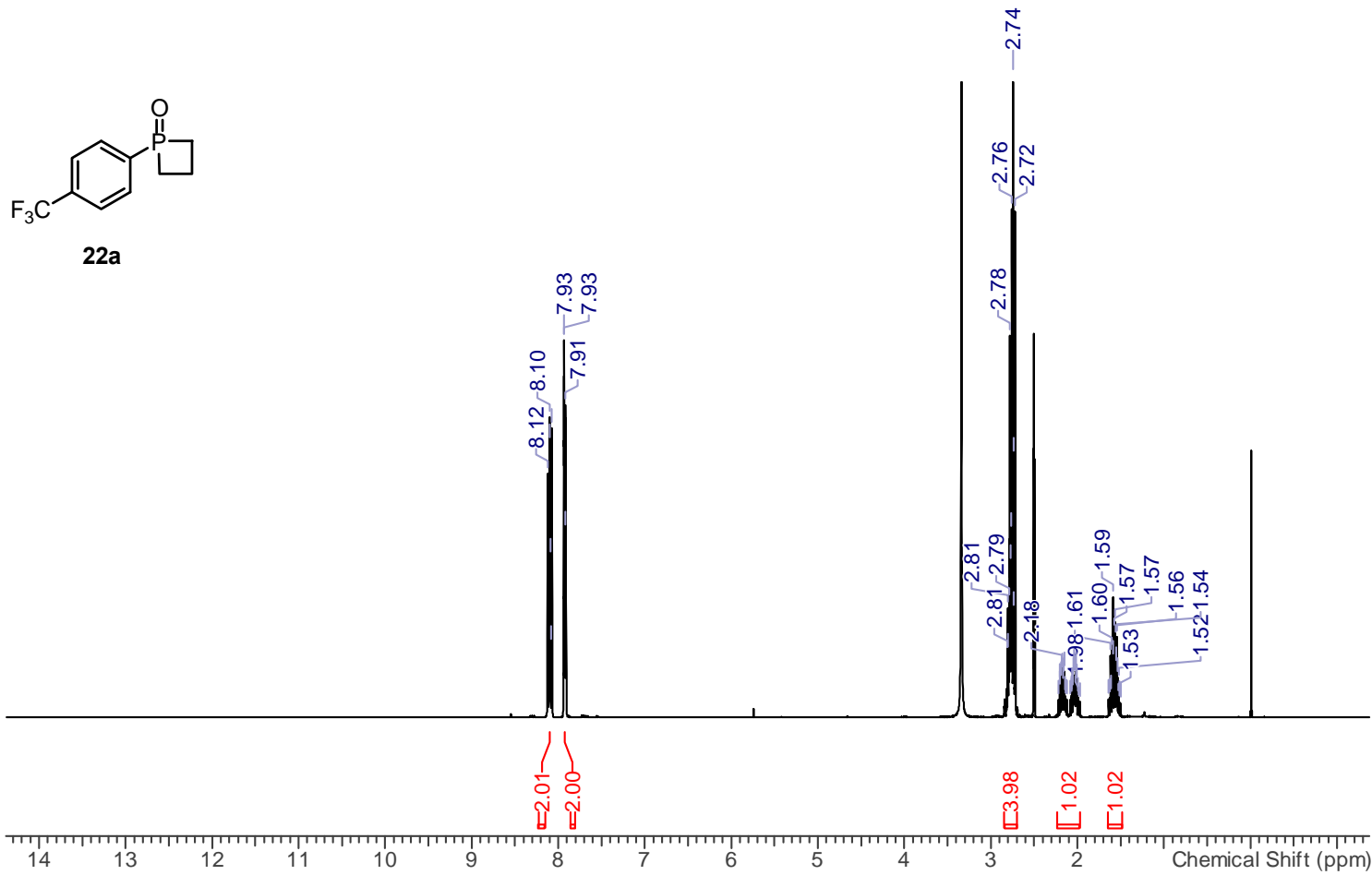

${ }^{13} \mathrm{C}-\mathrm{NMR}$

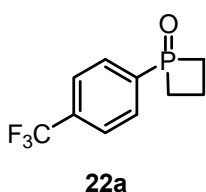

$$
\text { กฺฺุ }
$$$$
\text { | }
$$
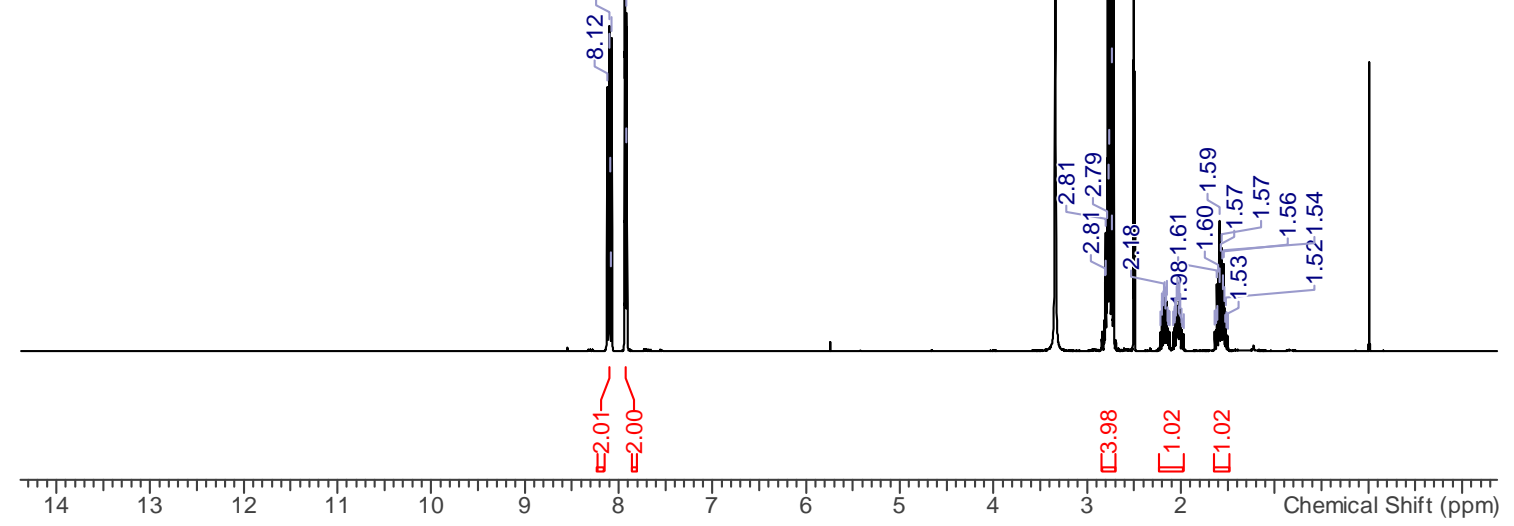

$22 a$

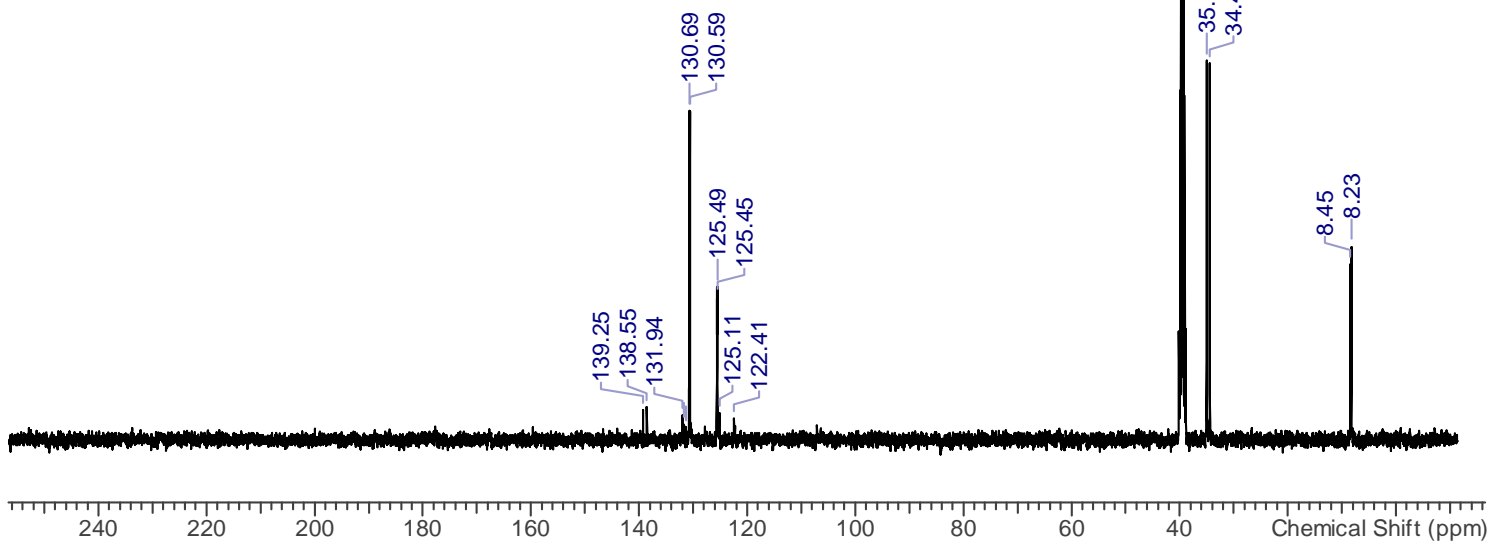



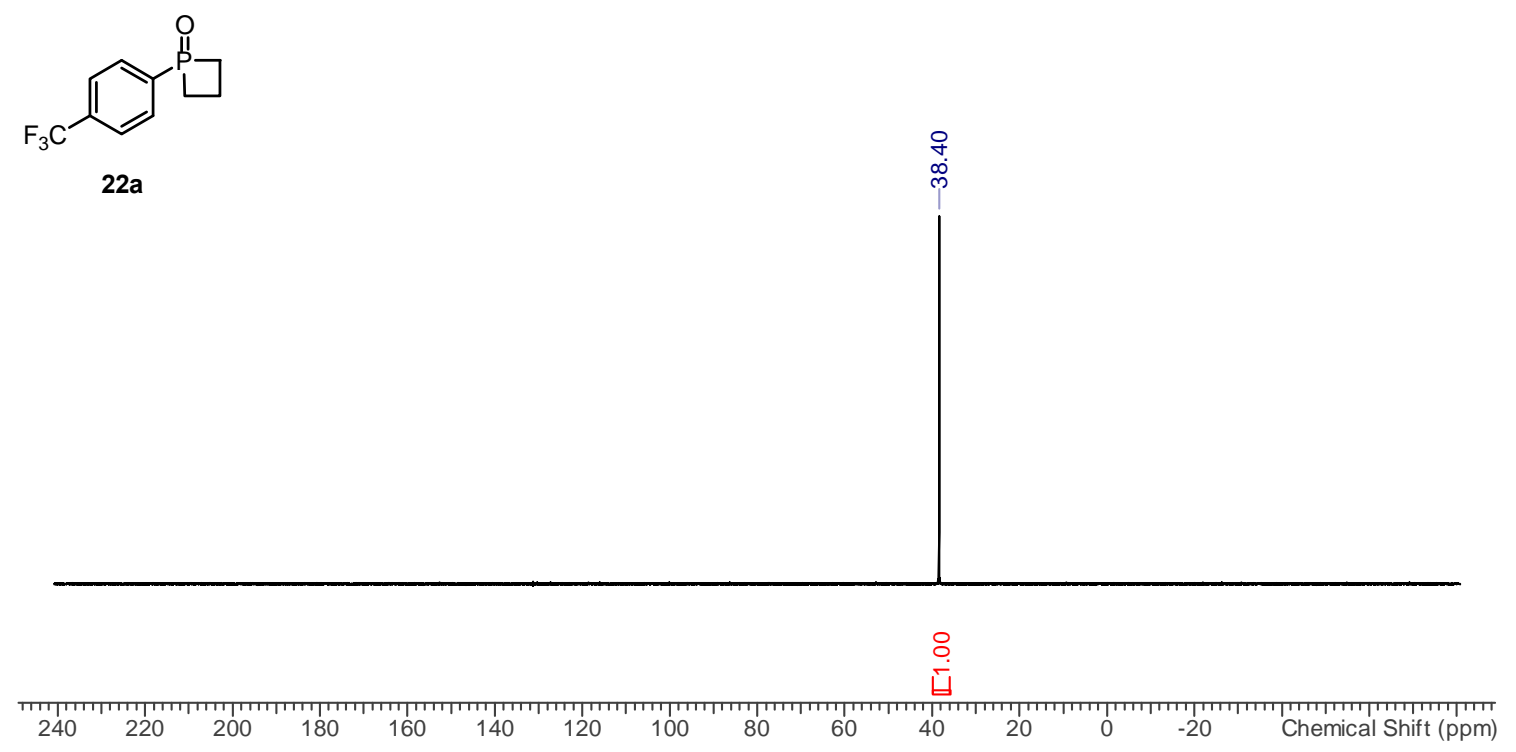

\section{1-[4-(Trifluoromethyl)phenyl]-1 $\lambda^{5}$-phospholan-1-one (22b)}

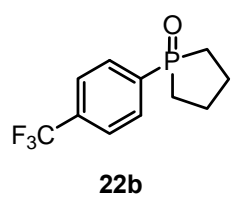

22b

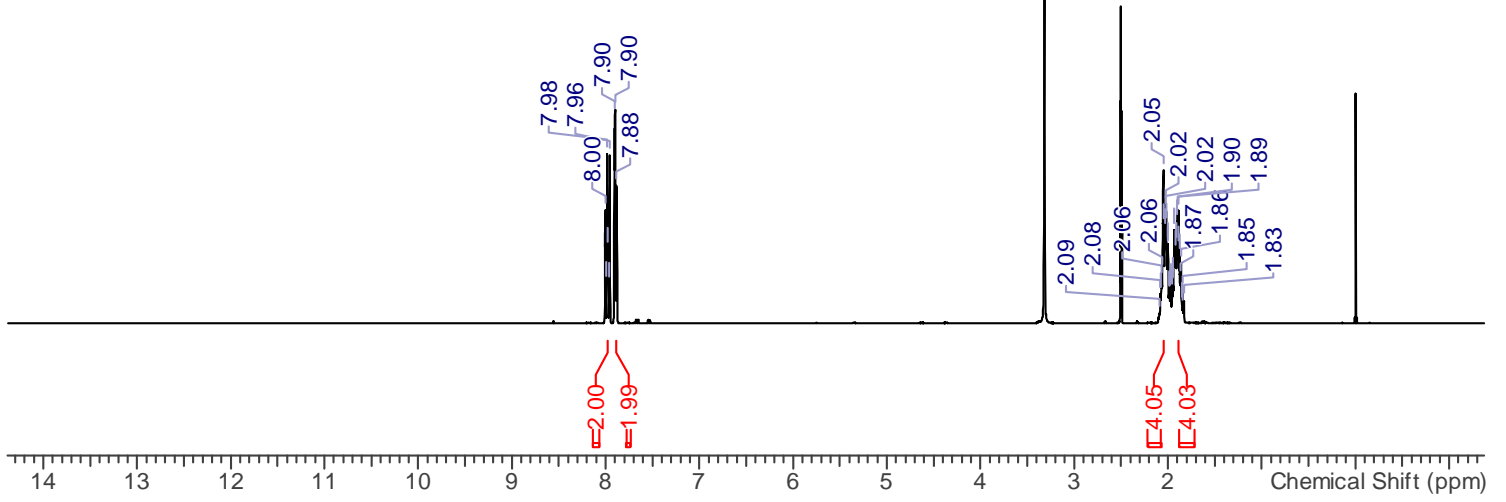


${ }^{13} \mathrm{C}-\mathrm{NMR}$<smiles>O=P1(c2ccc(C(F)(F)F)cc2)CCCC1</smiles>

22b
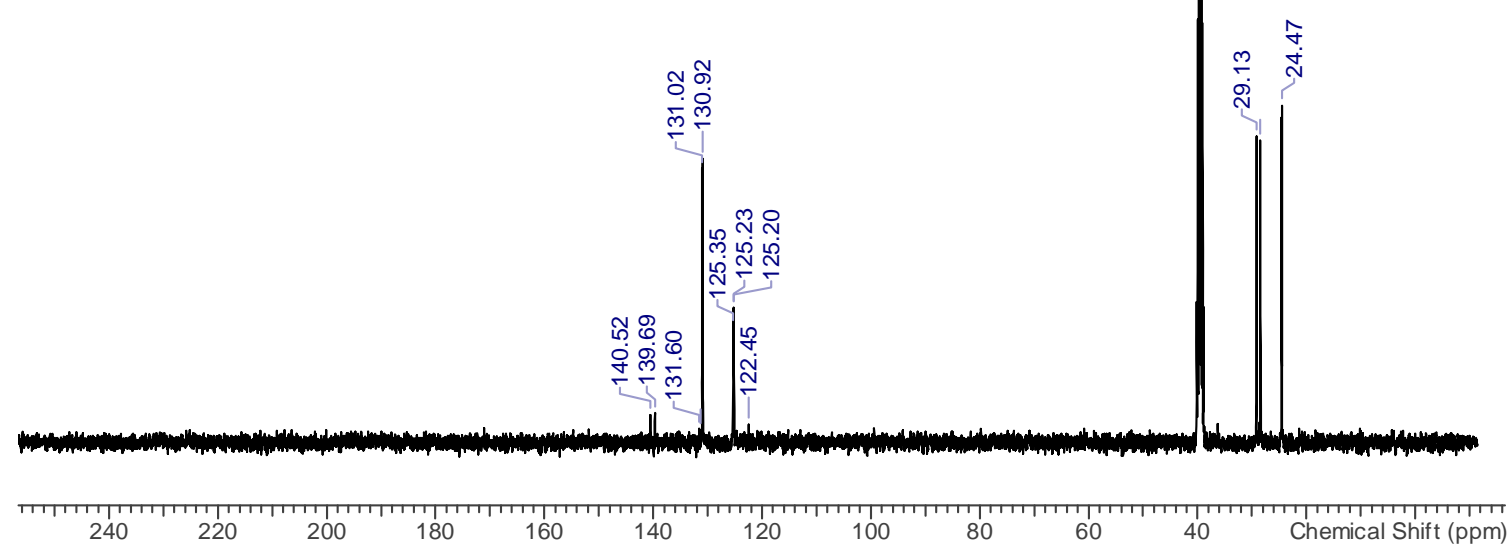

${ }^{31}$ P-NMR

(1)

22b

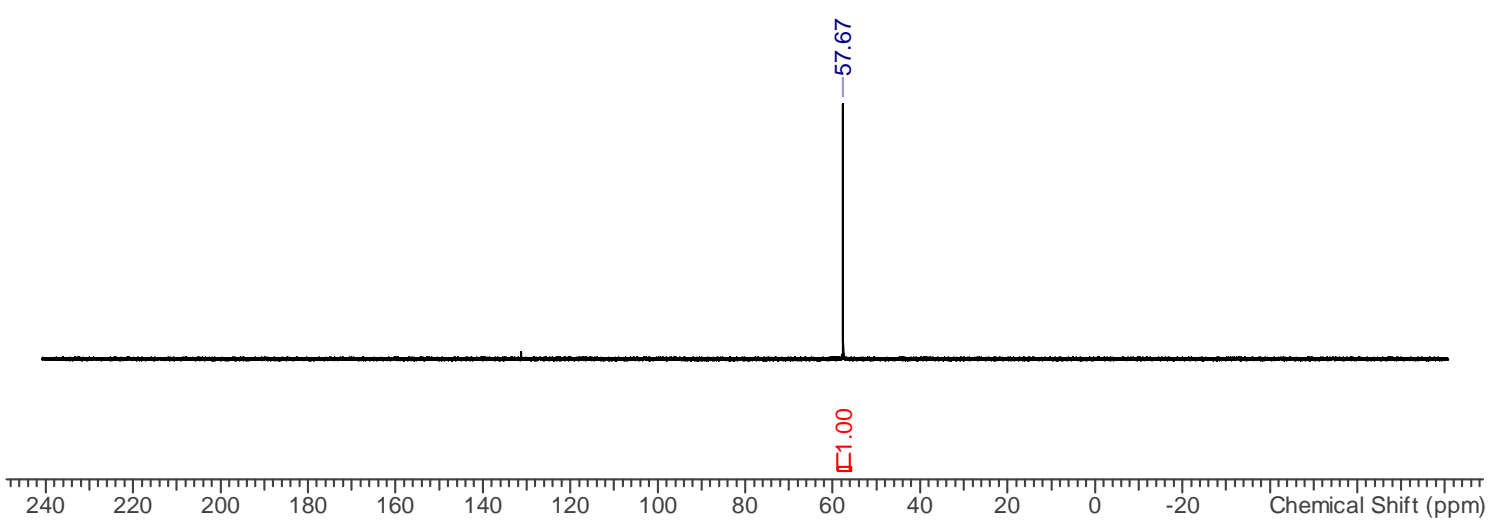


1-[4-(Trifluoromethyl)phenyl]-1 $\lambda^{5}$-phosphinan-1-one (22c)

${ }^{1} \mathrm{H}-\mathrm{NMR}$<smiles>O=P1(c2ccc(C(F)(F)F)cc2)CCCCC1</smiles>

22c

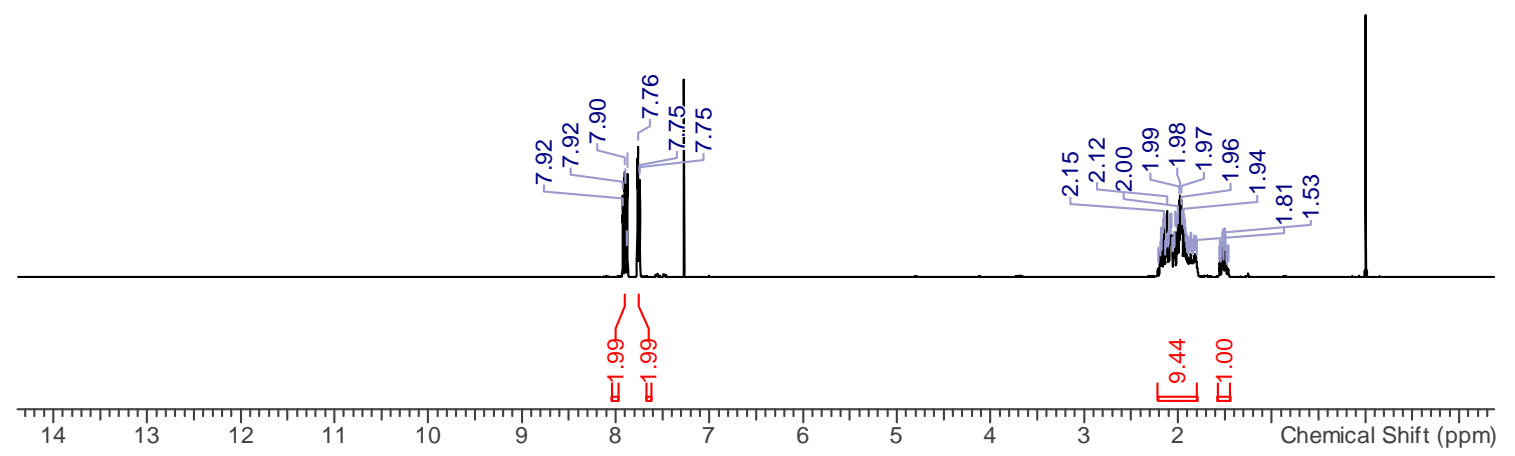

${ }^{13} \mathrm{C}$-NMR<smiles>O=P1(c2ccc(C(F)(F)F)cc2)CCCCC1</smiles>

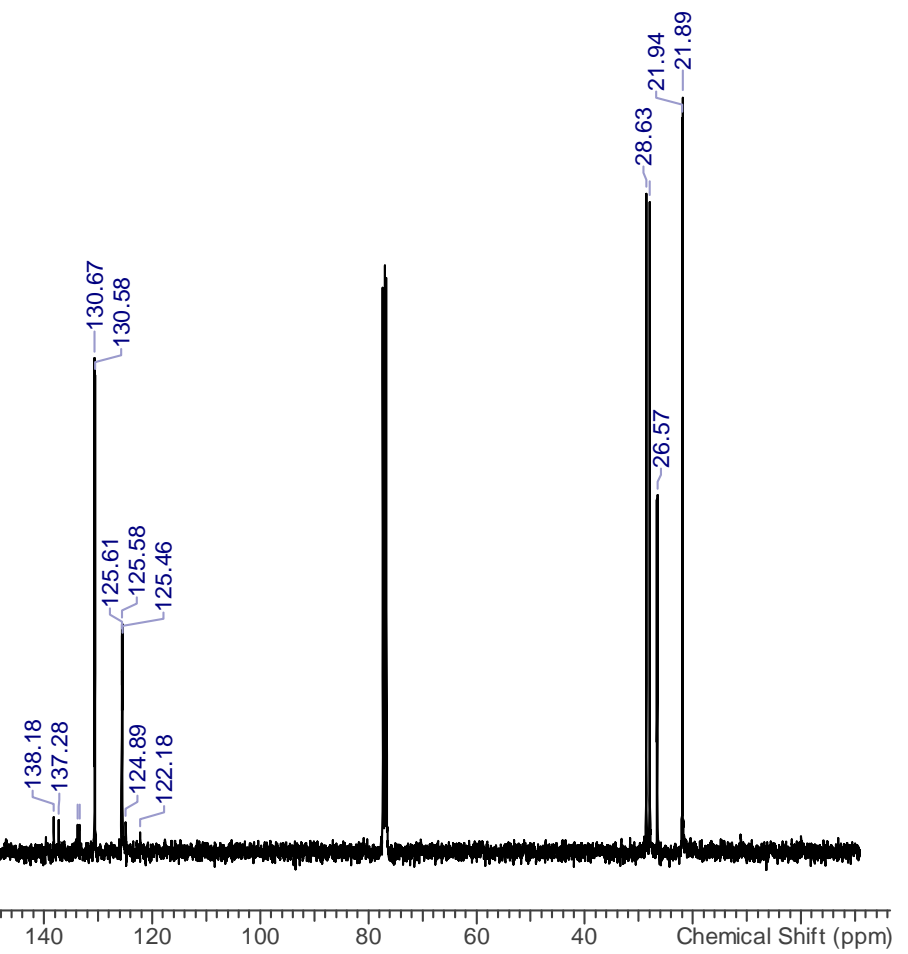


<smiles>O=P1(c2ccc(C(F)(F)F)cc2)CCCCC1</smiles>

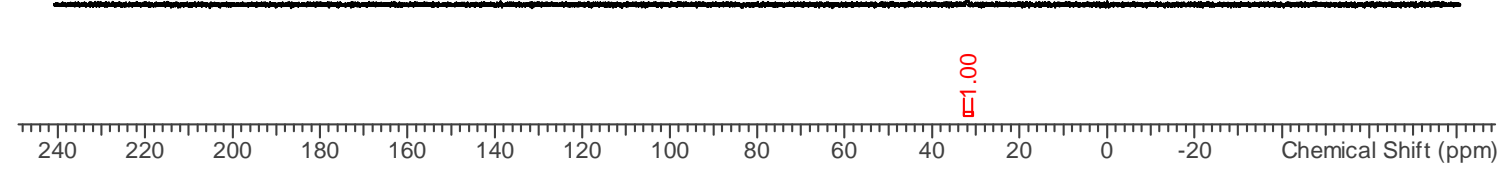

\section{4-[4-(Trifluoromethyl)phenyl]-1,4 $\lambda^{5}$-oxaphosphinan-4-one (22d)}

${ }^{1} \mathrm{H}-\mathrm{NMR}$<smiles>O=P1(c2ccc(C(F)(F)F)cc2)CCOCC1</smiles>

22d

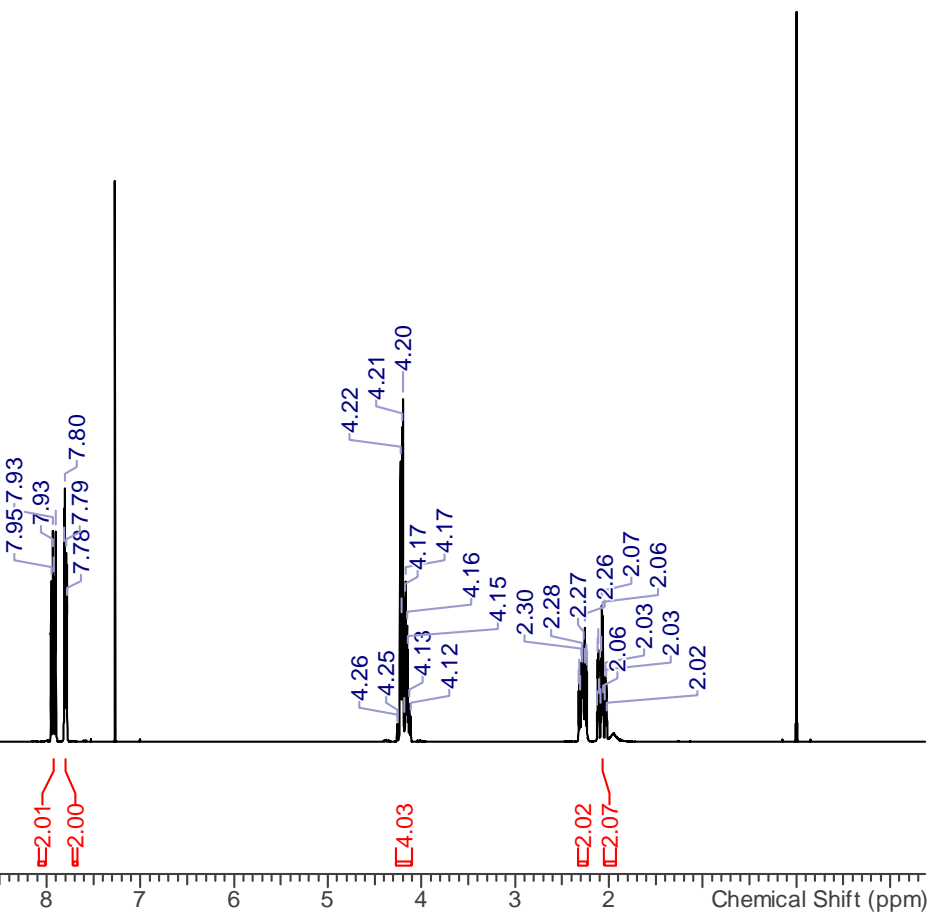


${ }^{13} \mathrm{C}-\mathrm{NMR}$
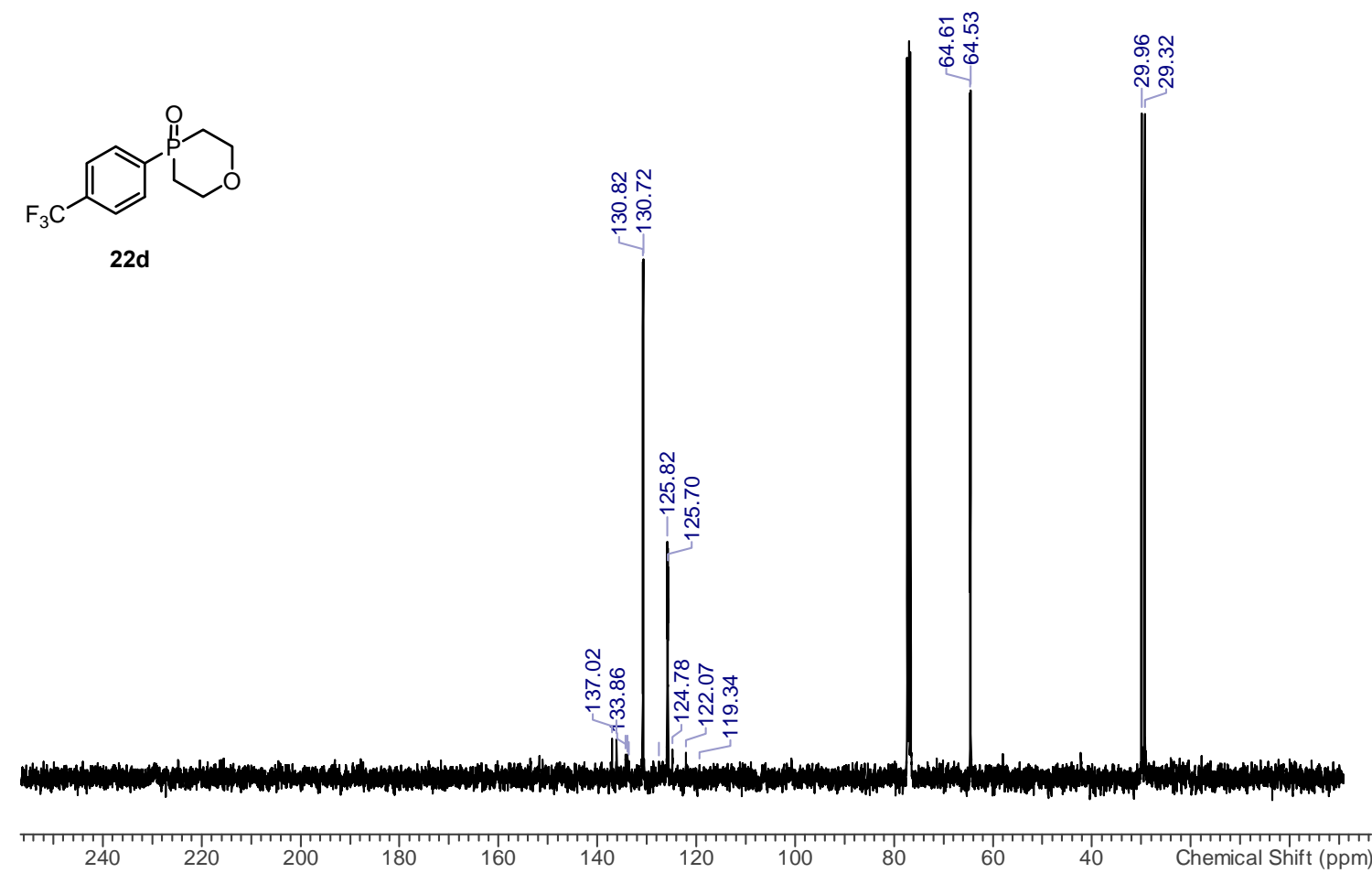

${ }^{31} \mathrm{P}-\mathrm{NMR}$<smiles>O=P1(c2ccc(C(F)(F)F)cc2)CCOCC1</smiles>

공

8

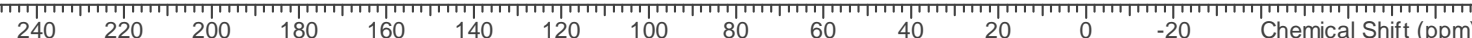



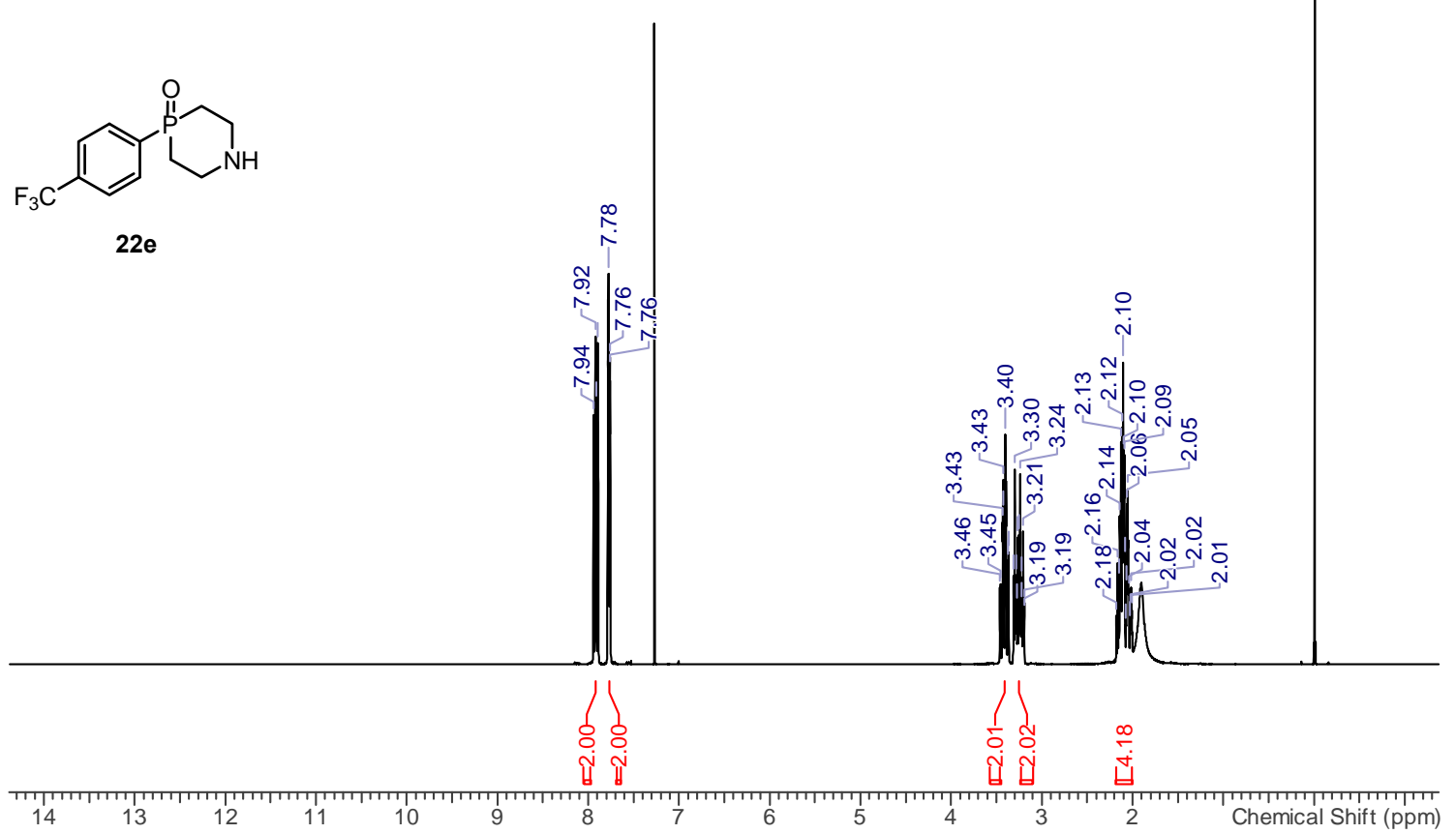

${ }^{13} \mathrm{C}-\mathrm{NMR}$<smiles>O=P1(c2ccc(C(F)(F)F)cc2)CCNCC1</smiles>

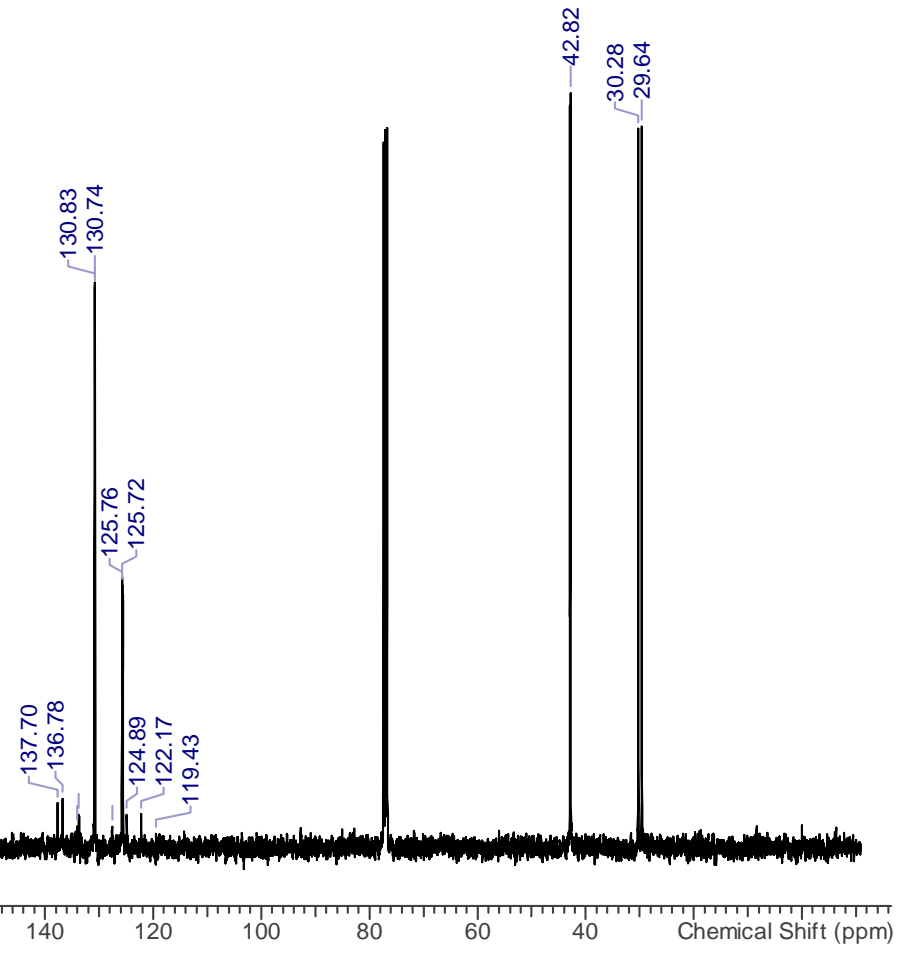



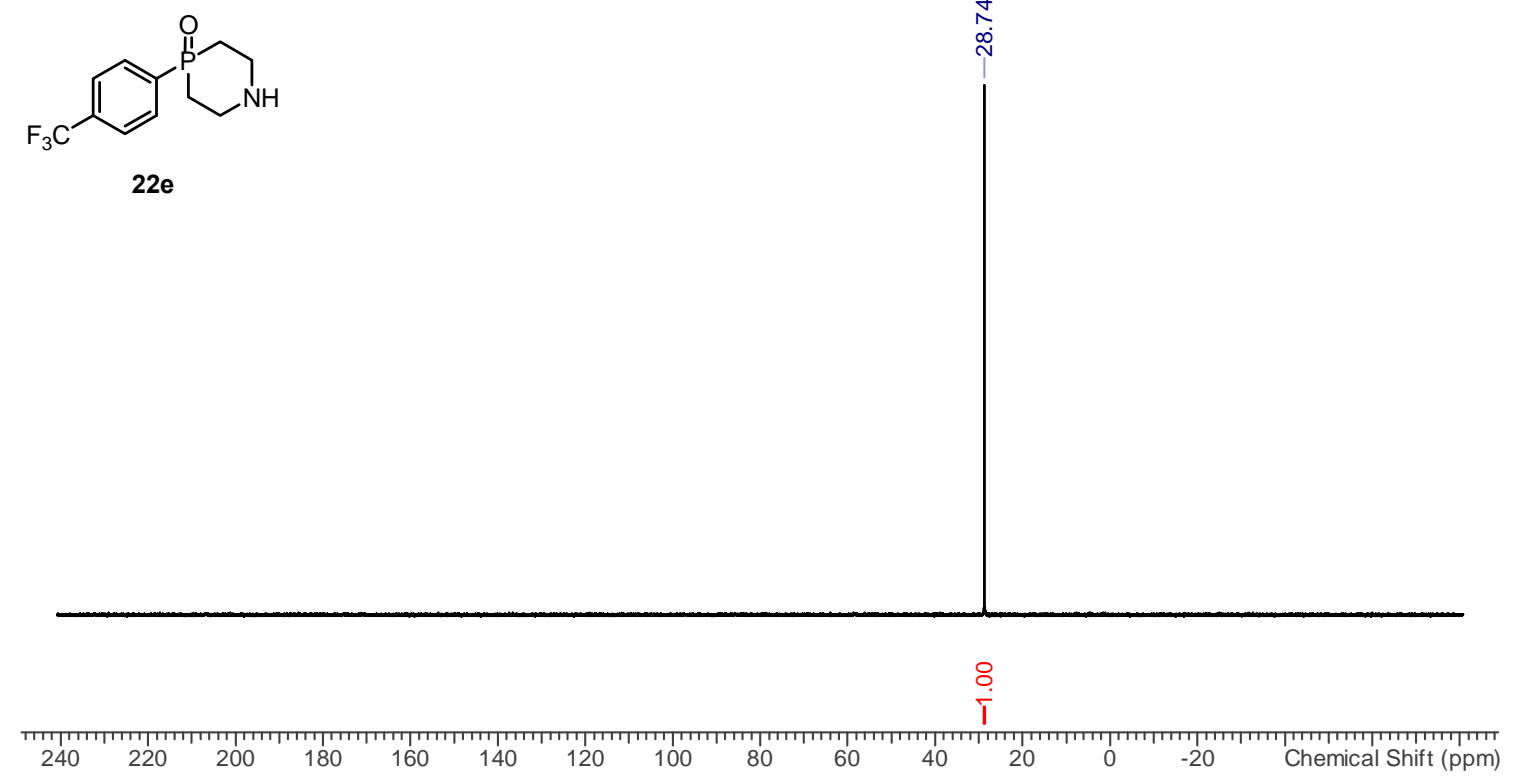

\section{1-Methyl-4-[4-(trifluoromethyl)phenyl]-1,4 $\lambda^{5}$-azaphosphinan-4-one (22f)}

${ }^{1} \mathrm{H}-\mathrm{NMR}$<smiles>CN1CC[SH](=O)(c2ccc(C(F)(F)F)cc2)CC1</smiles>

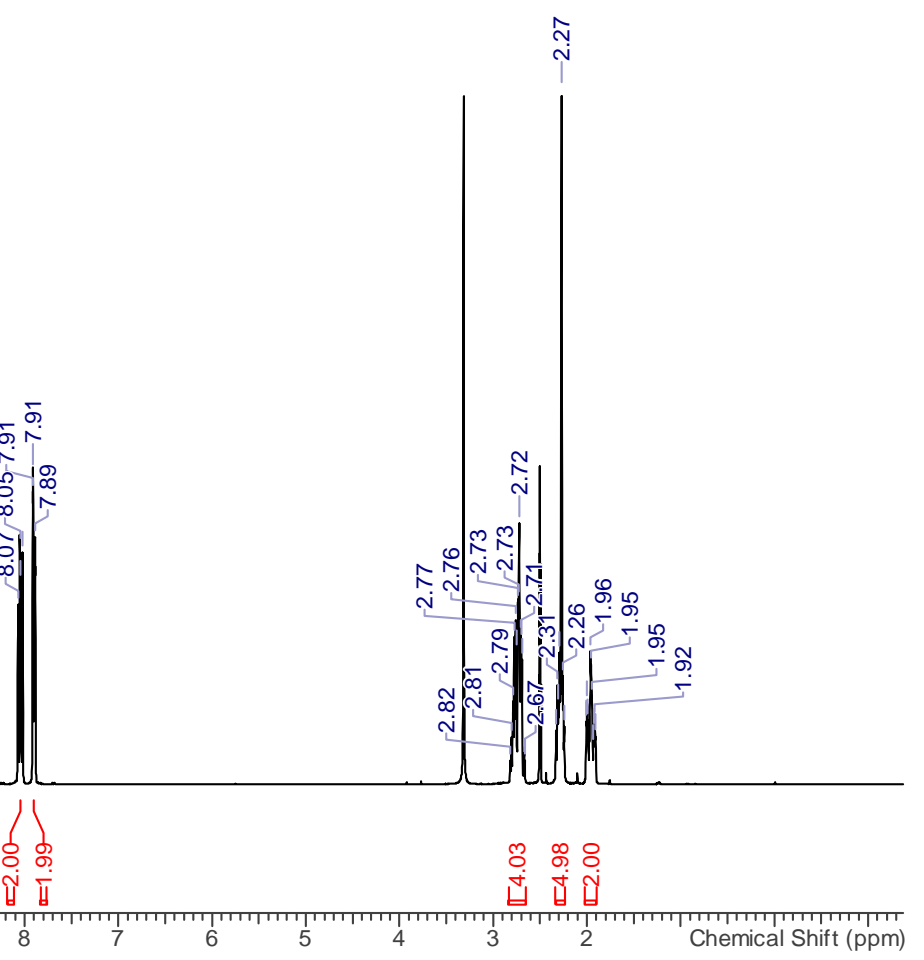


${ }^{13} \mathrm{C}-\mathrm{NMR}$
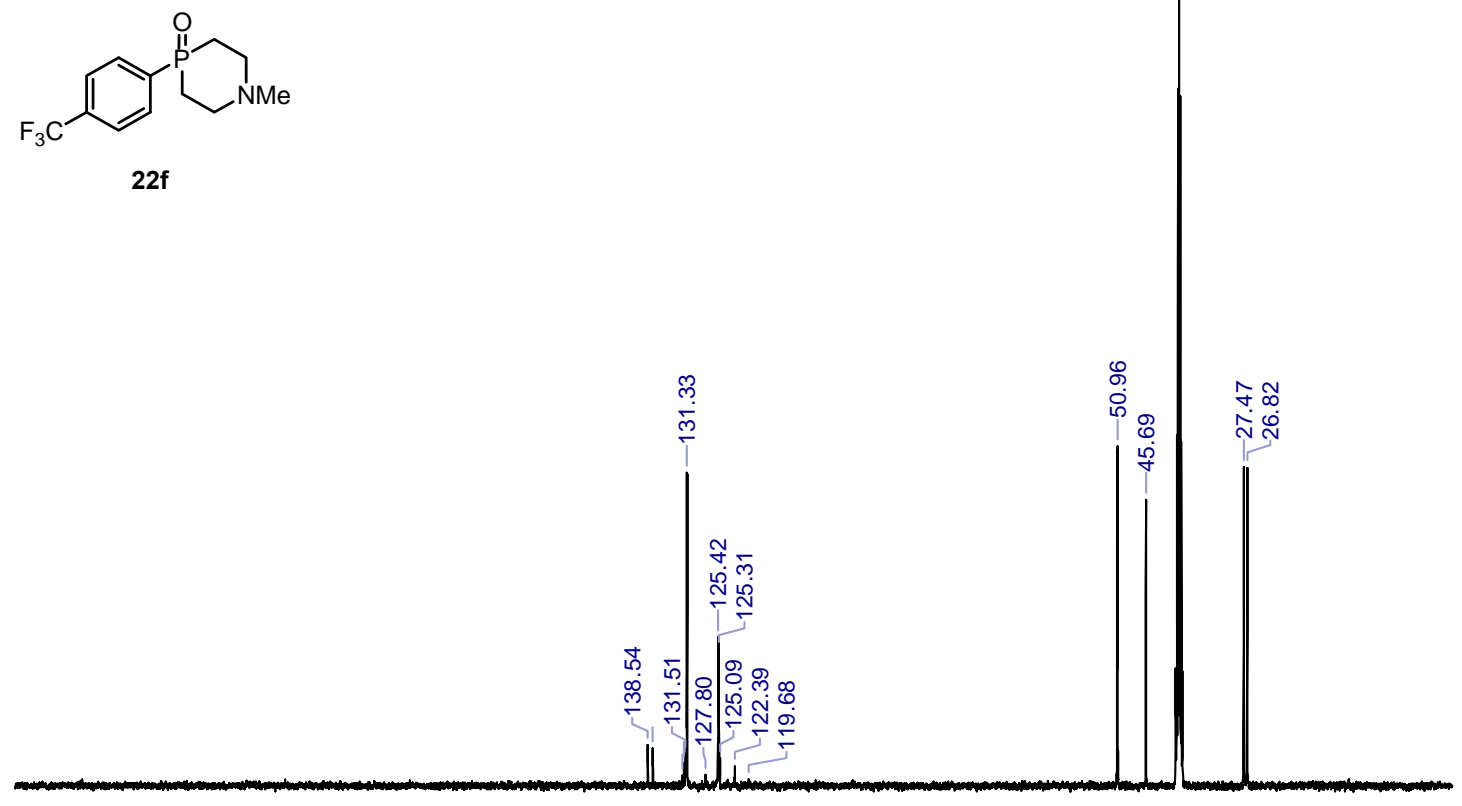

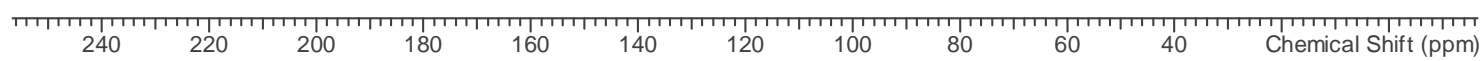

${ }^{31} \mathrm{P}-\mathrm{NMR}$
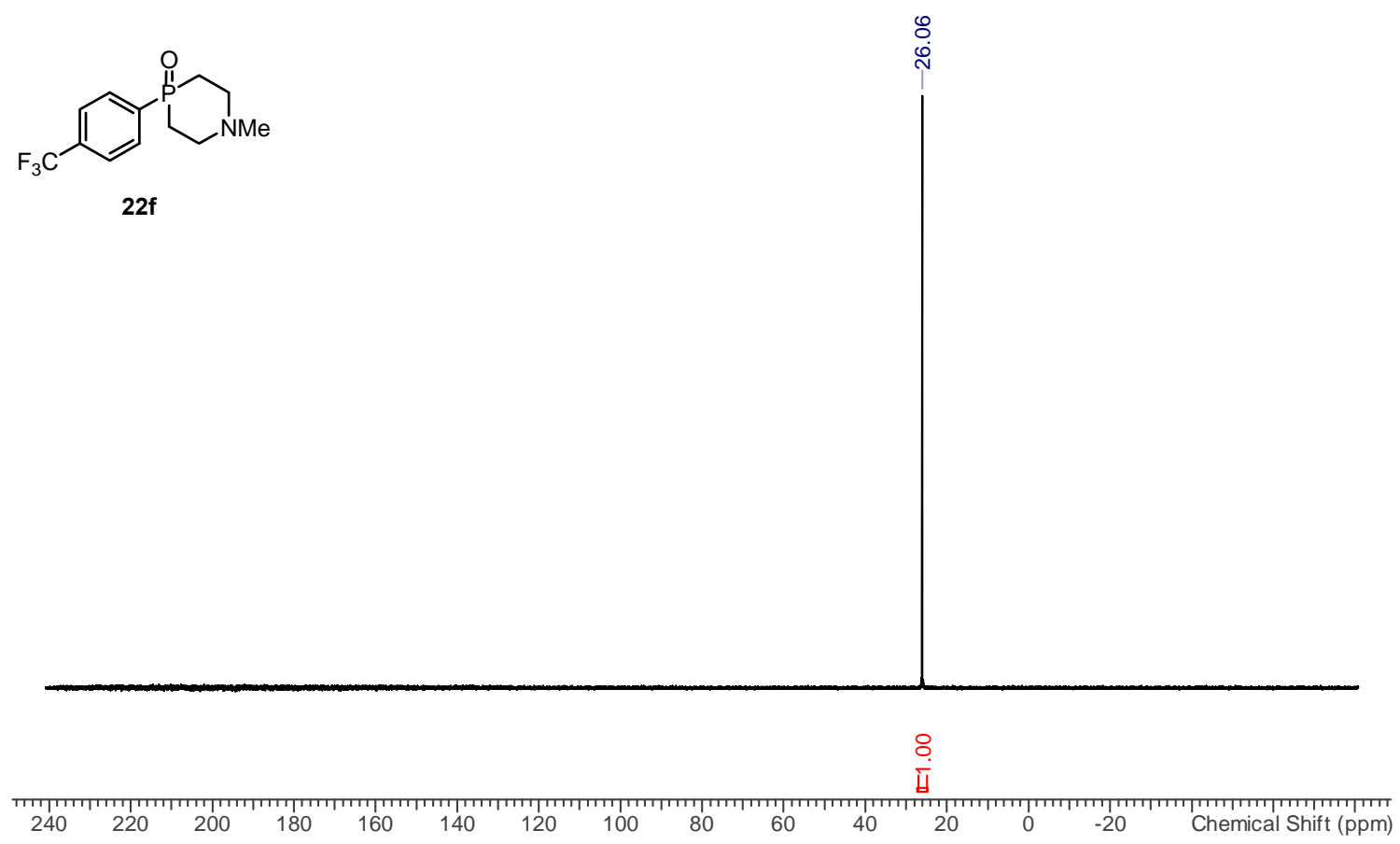

S25 
1-Isopropyl-4-[4-(trifluoromethyl)phenyl]-1,4 $\lambda^{5}$-azaphosphinan-4-one (22g)

${ }^{1} \mathrm{H}-\mathrm{NMR}$<smiles>O=P1(c2ccc(C(F)(F)F)cc2)CCN(P)CC1</smiles>

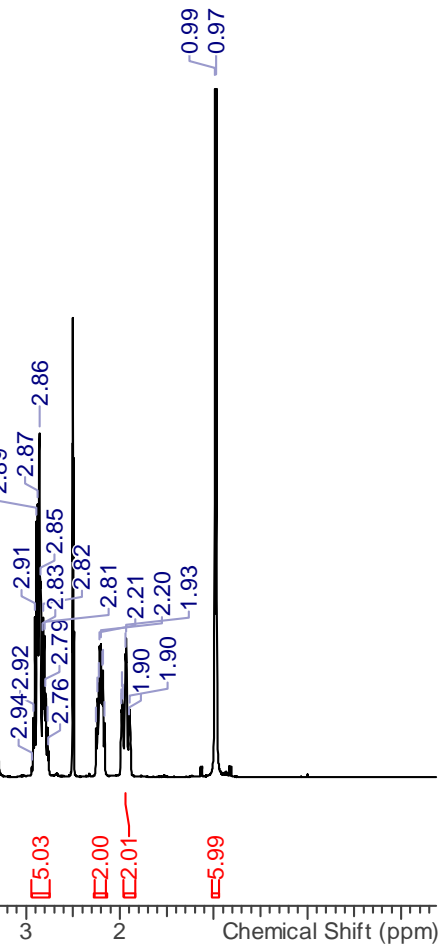

${ }^{13} \mathrm{C}-\mathrm{NMR}$
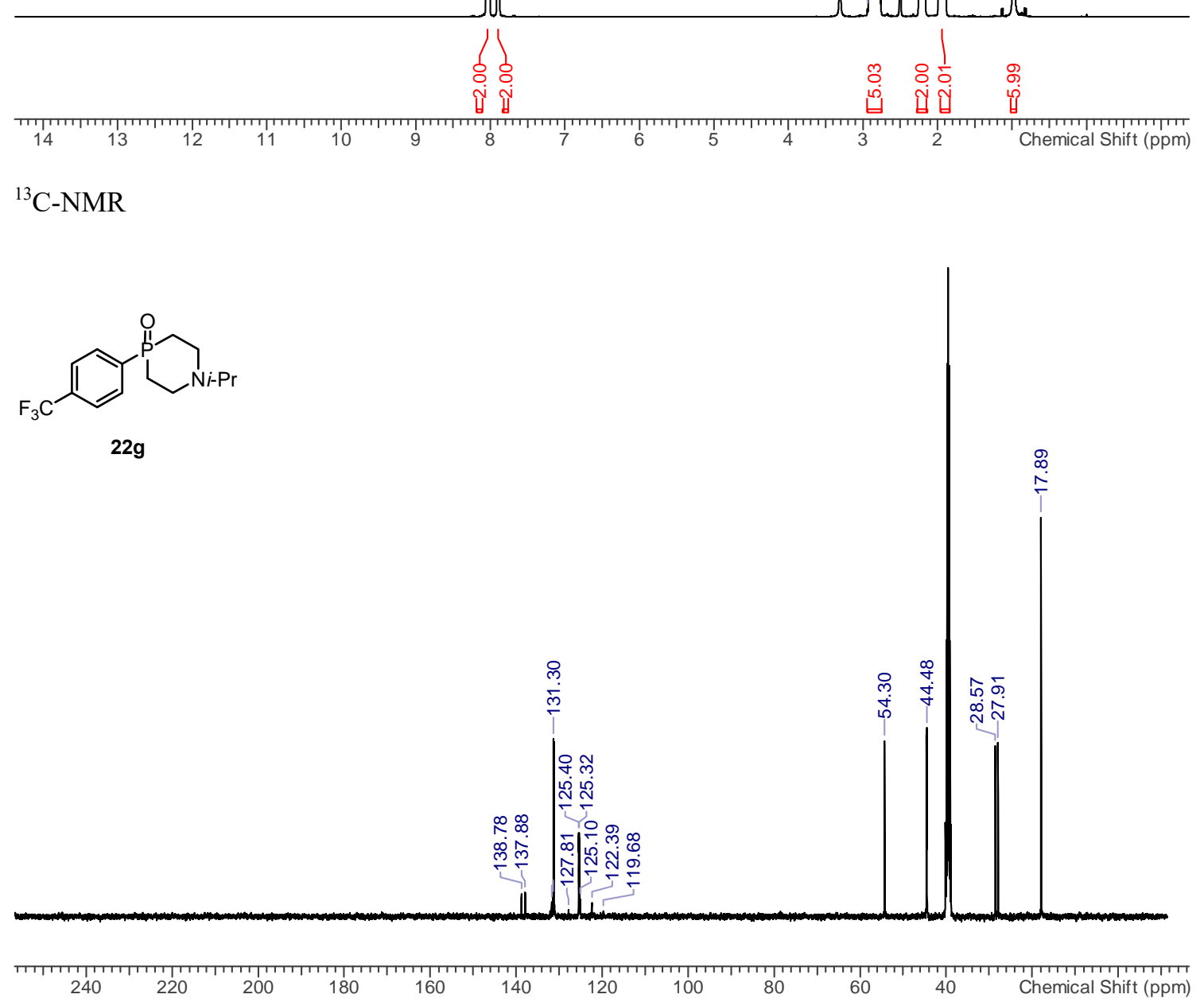
${ }^{31}$ P-NMR

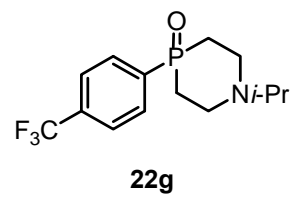

$22 \mathrm{~g}$

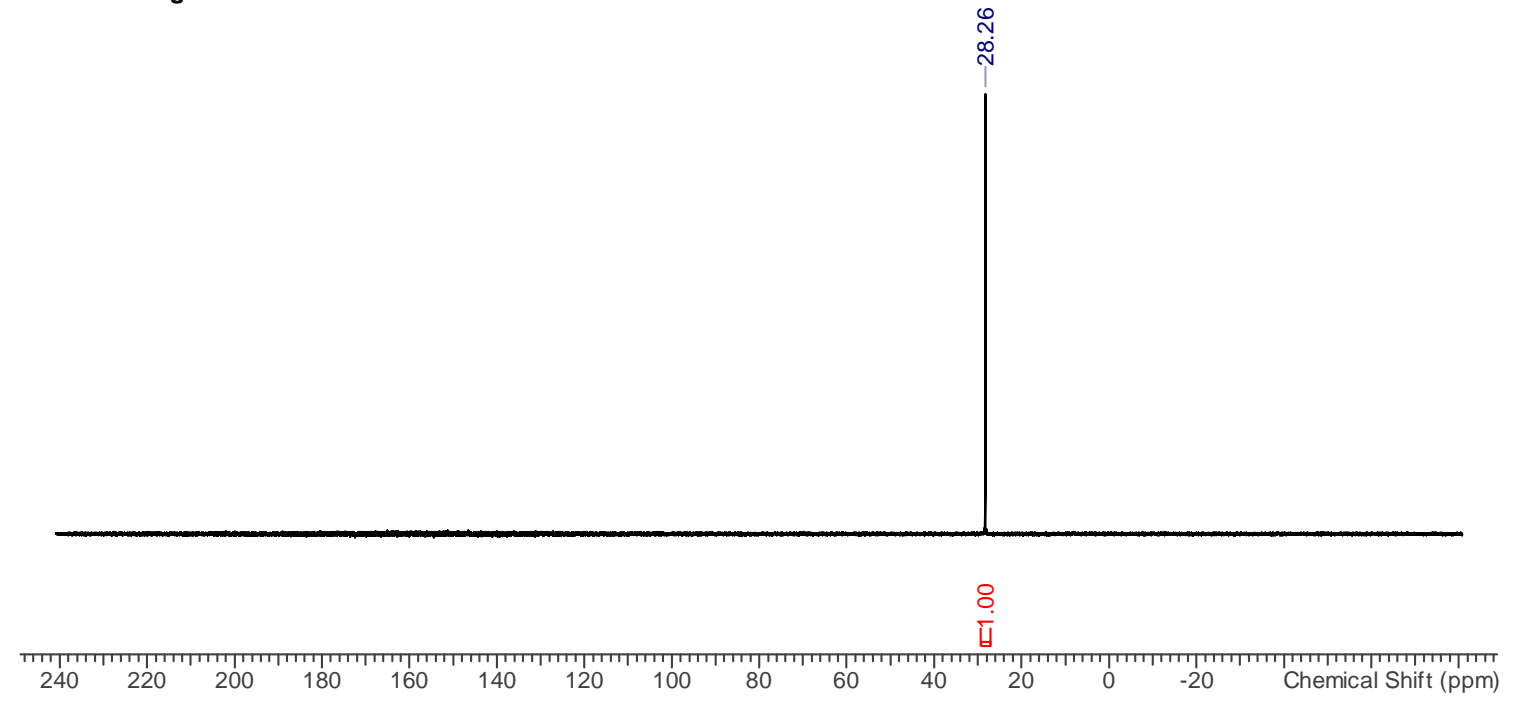

\section{4-[(Trifluoromethyl)phenyl]phosphinic Acid (23a)}

${ }^{1} \mathrm{H}-\mathrm{NMR}$
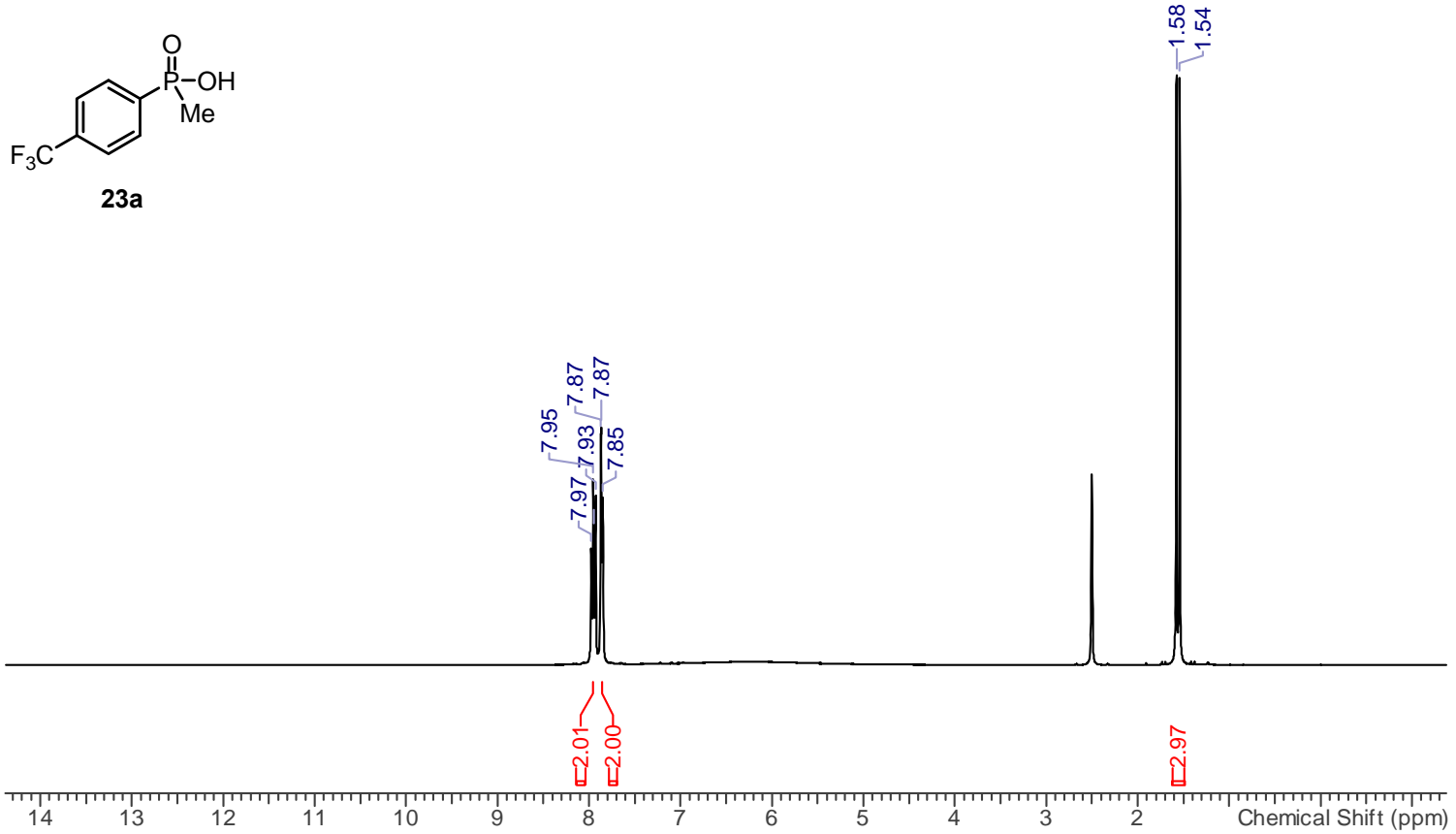
${ }^{13} \mathrm{C}-\mathrm{NMR}$<smiles>CP(=O)(O)c1ccc(C(F)(F)F)cc1</smiles>
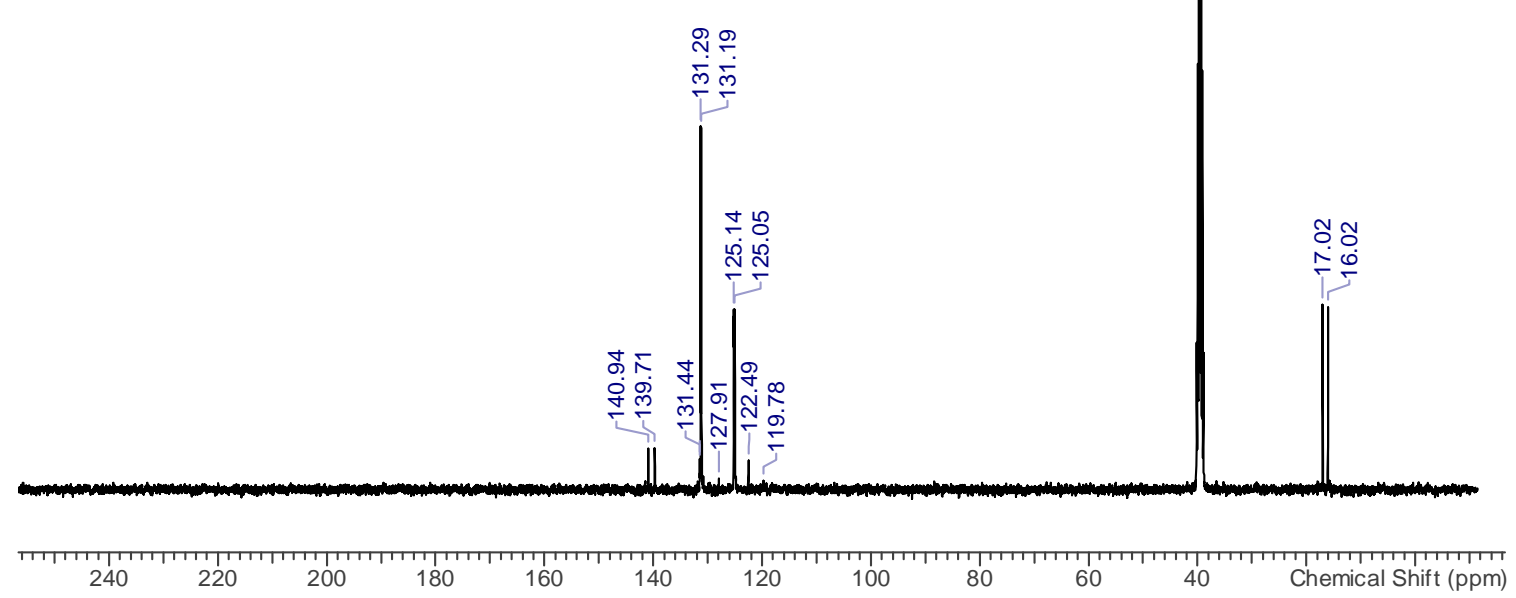

${ }^{31}$ P-NMR

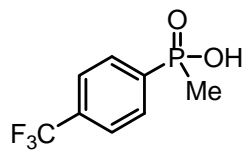

23a

$\hat{0}$

8

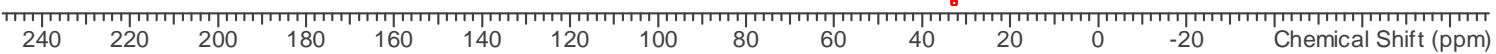


Ethyl 4-[(Trifluoromethyl)phenyl]phosphinate (23b)

${ }^{1} \mathrm{H}-\mathrm{NMR}$

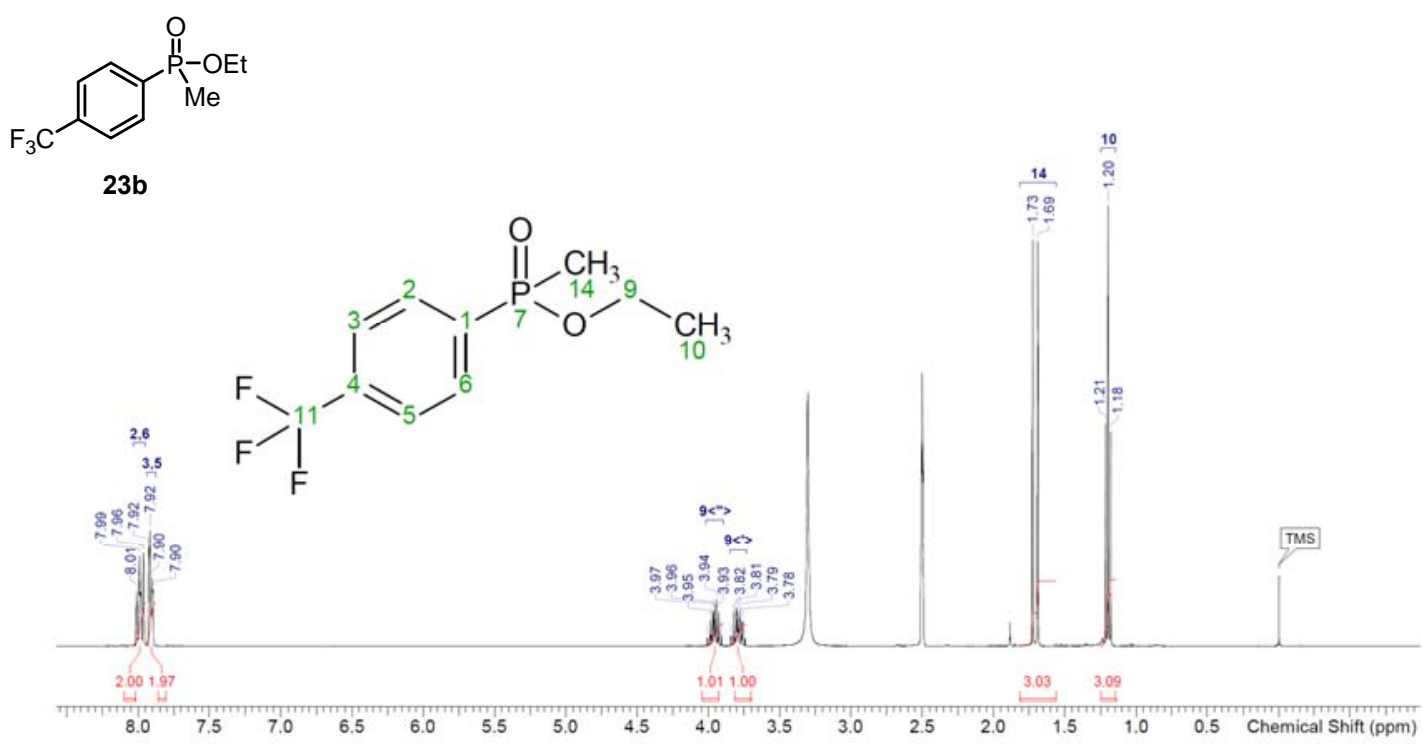

${ }^{13} \mathrm{C}-\mathrm{NMR}$<smiles>CCOP(C)(=O)c1ccc(C(F)(F)F)cc1</smiles>

23b<smiles></smiles>

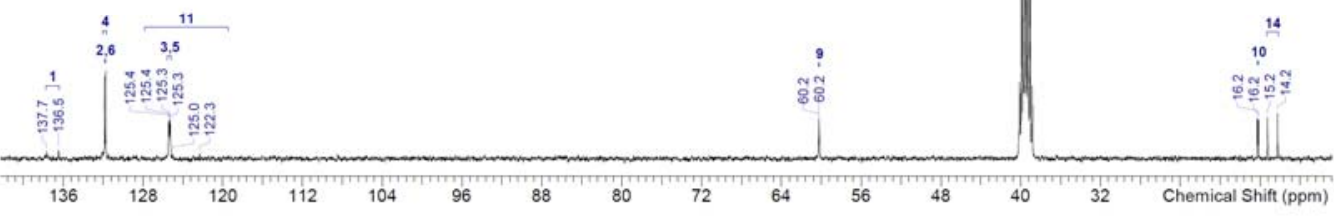


${ }^{31}$ P-NMR

23b

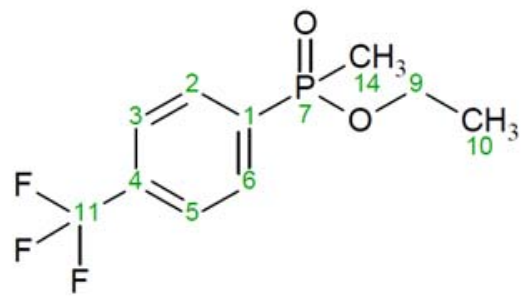

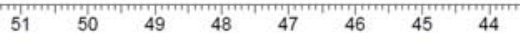

\section{Methoxy[4-(trifluoromethyl)phenyl]phosphinic Acid (24b)}

${ }^{1} \mathrm{H}-\mathrm{NMR}$
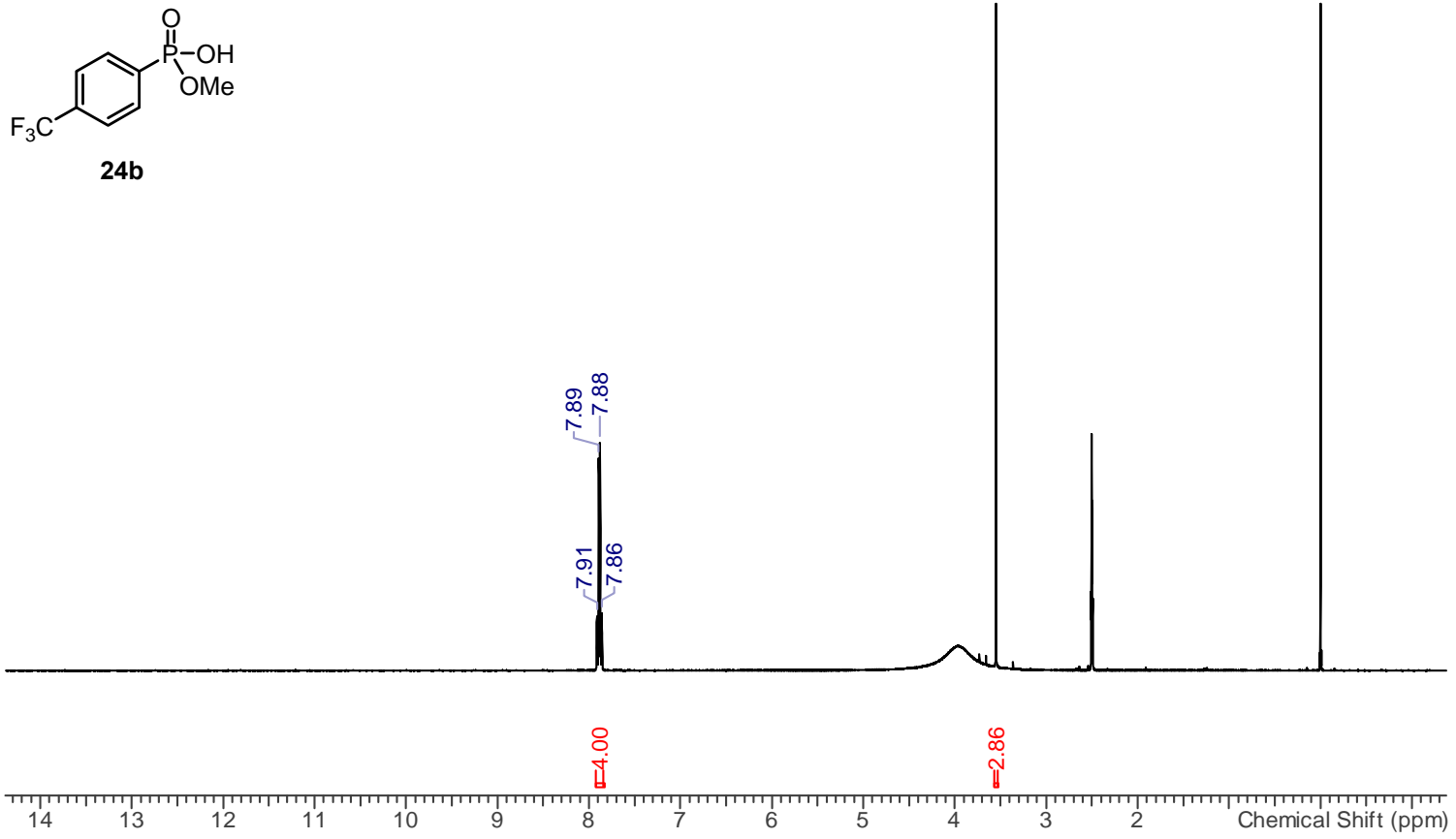


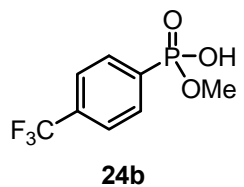

लें ले

(1)

ษ.

ஸे

:

เึ่

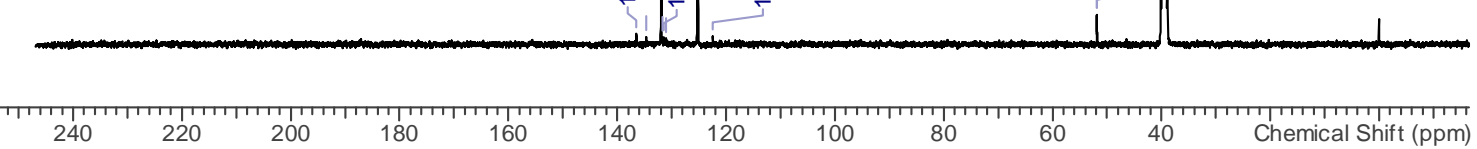

${ }^{31}$ P-NMR

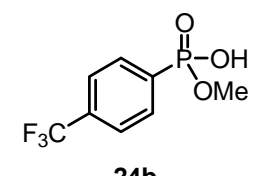

24b

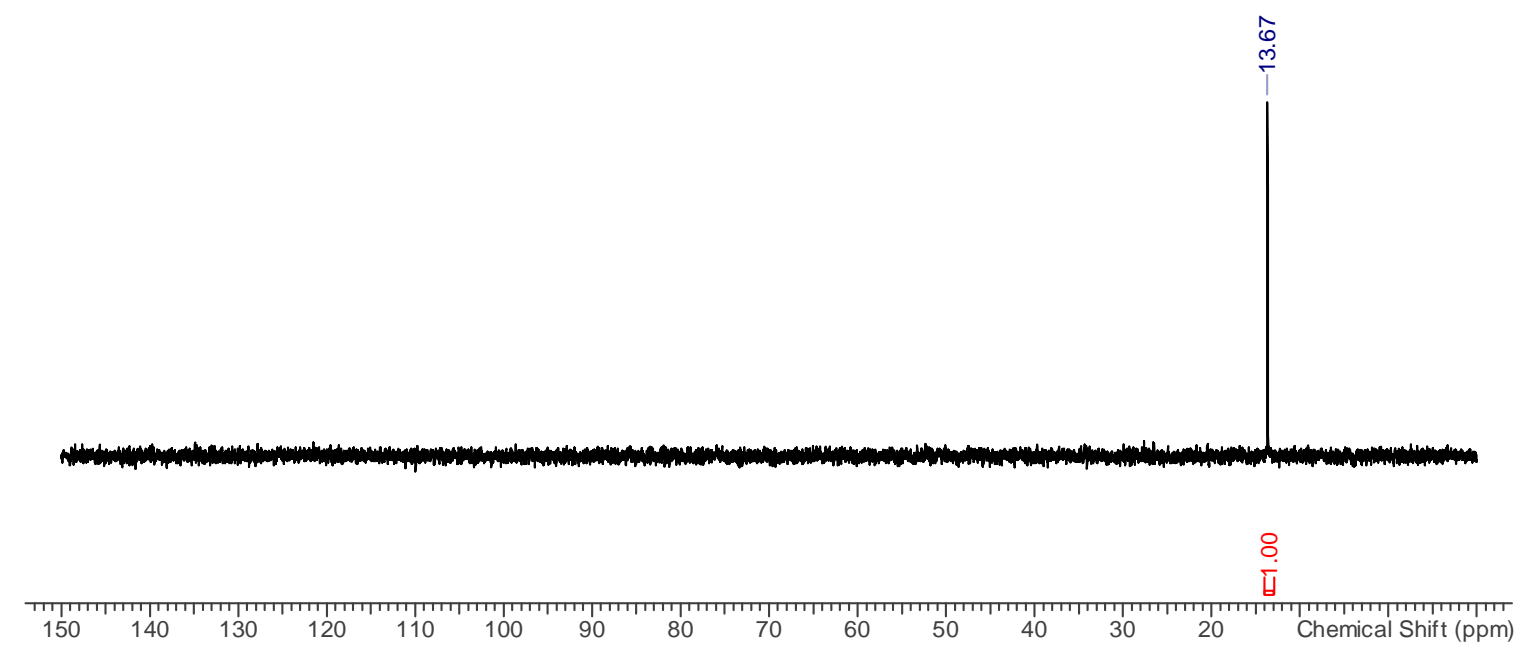


Ethoxy[4-(trifluoromethyl)phenyl]phosphinic Acid (24c)

${ }^{1} \mathrm{H}-\mathrm{NMR}$
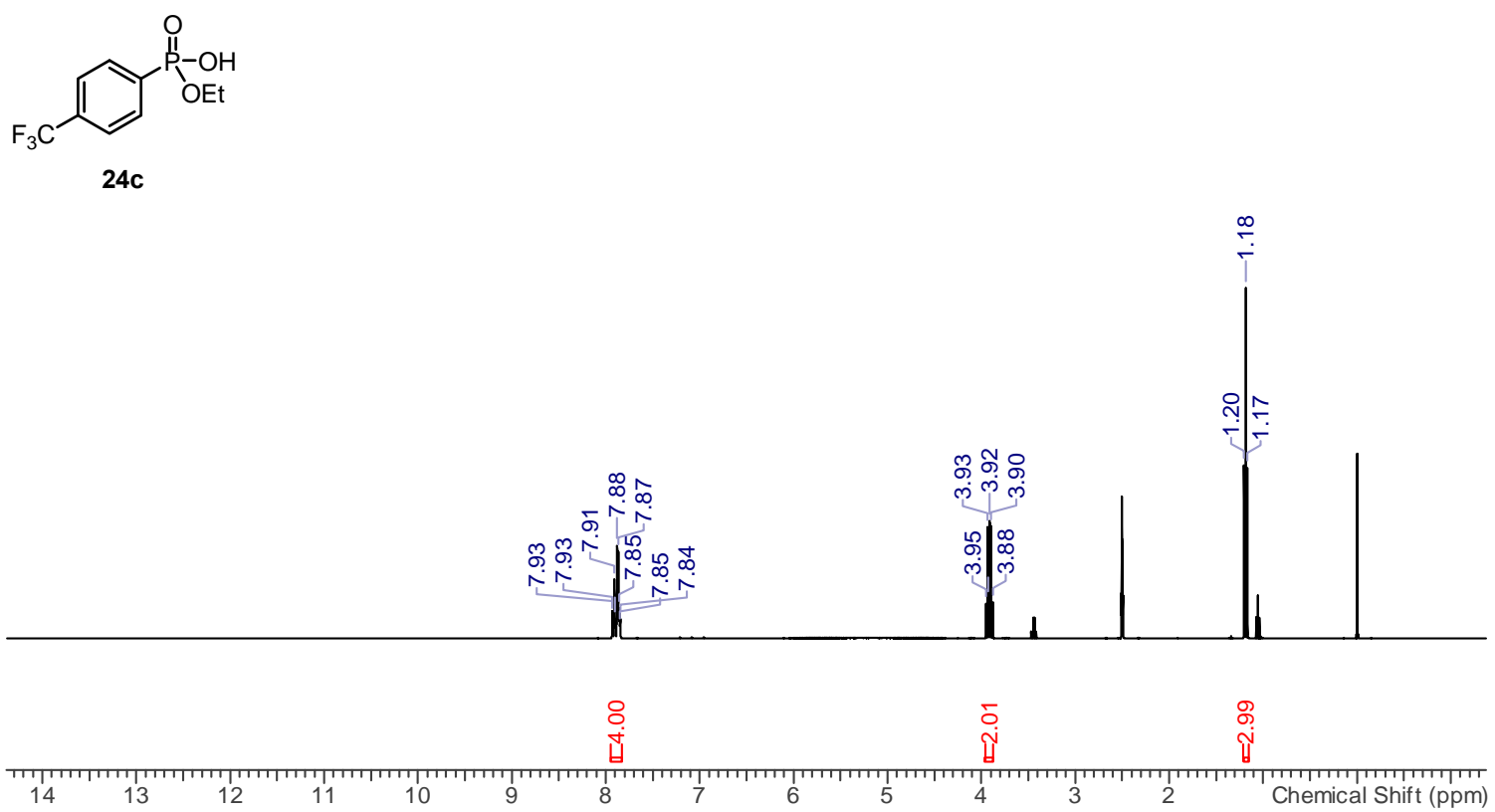

${ }^{13} \mathrm{C}-\mathrm{NMR}$<smiles>CCOP(=O)(O)c1ccc(C(F)(F)F)cc1</smiles>

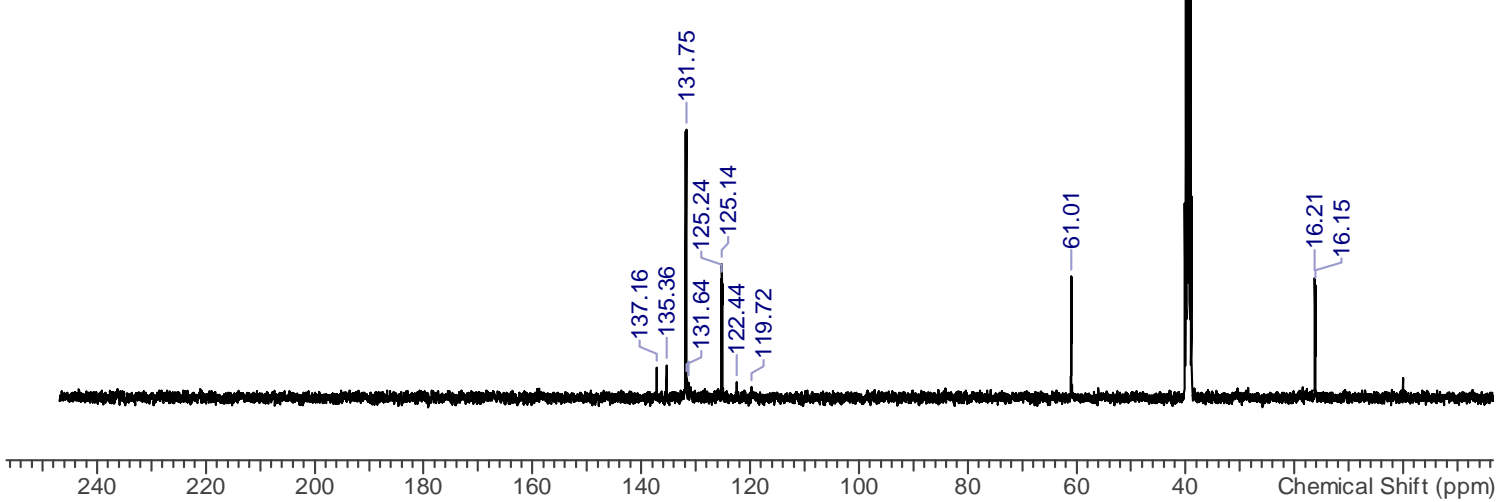


${ }^{31}$ P-NMR<smiles>CCOP(=O)(O)c1ccc(C(F)(F)F)cc1</smiles>

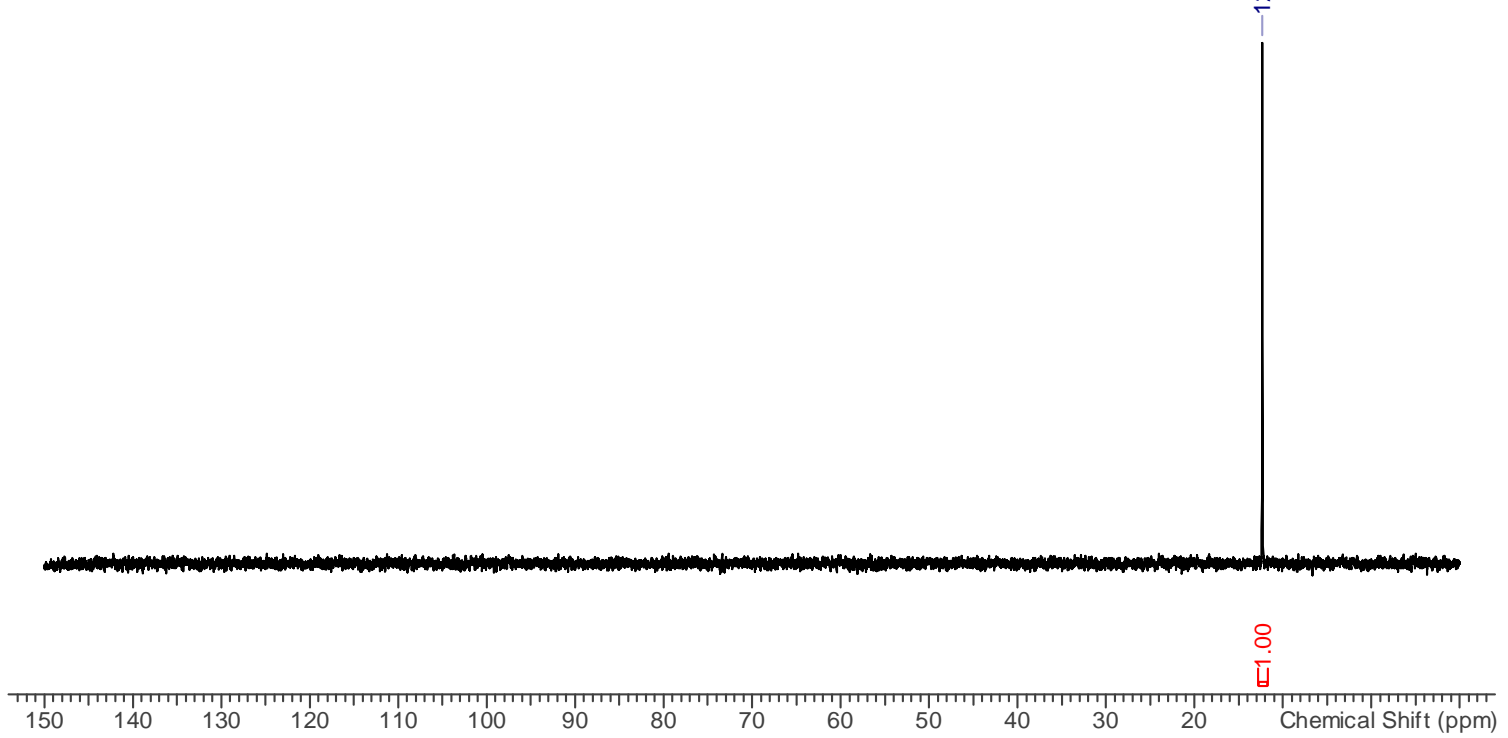

\section{2-Hydroxyethoxy(4-(trifluoromethyl)phenyl)phosphinic Acid (24g)}

${ }^{1} \mathrm{H}-\mathrm{NMR}$

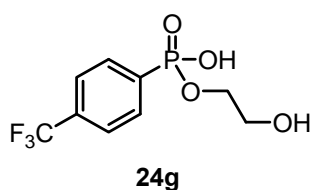

$24 \mathrm{~g}$

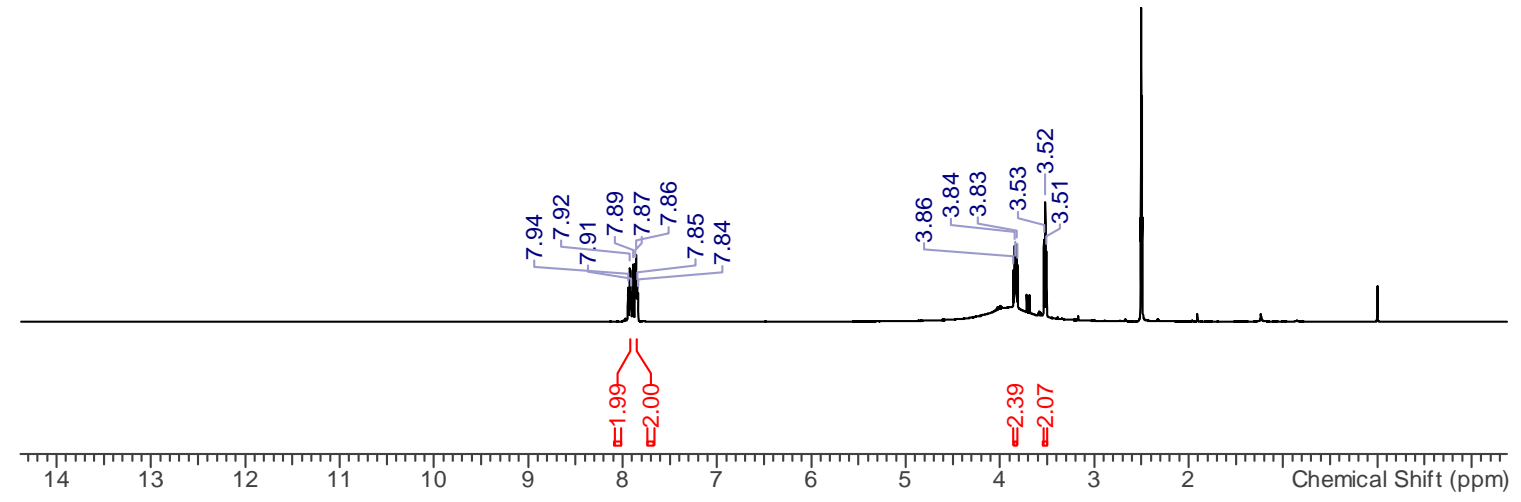


${ }^{13} \mathrm{C}-\mathrm{NMR}$
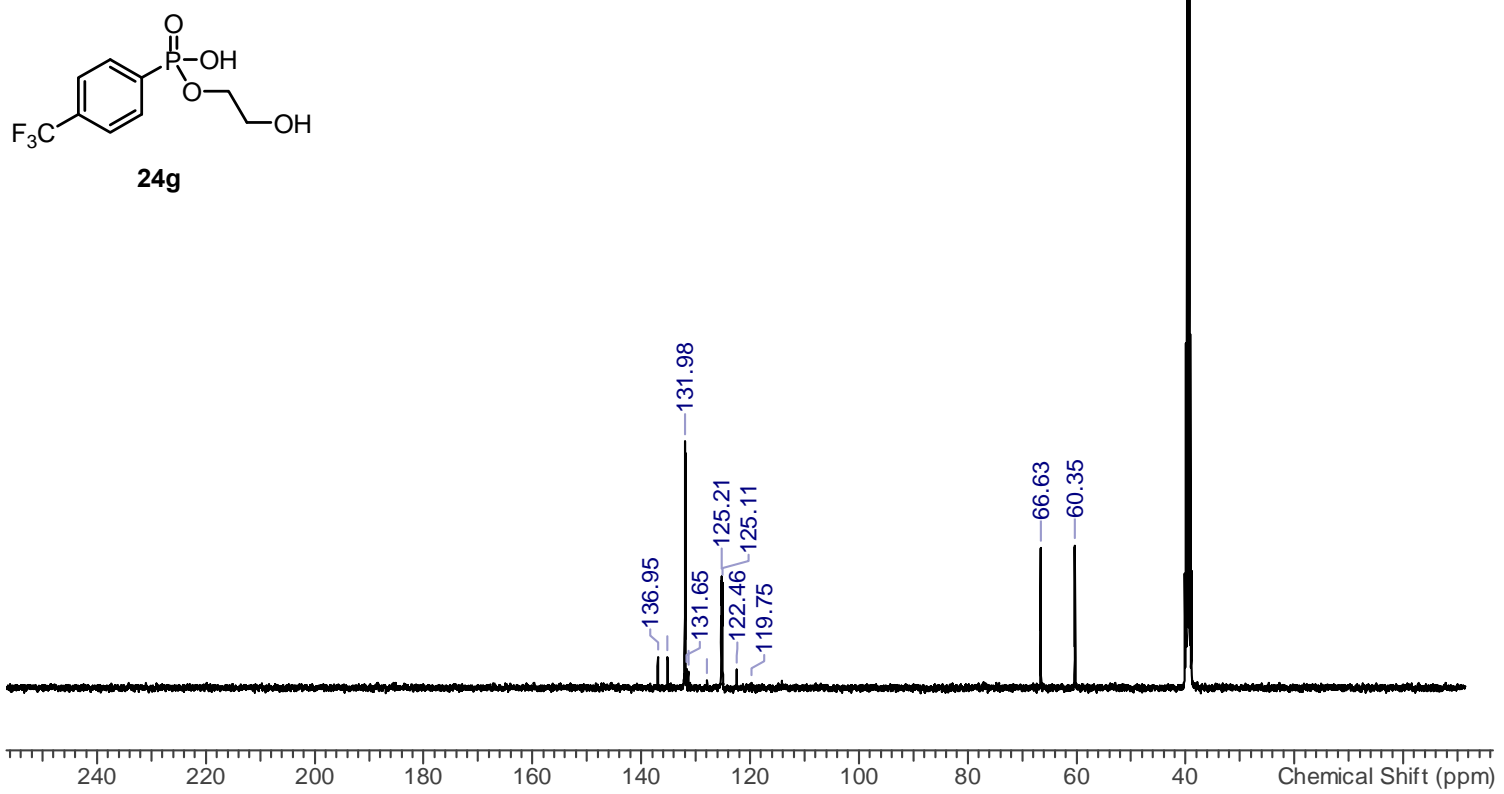

${ }^{31} \mathrm{P}-\mathrm{NMR}$

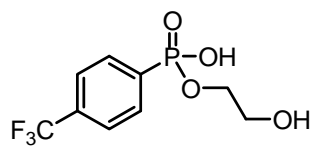

24g

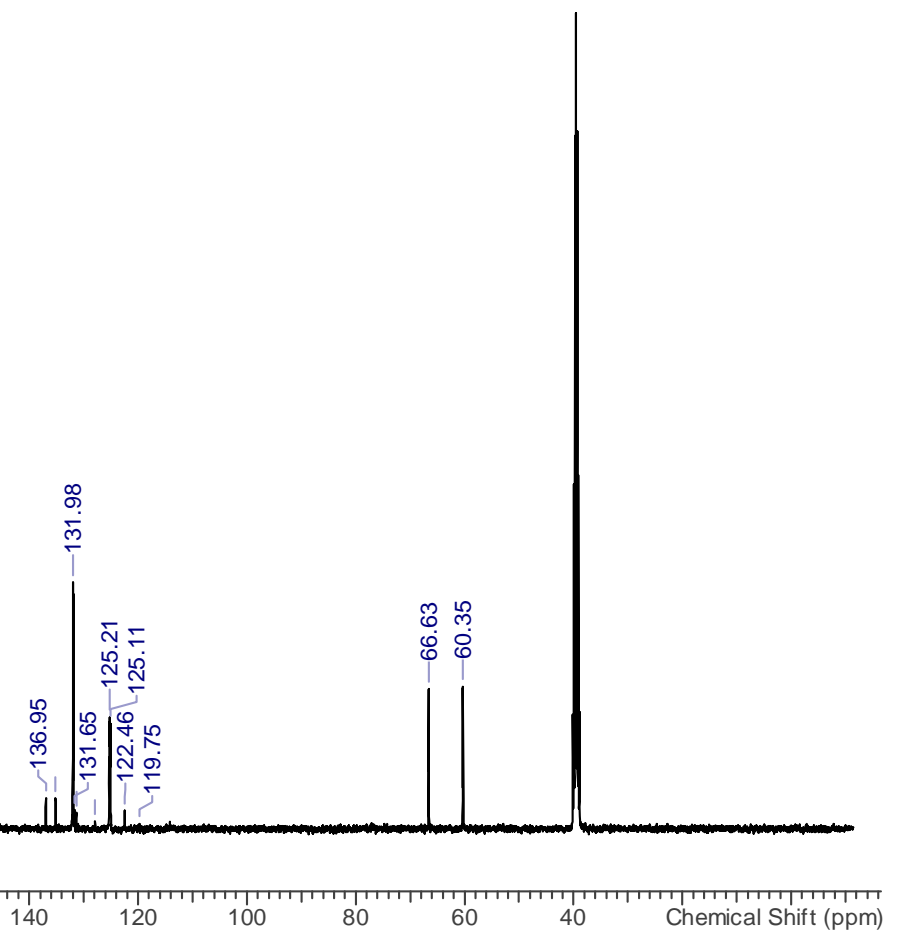


2-[4-(Trifluoromethyl)phenyl]-1,3,2 $\lambda^{5}$-dioxaphosphinan-2-one (25b)

${ }^{1}$ H-NMR<smiles>O=P1(c2ccc(C(F)(F)F)cc2)OCCCO1</smiles>

25b

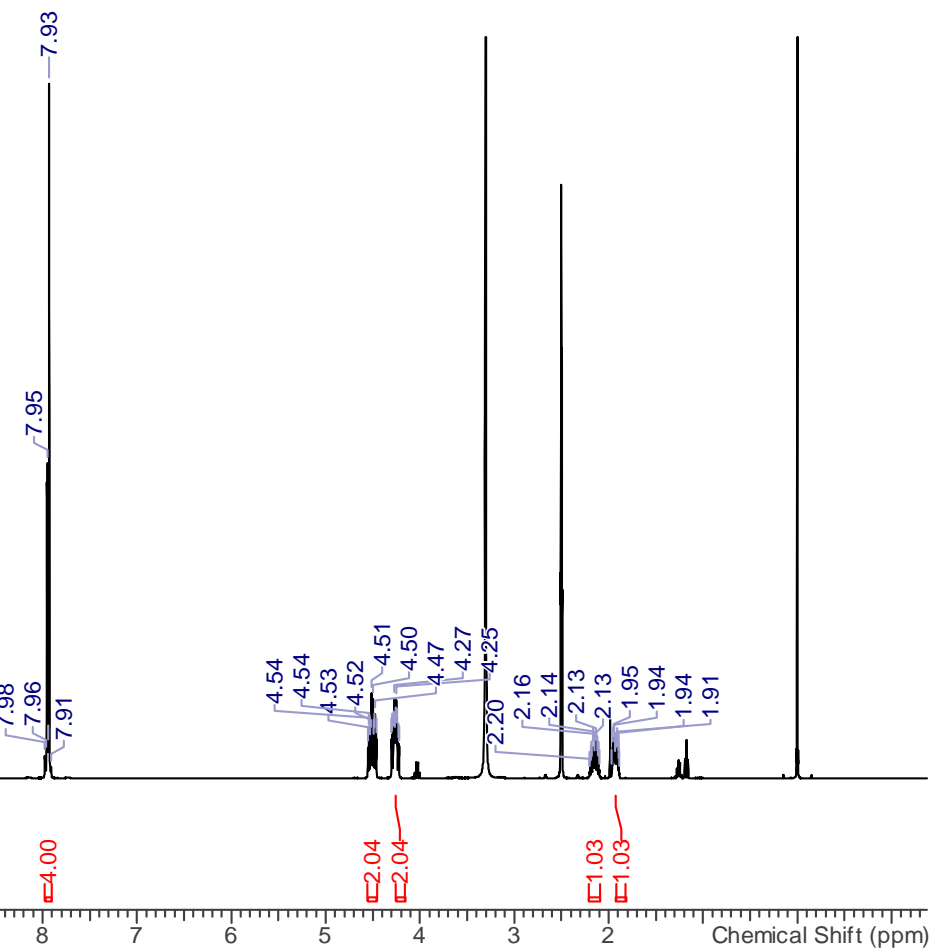

${ }^{13} \mathrm{C}-\mathrm{NMR}$<smiles>O=P1(c2ccc(C(F)(F)F)cc2)OCCCO1</smiles>

25b

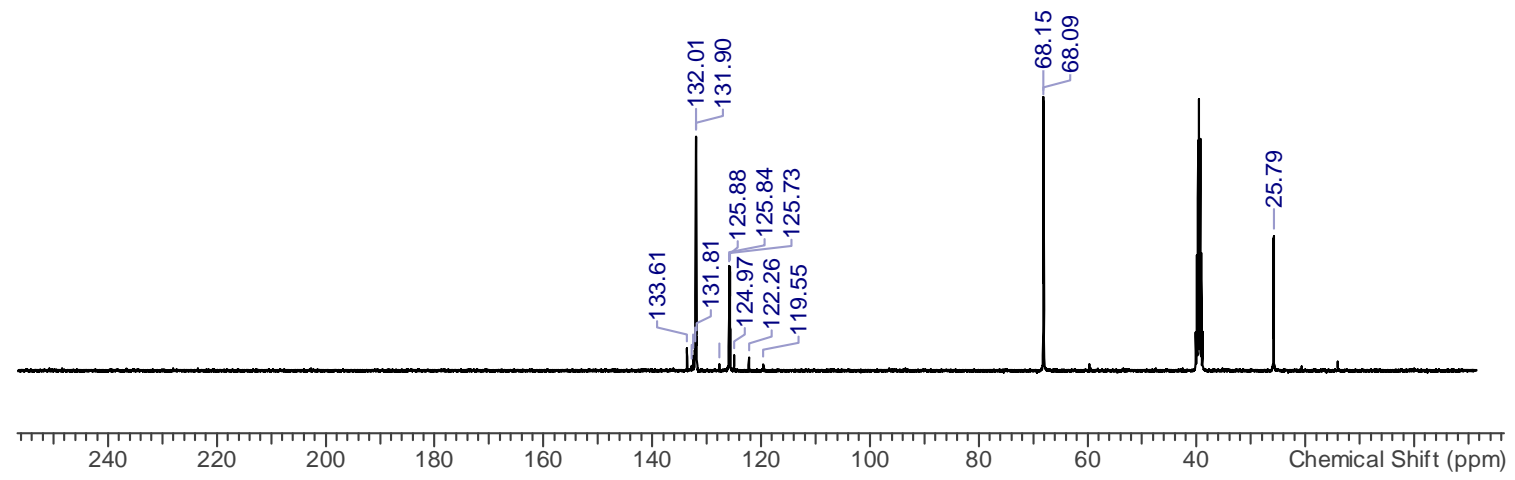


<smiles>O=P1(c2ccc(C(F)(F)F)cc2)OCCCO1</smiles>

$25 b$

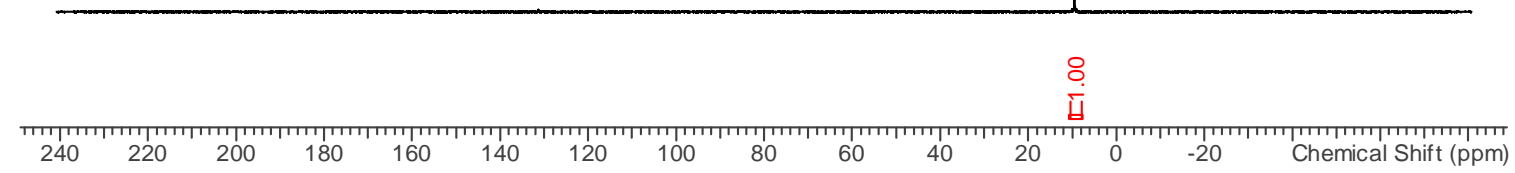

\section{5,5-Dimethyl-2-[4-(trifluoromethyl)phenyl]-1,3,2 $2 \lambda^{5}$-dioxaphosphinan-2-one (25c)}

${ }^{1} \mathrm{H}-\mathrm{NMR}$
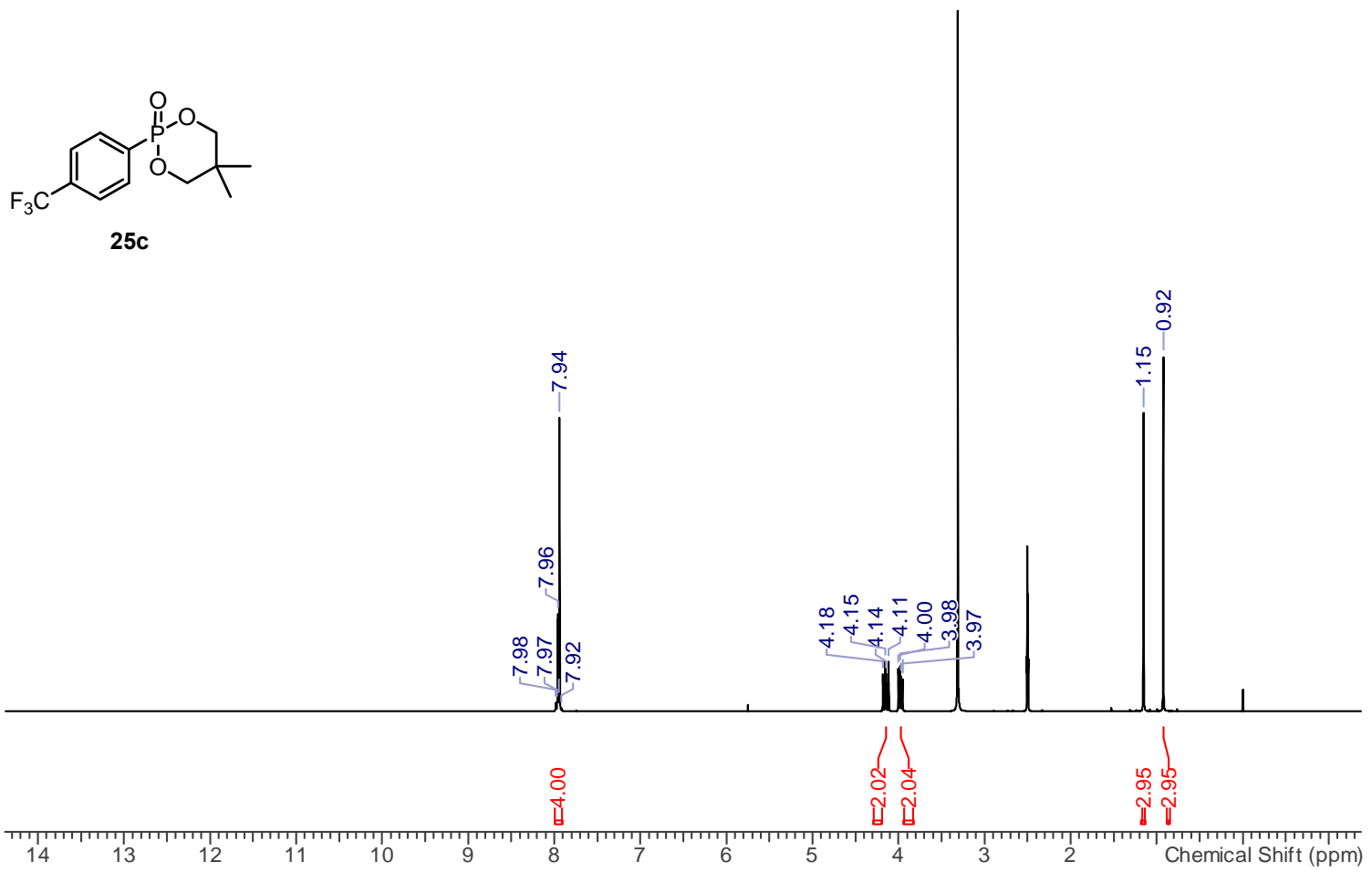


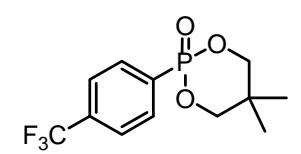

$25 \mathrm{c}$
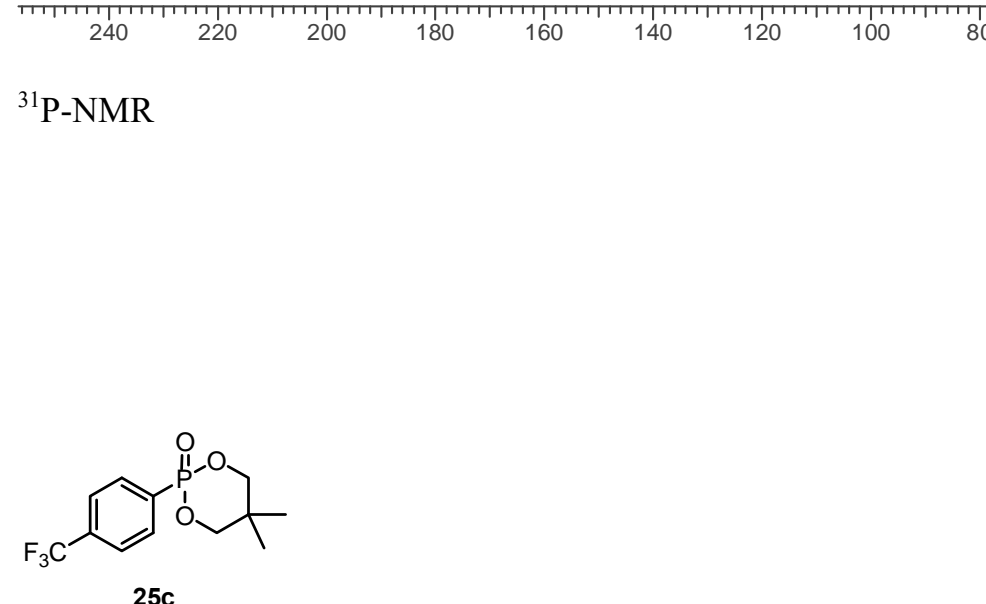

80

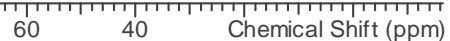

${ }^{31} \mathrm{P}-\mathrm{NMR}$

$25 c$

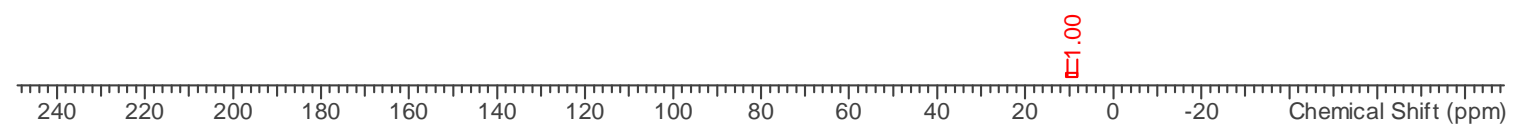


2-[4-(Trifluoromethyl)phenyl]-1,3,6,2 $\lambda^{5}$-dioxazaphosphocan-2-one Hydrochloride salt (25d)

${ }^{1} \mathrm{H}-\mathrm{NMR}$<smiles>O=P1(c2ccc(C(F)(F)F)cc2)CCNCCO1</smiles>

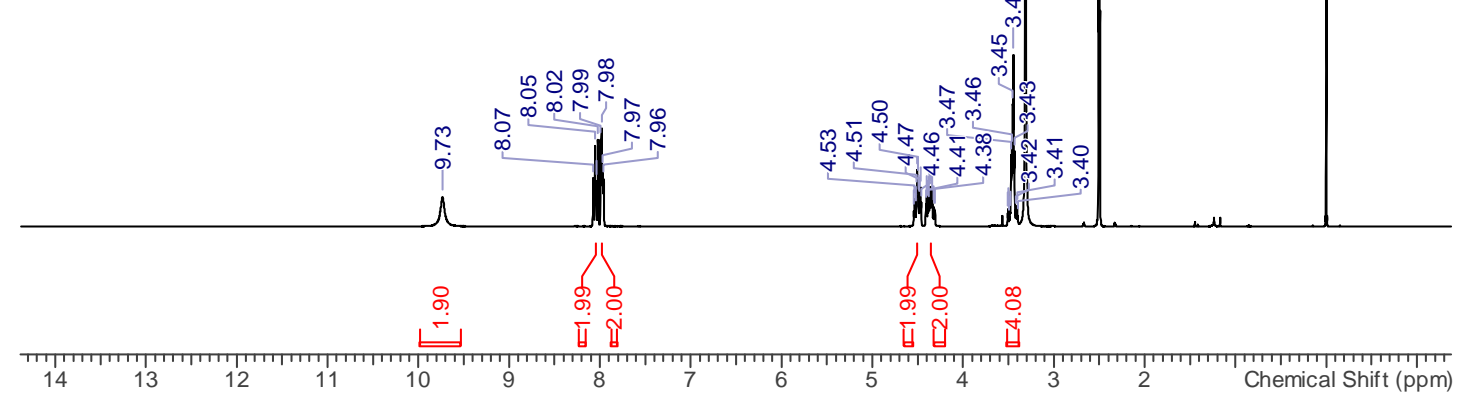

${ }^{13} \mathrm{C}-\mathrm{NMR}$

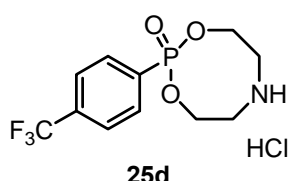

25d

$\mathrm{HCl}$

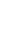

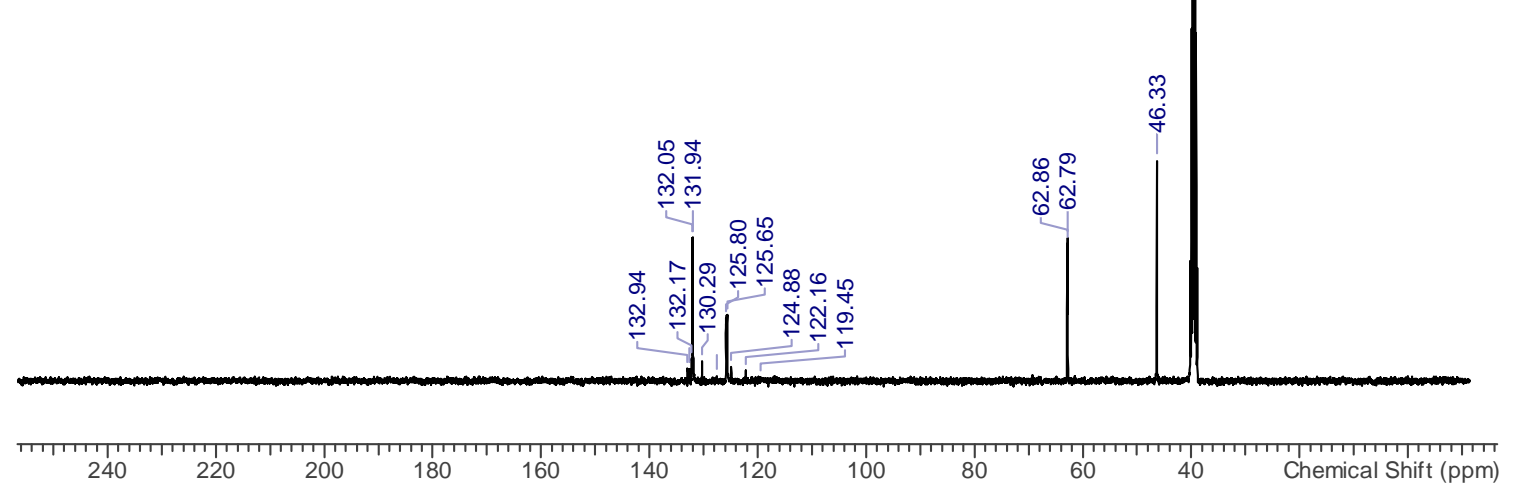



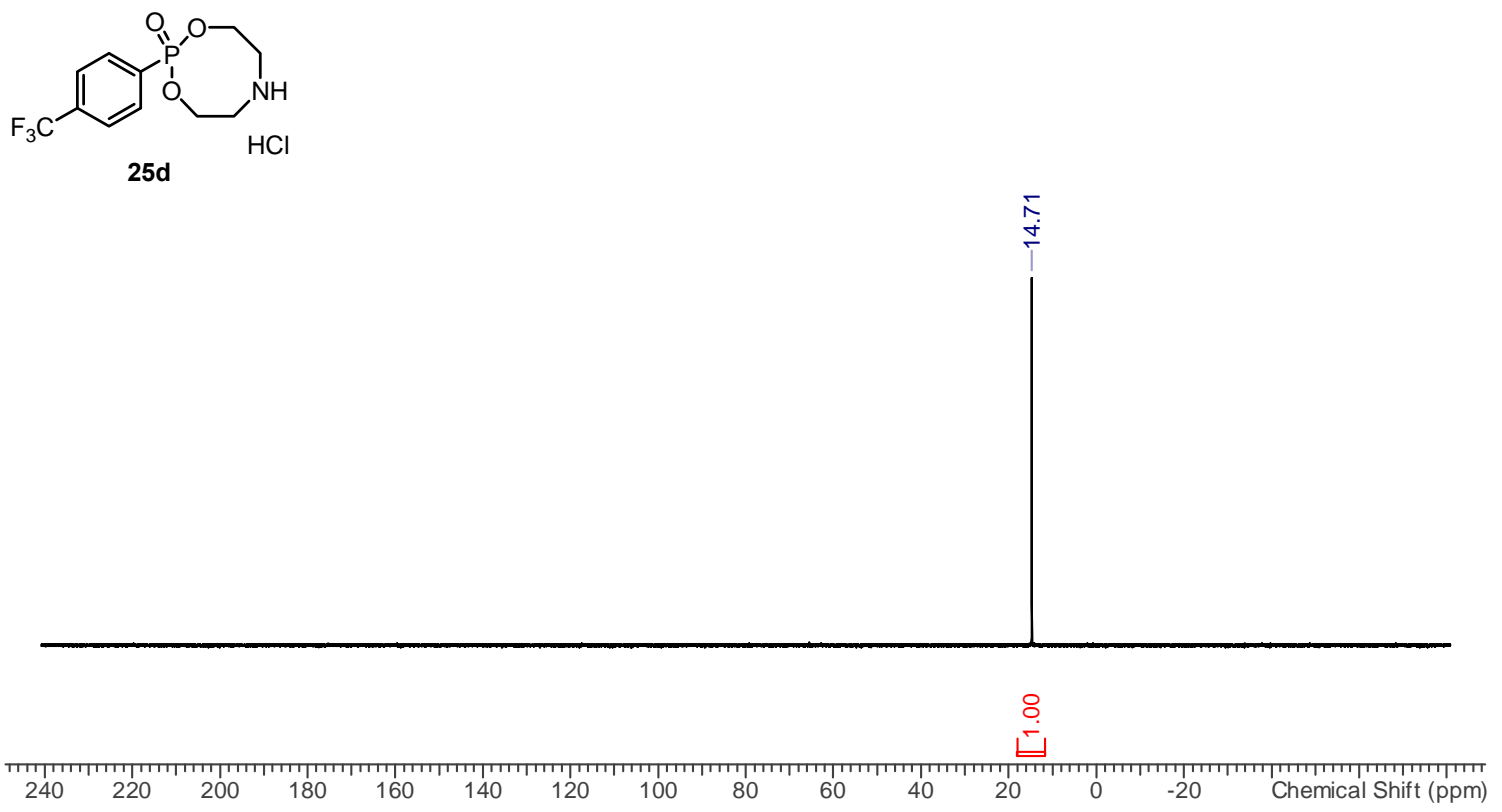

\section{2-[4-(Trifluoromethyl)phenyl]-1,3,2 $\lambda^{5}$-oxazaphosphinan-2-one (26a)}

${ }^{1} \mathrm{H}-\mathrm{NMR}$<smiles>O=P1(c2ccc(C(F)(F)F)cc2)NCCCO1</smiles>

26a

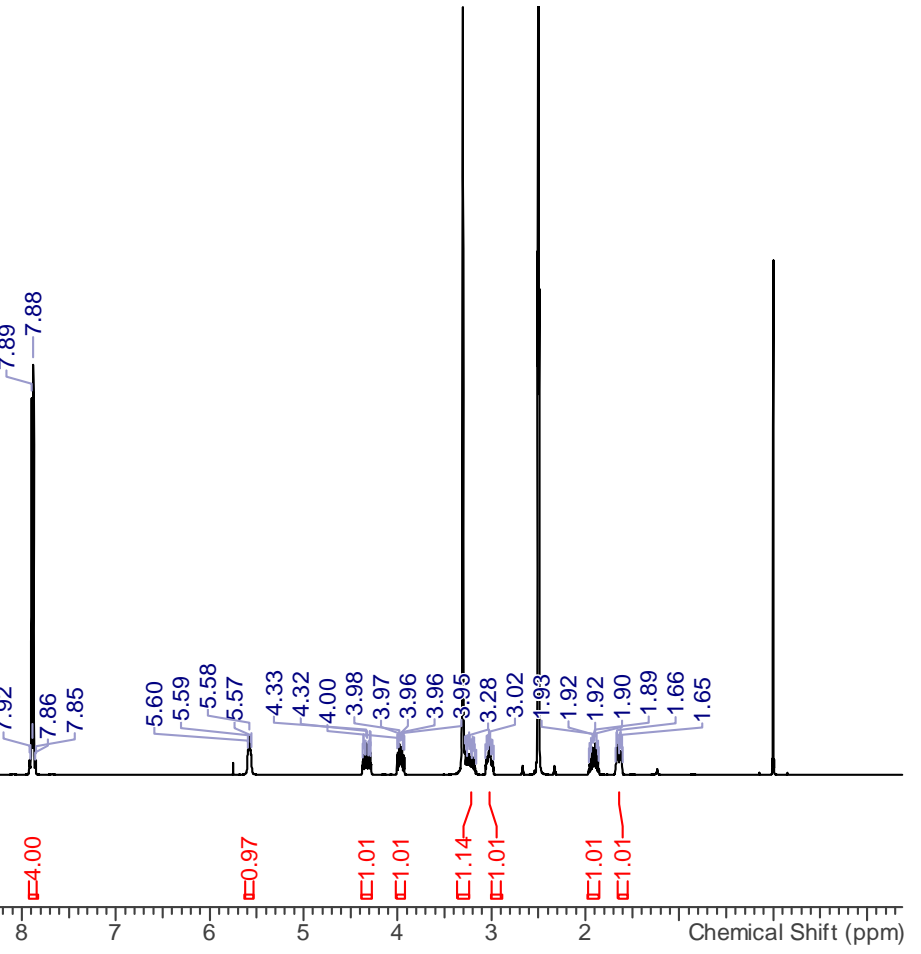


${ }^{13} \mathrm{C}-\mathrm{NMR}$<smiles>O=P1(c2ccc(C(F)(F)F)cc2)NCCCO1</smiles>

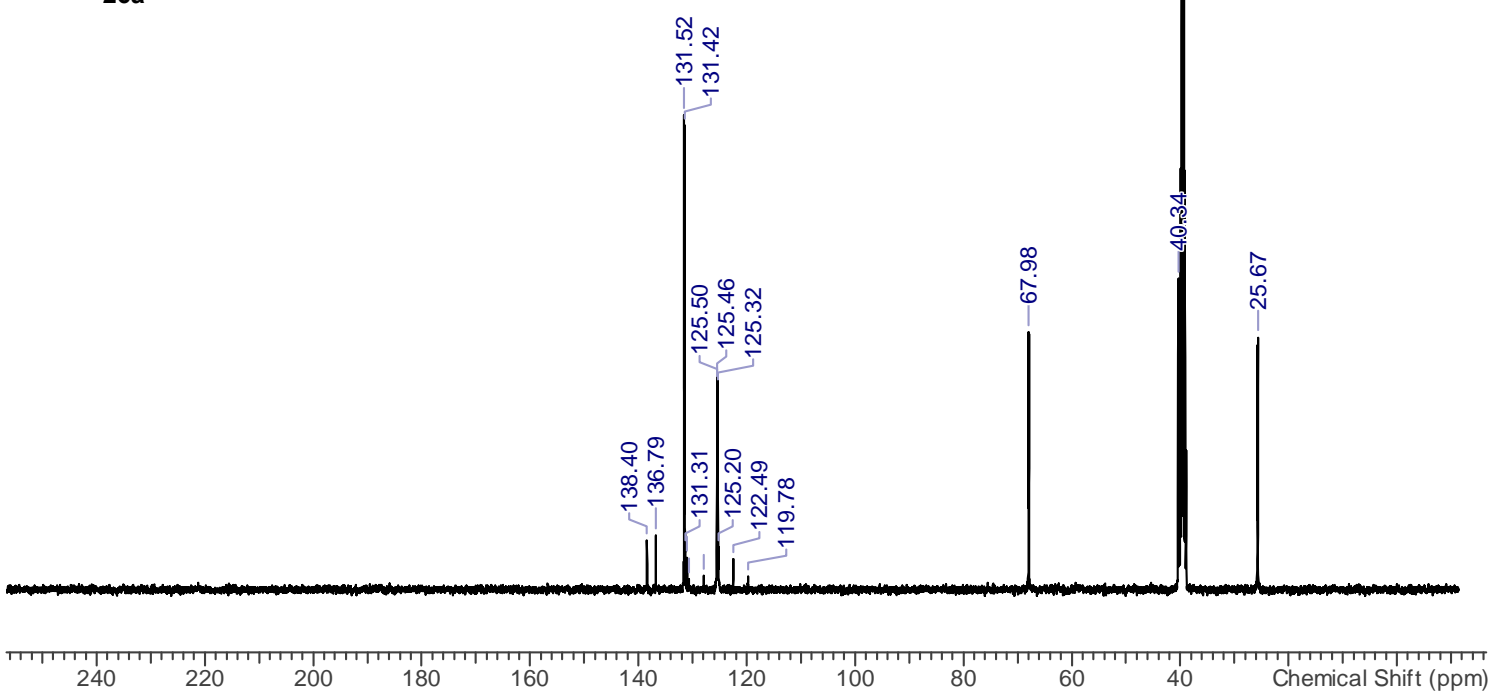

${ }^{31} \mathrm{P}-\mathrm{NMR}$<smiles>O=P1(c2ccc(C(F)(F)F)cc2)NCCCO1</smiles>

26a

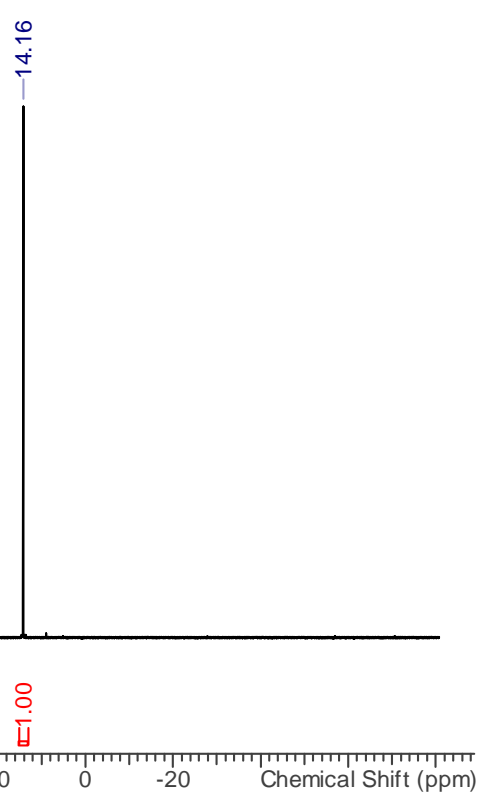




\section{3-Methyl-2-[4-(trifluoromethyl)phenyl]-1,3,2 $\lambda^{5}$-oxazaphosphinan-2-one (26b)}

${ }^{1} \mathrm{H}-\mathrm{NMR}$<smiles>CN1CCCOP1(=O)c1ccc(C(F)(F)F)cc1</smiles>

26b

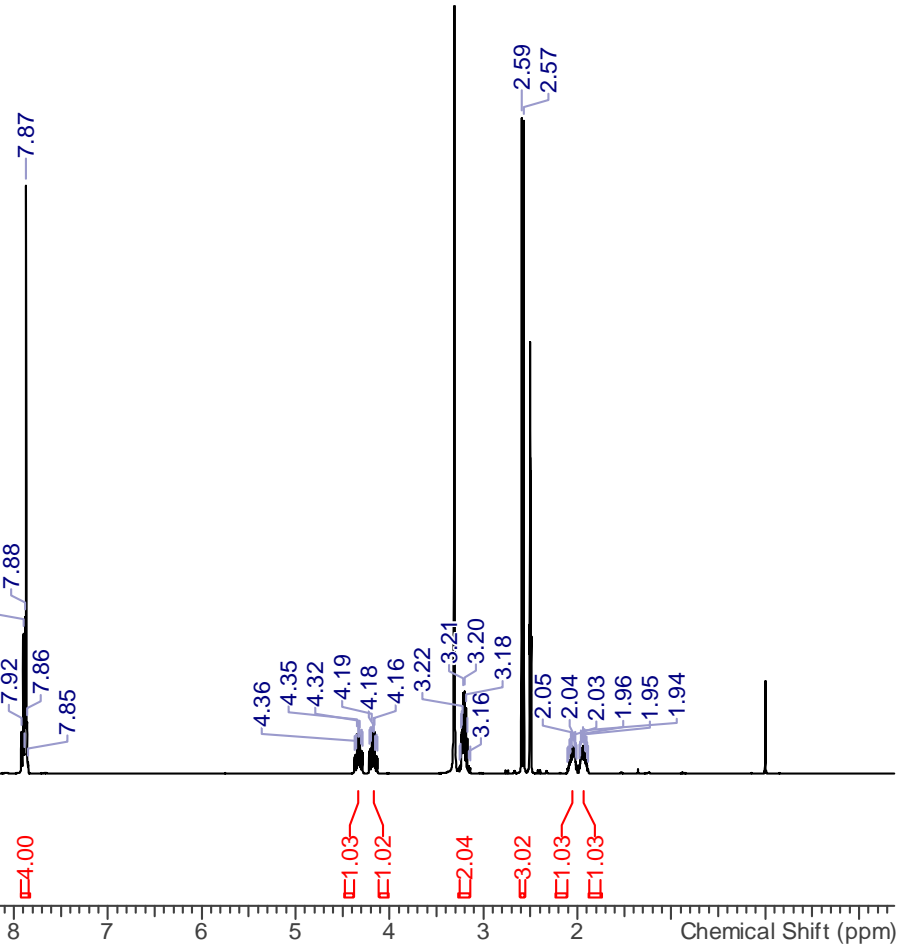

${ }^{13} \mathrm{C}-\mathrm{NMR}$<smiles>O=P1(c2ccc(C(F)(F)F)cc2)OCCC[N+]1([O-])c1ccccc1</smiles>

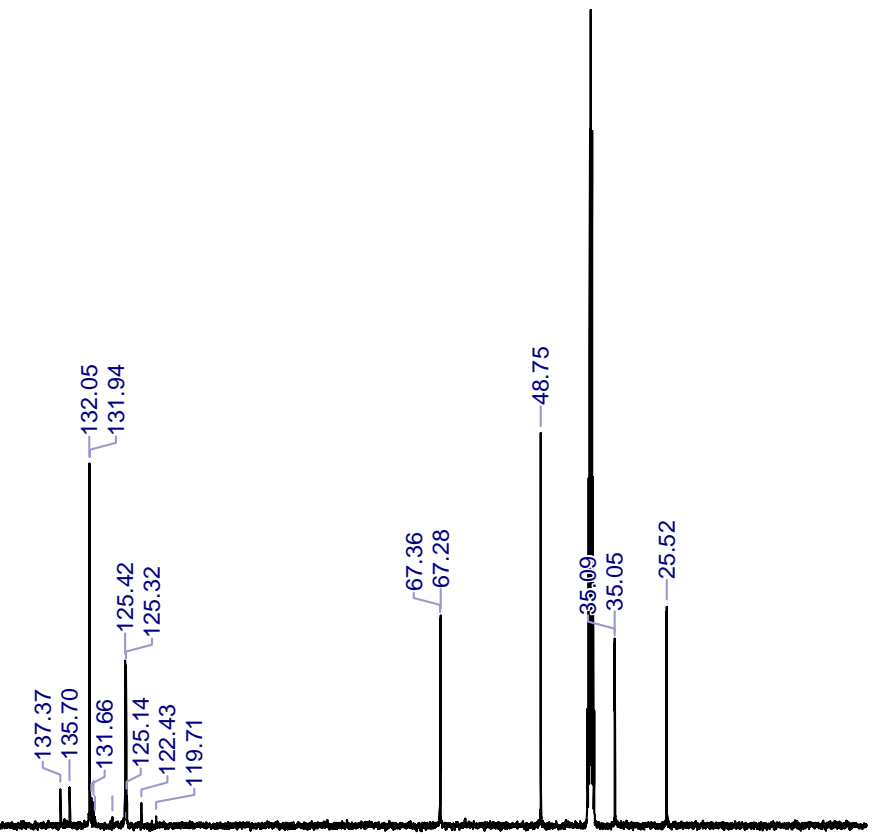

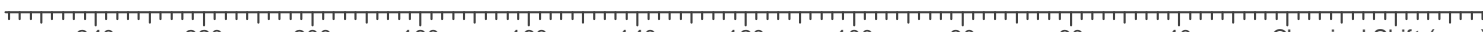
$\begin{array}{llllllllllll}240 & 220 & 200 & 180 & 160 & 140 & 120 & 100 & 80 & 60 & 40 & \text { Chemical Shift (ppm) }\end{array}$ 

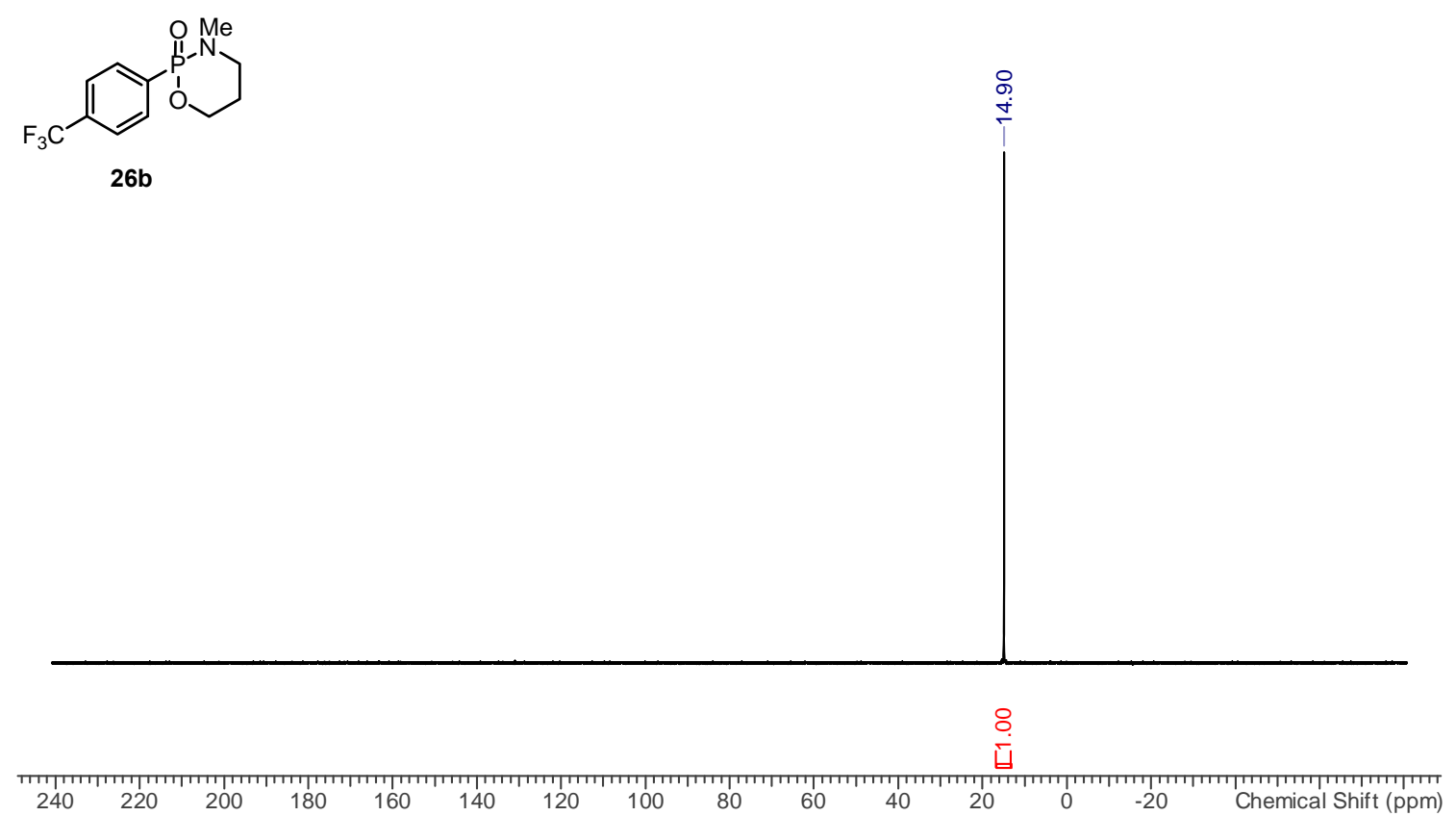

\section{1,3-Dimethyl-2-[4-(trifluoromethyl)phenyl]-1,3,2 $2 \lambda^{5}$-diazaphospholan-2-one (27a)}

${ }^{1} \mathrm{H}-\mathrm{NMR}$

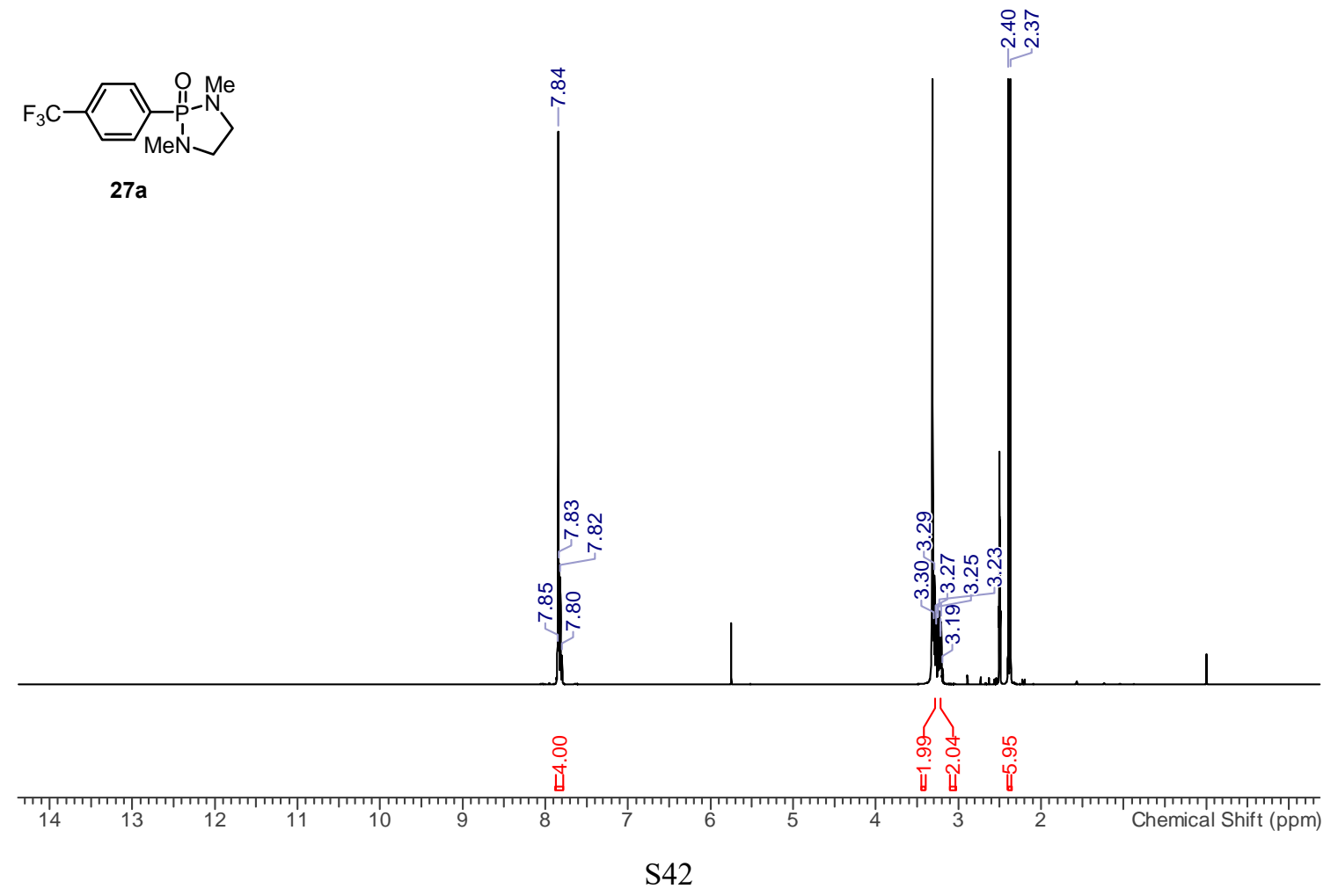


${ }^{13} \mathrm{C}-\mathrm{NMR}$
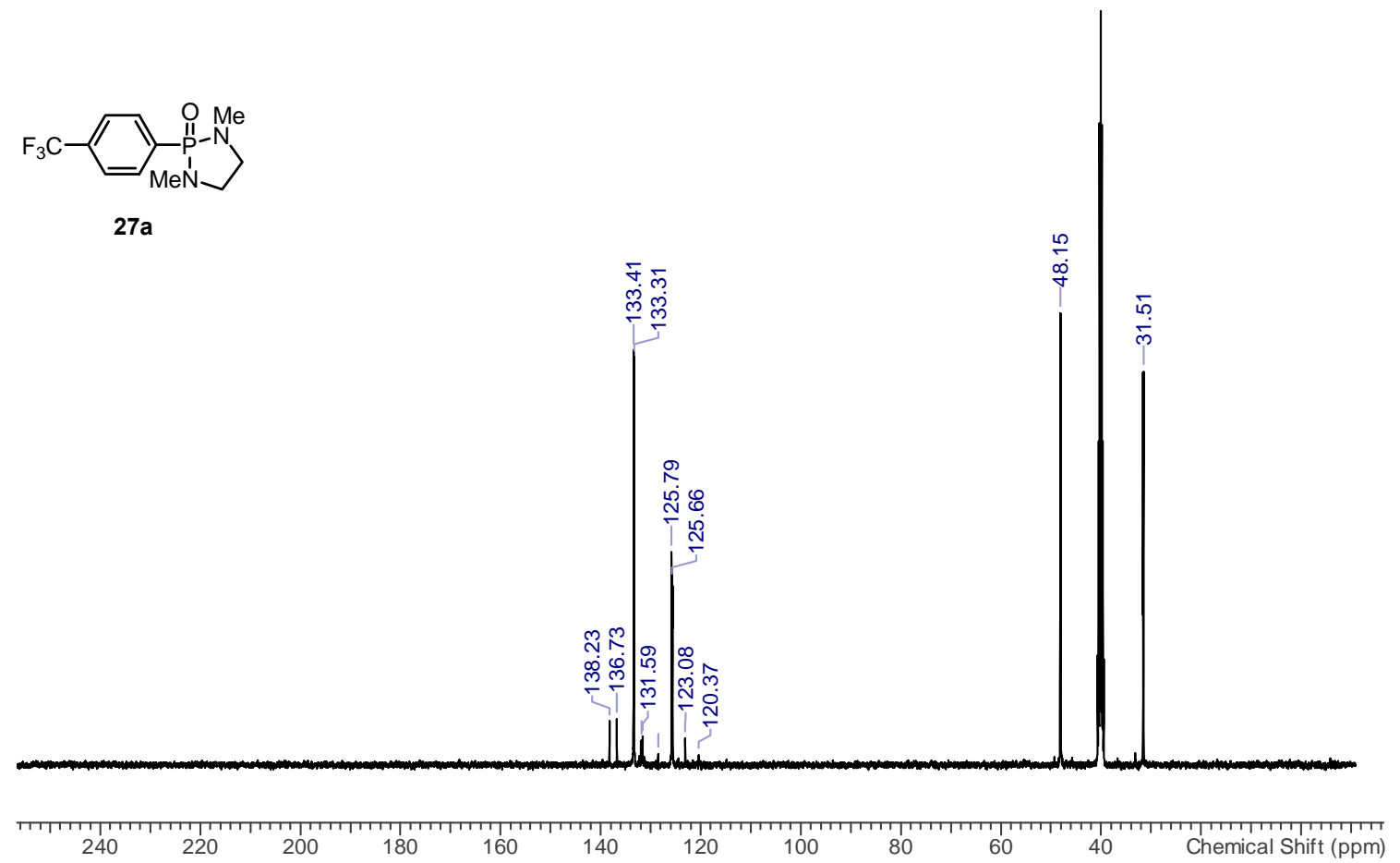

${ }^{31} \mathrm{P}-\mathrm{NMR}$

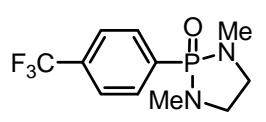

27a

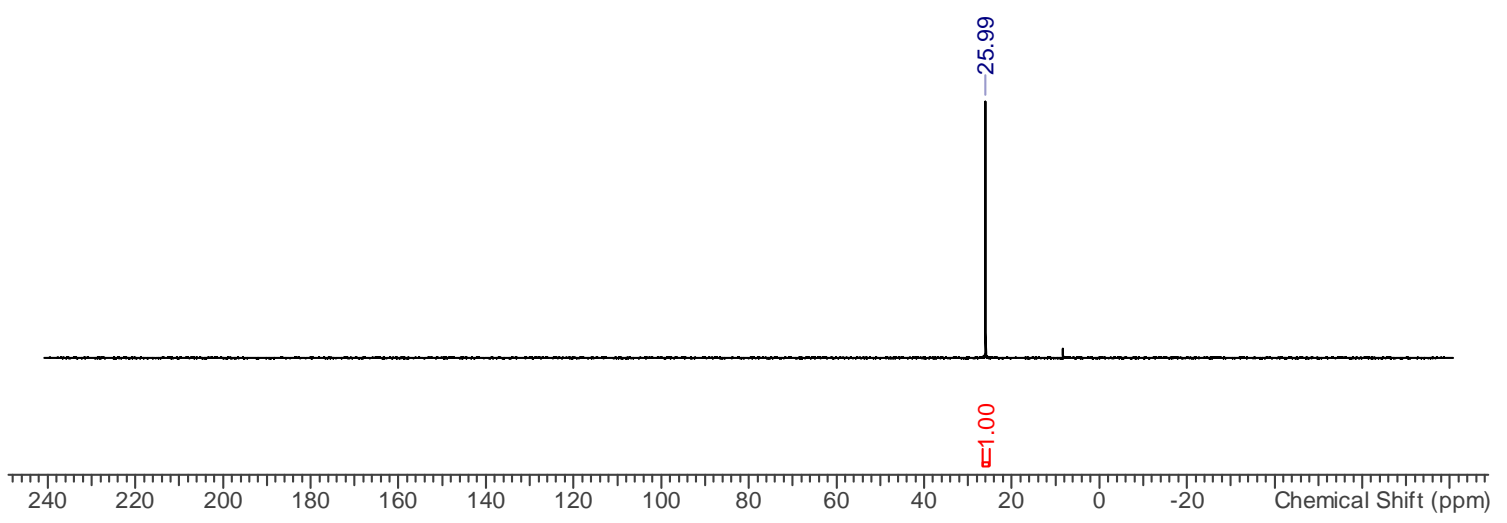


2-[4-(Trifluoromethyl)phenyl]-1,3,2 $\lambda^{5}$-diazaphosphinan-2-one (27b)

${ }^{1} \mathrm{H}-\mathrm{NMR}$<smiles>O=P1(c2ccc(C(F)(F)F)cc2)NCCCN1</smiles>

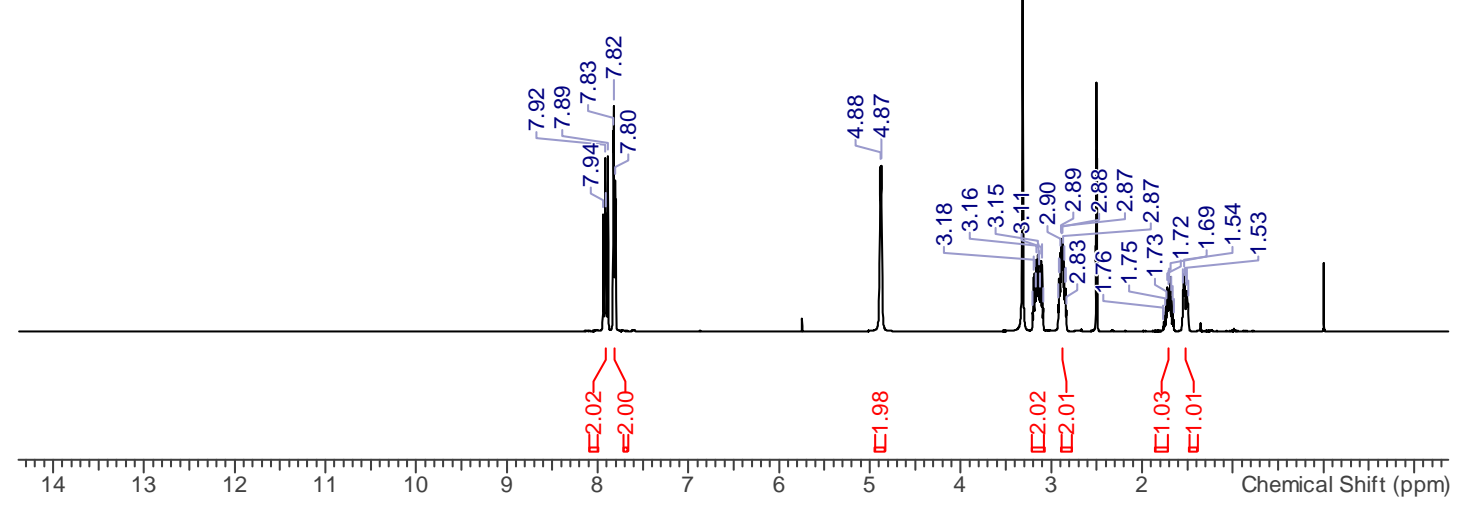

${ }^{13} \mathrm{C}-\mathrm{NMR}$<smiles>O=P1(c2ccc(C(F)(F)F)cc2)NCCCN1</smiles>
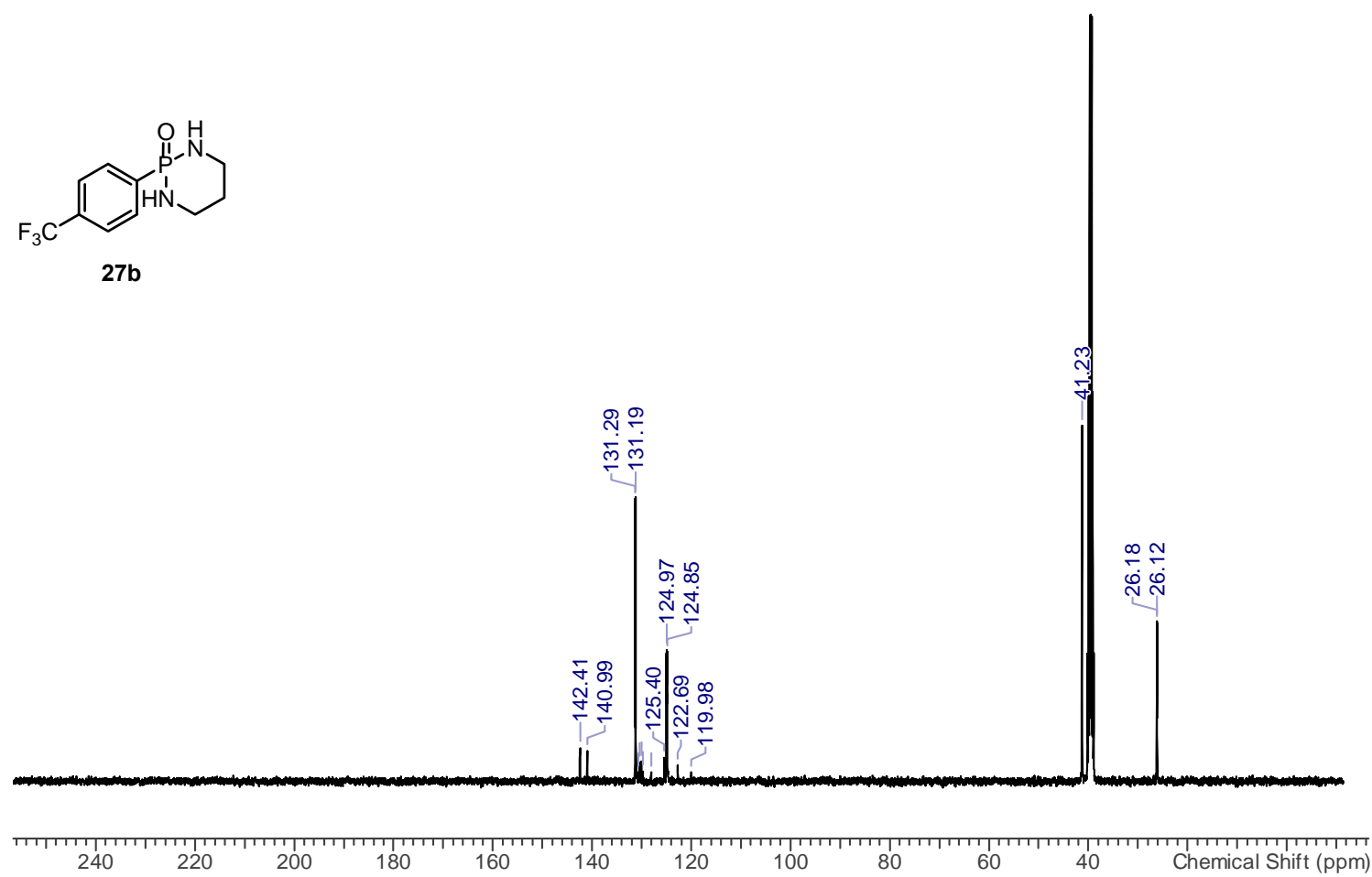
<smiles>O=P1(c2ccc(C(F)(F)F)cc2)NCCCN1</smiles>

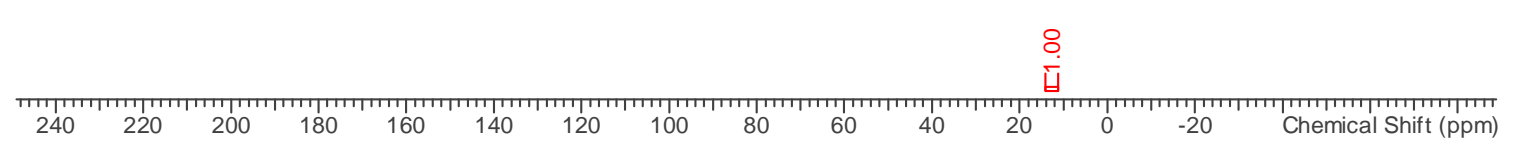

\section{1,3-Dimethyl-2-[4-(trifluoromethyl)phenyl]-1,3,2 $2 \lambda^{5}$-diazaphosphinan-2-one (27c)}

${ }^{1} \mathrm{H}-\mathrm{NMR}$

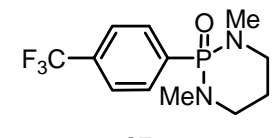

27c

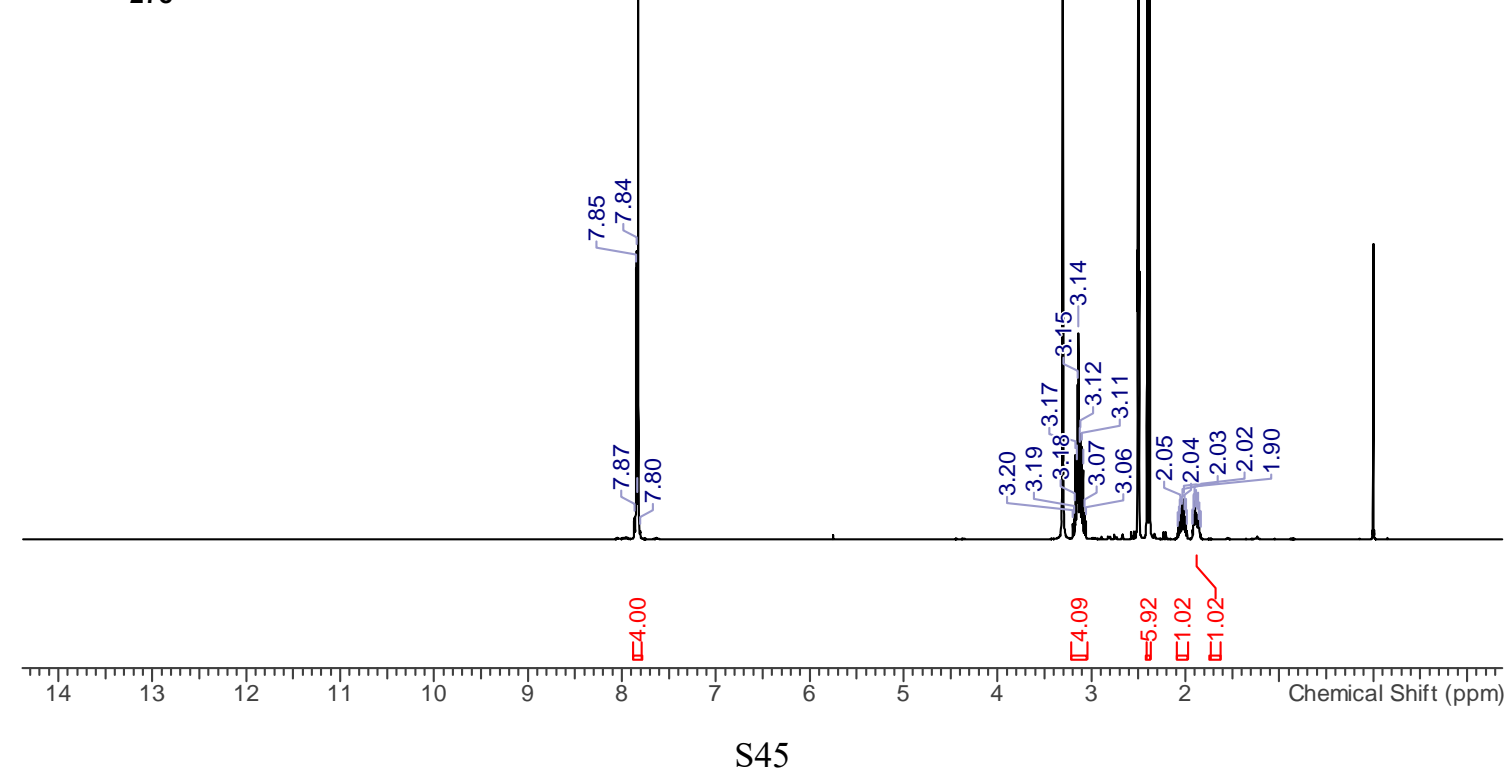


${ }^{13} \mathrm{C}-\mathrm{NMR}$

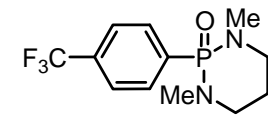

27c
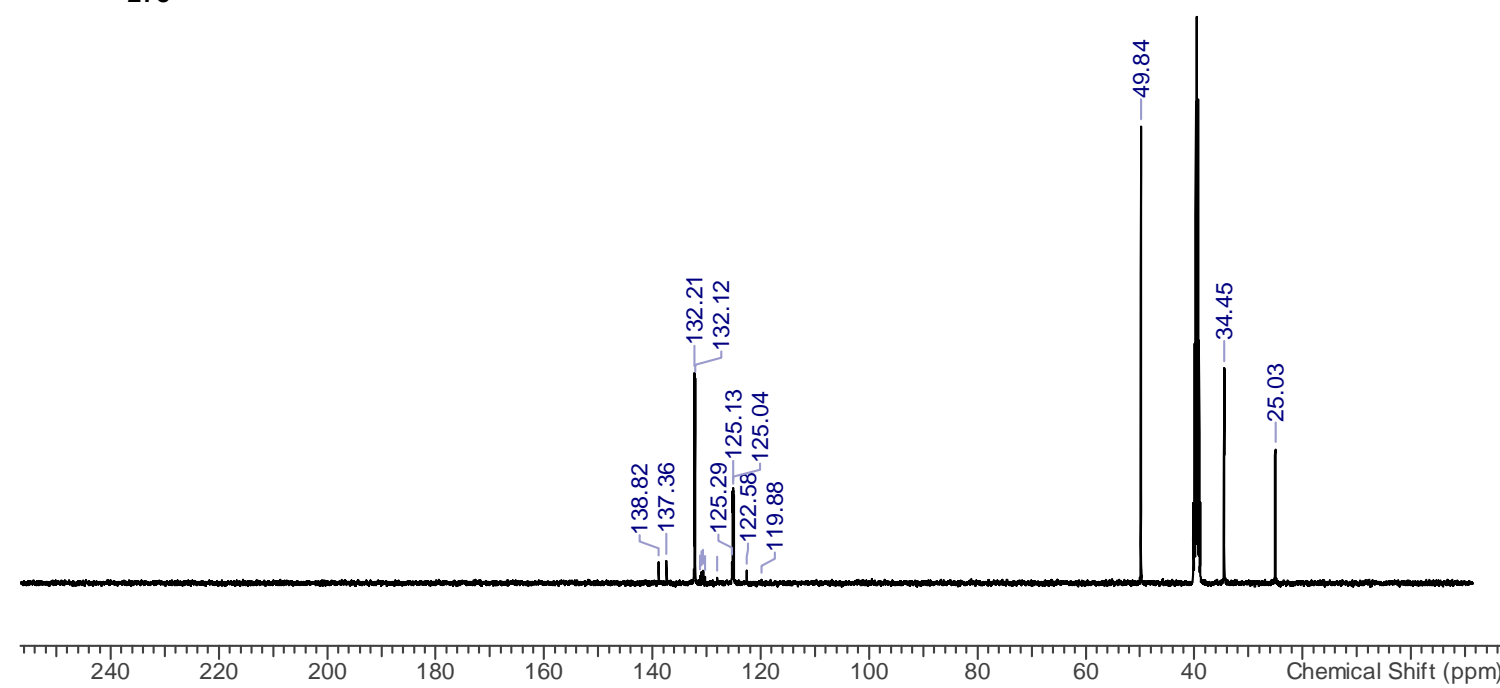

${ }^{31}$ P-NMR

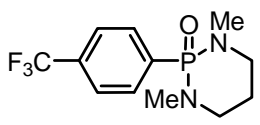

27c



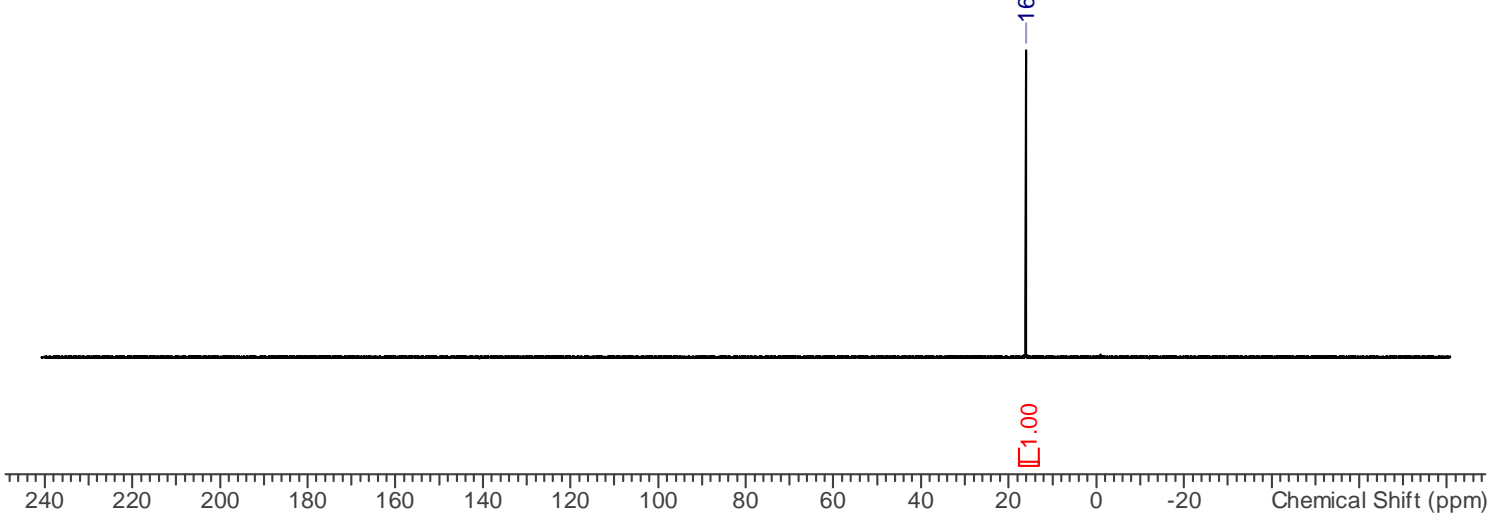


4-(Diethylphosphoryl)pyridine (28a)

${ }^{1} \mathrm{H}-\mathrm{NMR}$<smiles>CCP(=O)(c1ccncc1)c1cccnc1</smiles>

28a

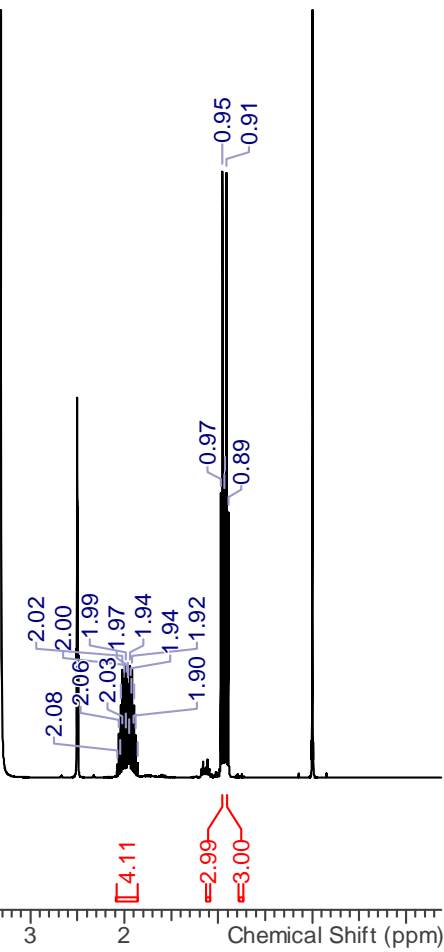

\section{Ethyl Methyl(pyridine-4-yl)phosphinate (28b)}

${ }^{1} \mathrm{H}-\mathrm{NMR}$
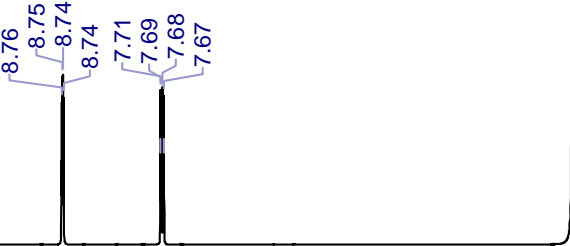

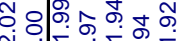

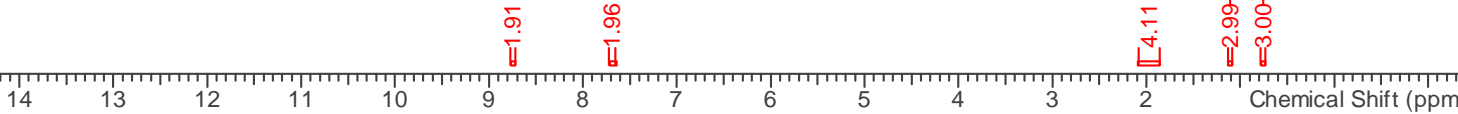

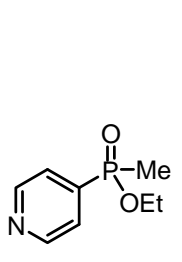

$28 b$

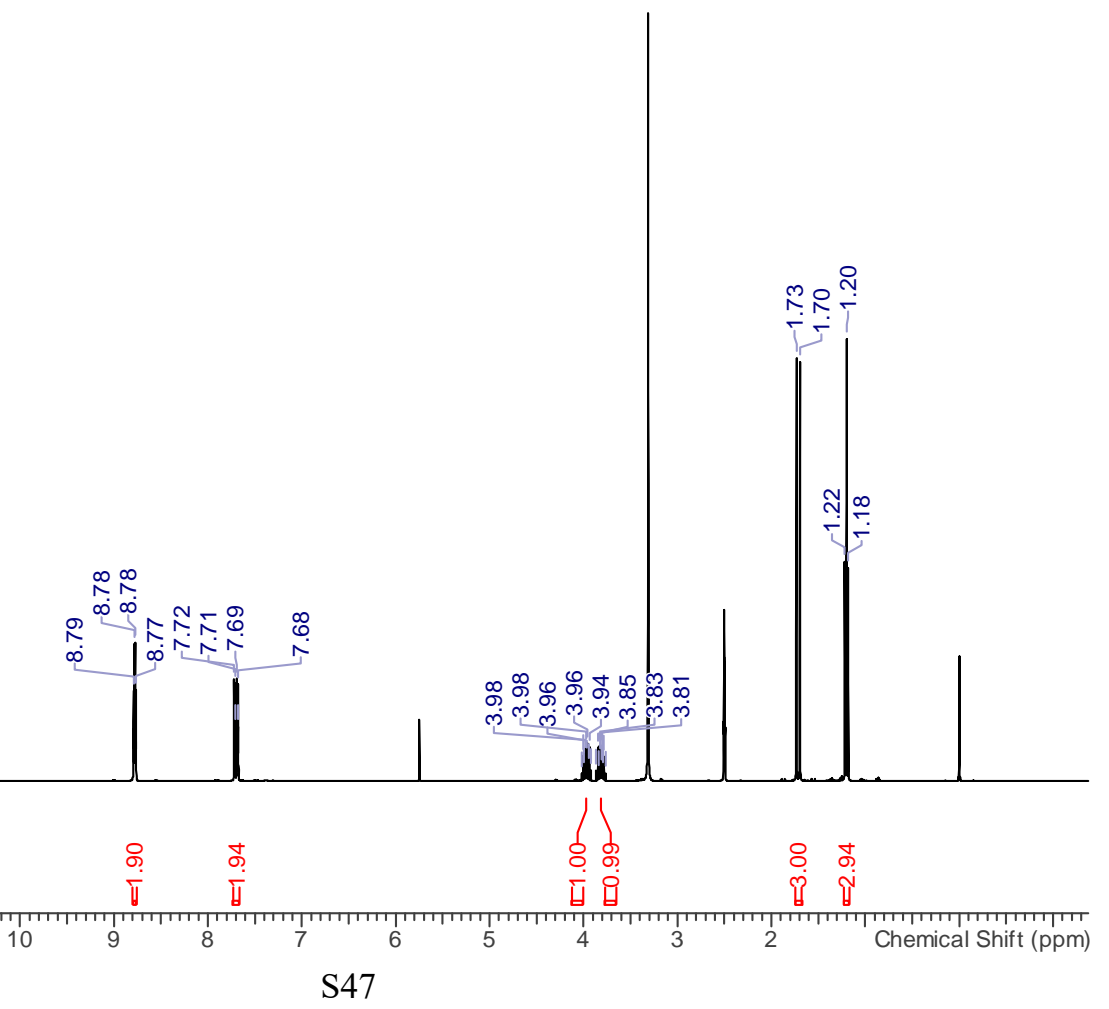


${ }^{13} \mathrm{C}-\mathrm{NMR}$

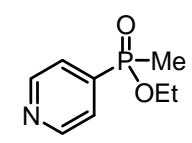

$28 b$
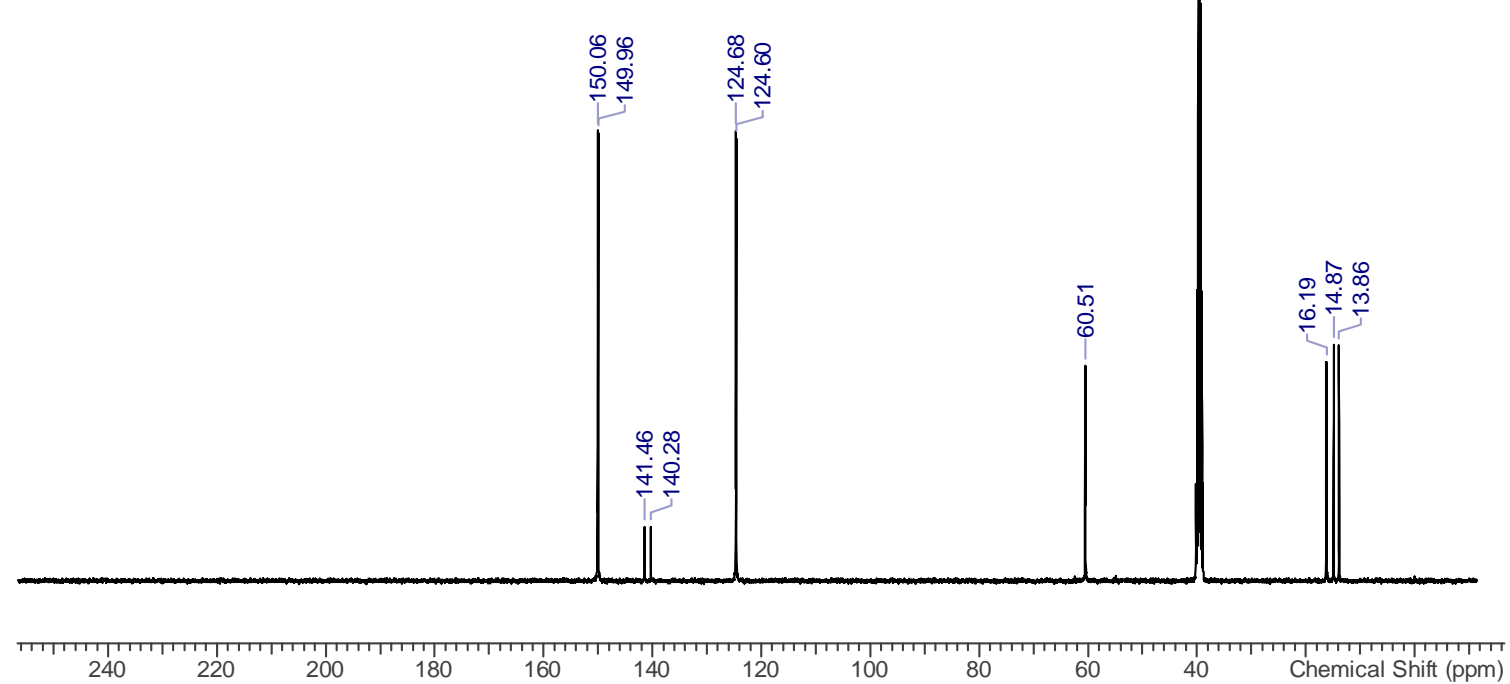

${ }^{31} \mathrm{P}-\mathrm{NMR}$

N

$28 b$ 


\section{4-((4-Methyl-3-((4-(pyridin-3-yl)pyrimidin-2-yl)amino)phenyl)carbamoyl)benzoic Acid}

Trifluoroacetate salt $(37 \mathrm{a} \cdot \mathrm{TFA})$

${ }^{1} \mathrm{H}-\mathrm{NMR}$

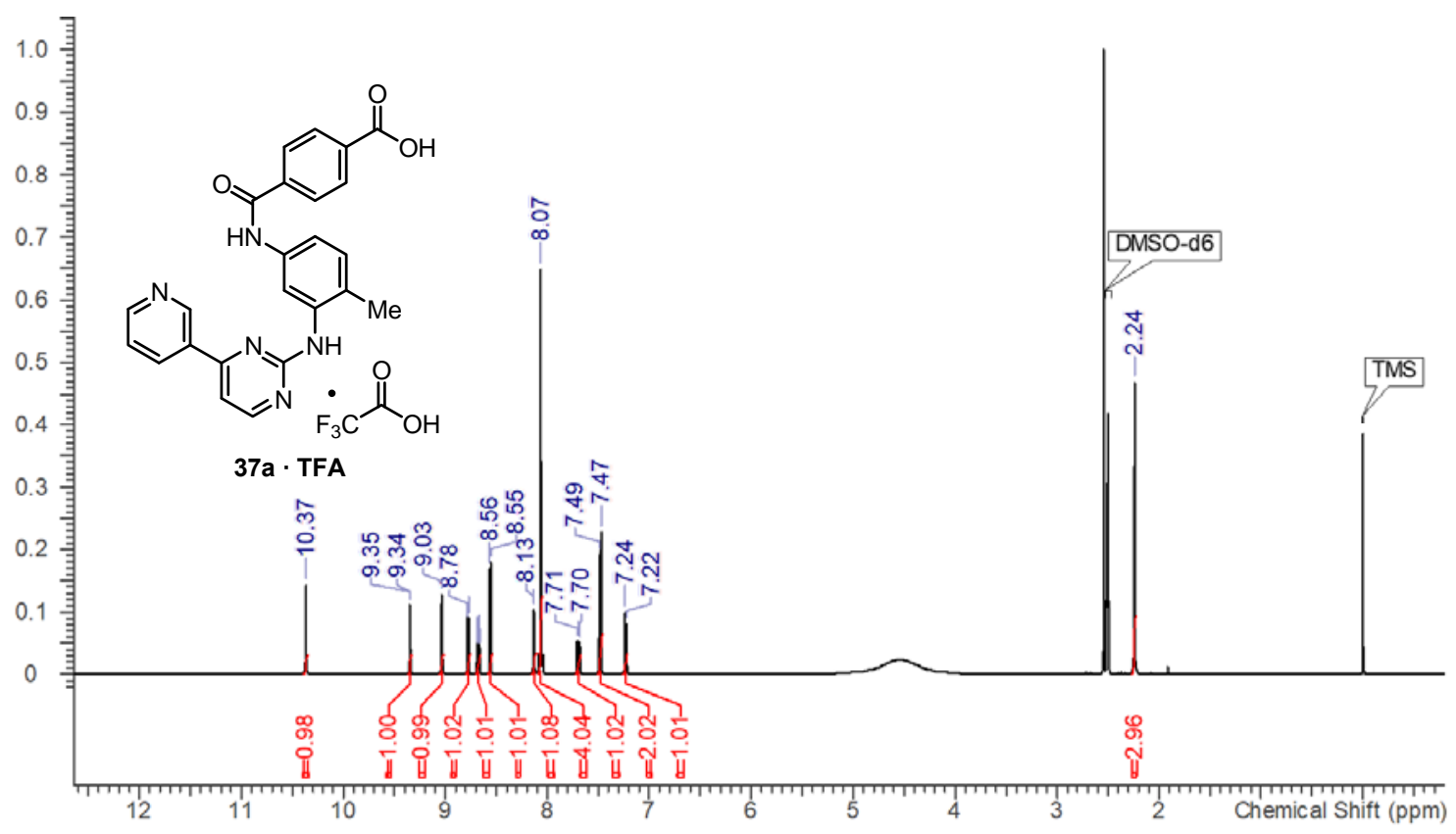

${ }^{13} \mathrm{C}-\mathrm{NMR}$

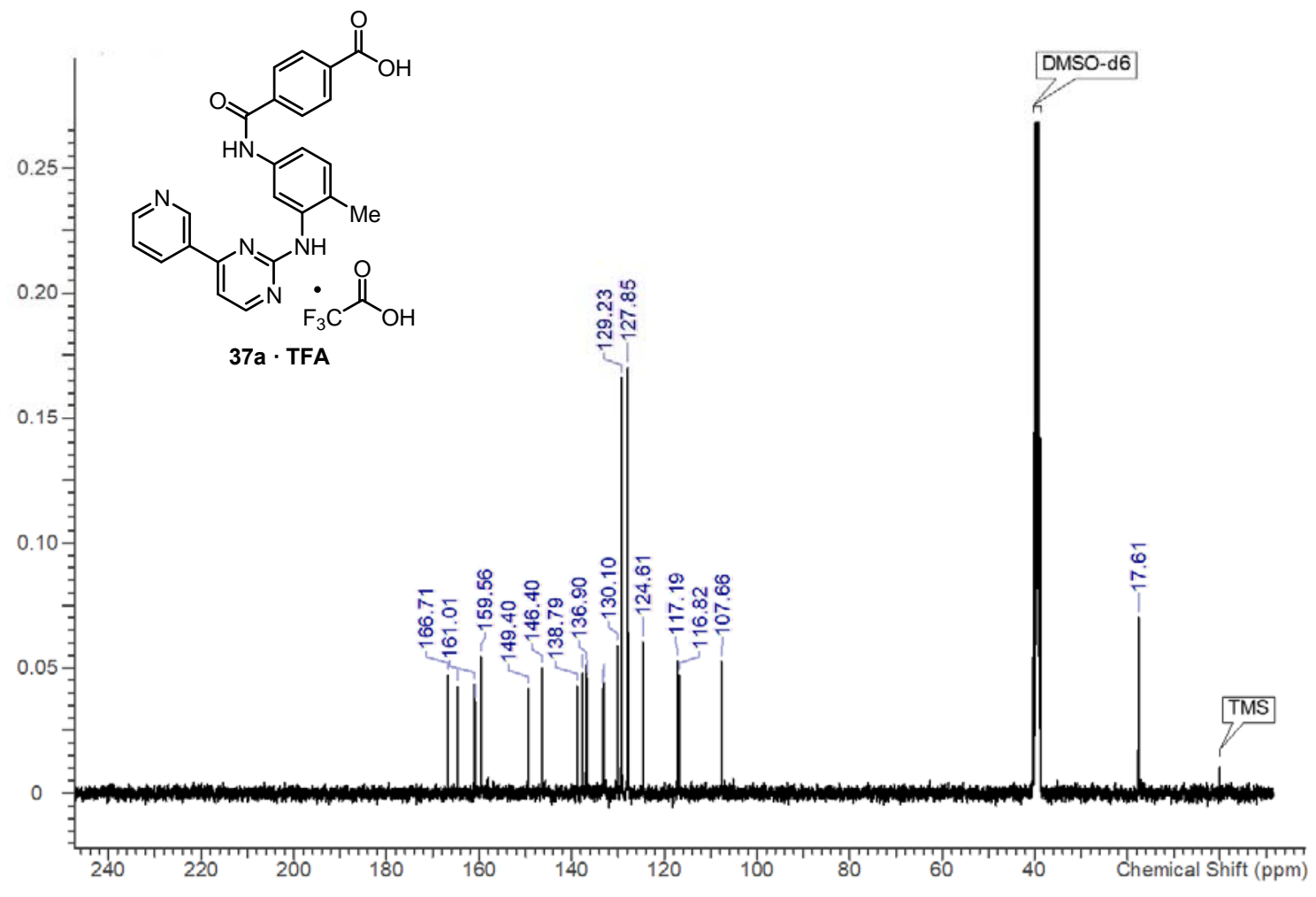


Ethyl 4'-Methyl-3'-\{[4-(pyridine-3-yl)pyrimidin-2-yl]amino\}-[1,1'-biphenyl]-4-carboxylate

Trifluoroacetate salt (37b·TFA)

${ }^{1} \mathrm{H}-\mathrm{NMR}$<smiles>CCOC(=O)c1ccc(C(=O)Nc2ccc(C)c(Nc3nccc(-c4cccnc4)n3)c2)cc1</smiles>

37b · TFA
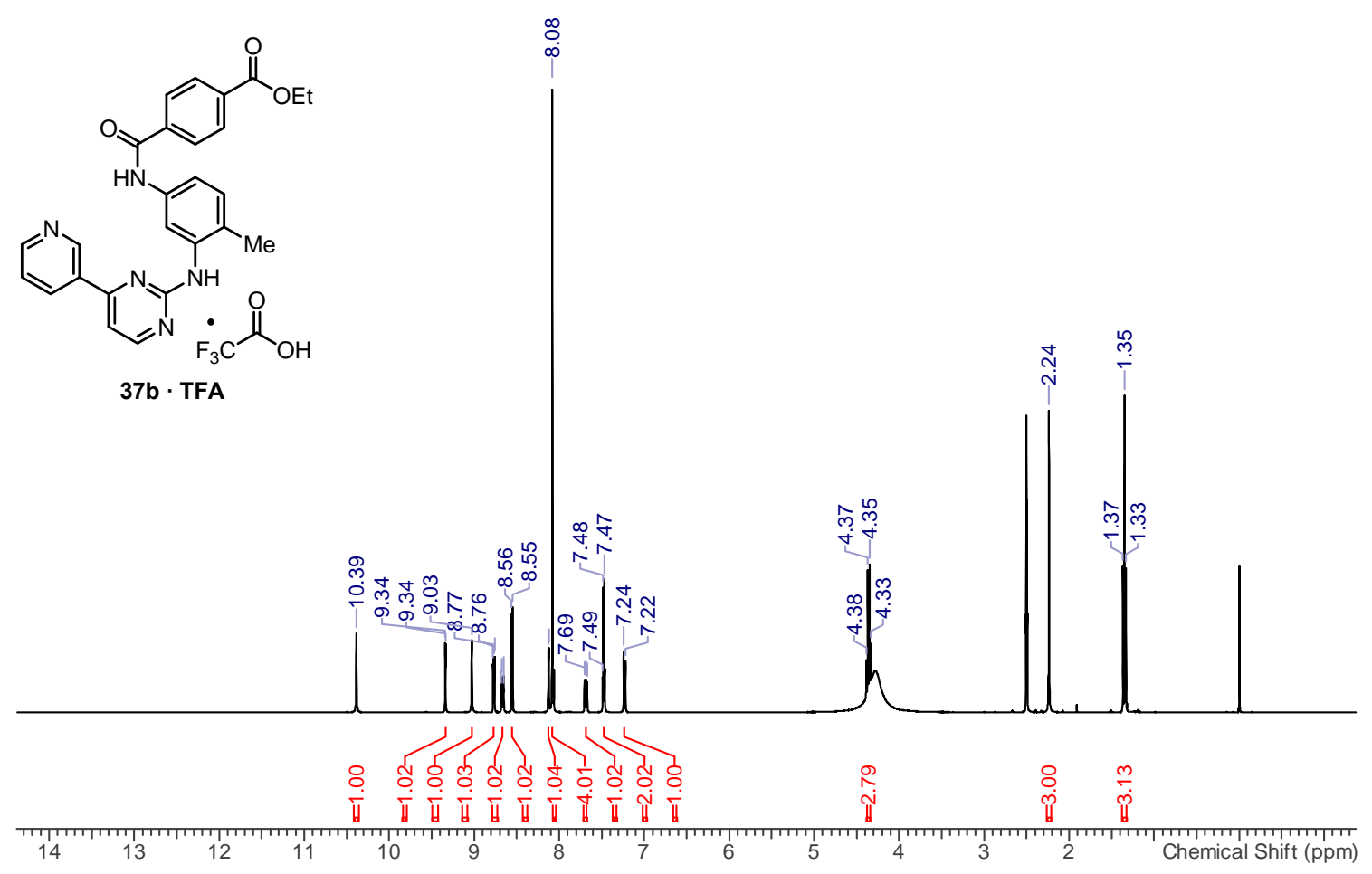

${ }^{13} \mathrm{C}-\mathrm{NMR}$<smiles>CCOC(=O)c1ccc(C(=O)Nc2ccc(C)c(Nc3nccc(-c4cccnc4)n3)c2)cc1</smiles>

37b - TFA

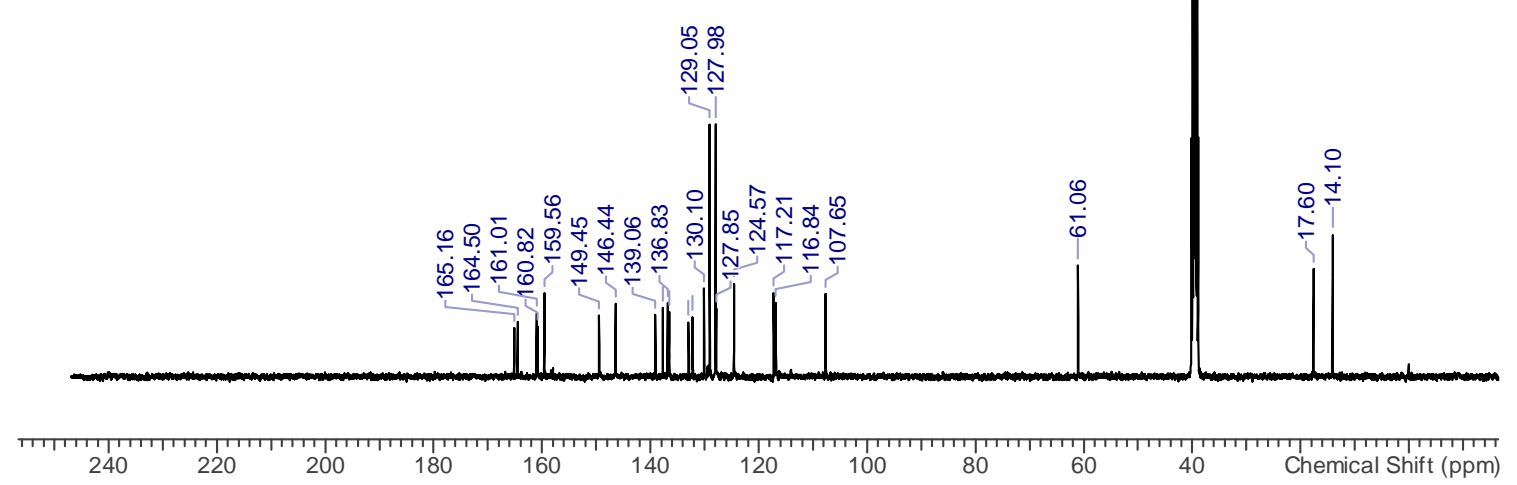




\section{$N^{I}$-(4-Methyl-3-\{[4-(pyridin-3-yl)pyrimidin-2-yl]amino\}phenyl)benzene-1,4-dicarboxamide}

Trifluoroacetate salt $(38 \mathrm{a} \cdot \mathrm{TFA})$

${ }^{1} \mathrm{H}-\mathrm{NMR}$<smiles>Cc1ccc(NC(=O)c2ccc(C(N)=O)cc2)c(Nc2nccc(-c3cccnc3)n2)c1</smiles>

38a $\cdot$ TFA

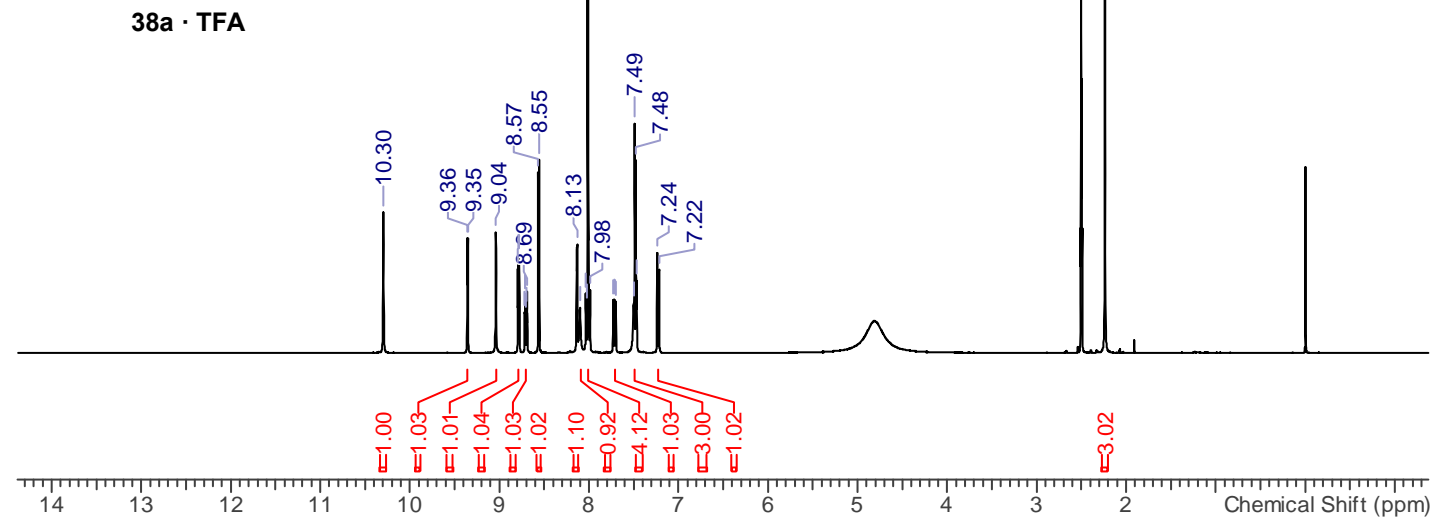

${ }^{13} \mathrm{C}-\mathrm{NMR}$<smiles>Cc1ccc(NC(=O)c2ccc(C(N)=O)cc2)c(Nc2nccc(-c3cccnc3)n2)c1</smiles>

38a $\cdot$ TFA

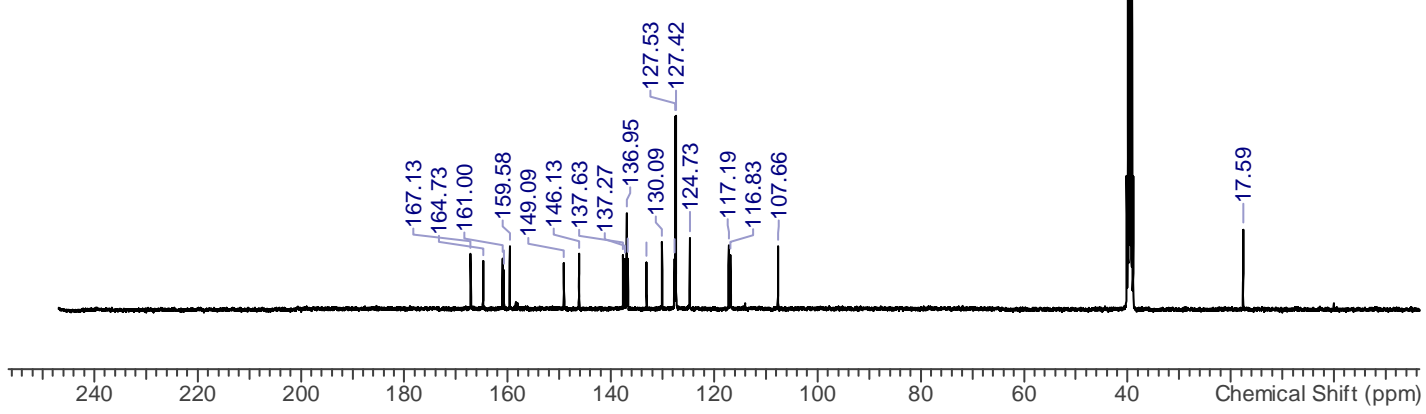


$N^{I}$-Methyl- $N^{4}$-(4-methyl-3-\{[4-(pyridin-3-yl)pyrimidin-2-yl]amino\} phenyl)benzene-1,4dicarboxamide Trifluoroacetate salt $(38 \mathrm{~b} \cdot$ TFA)

${ }^{1} \mathrm{H}-\mathrm{NMR}$
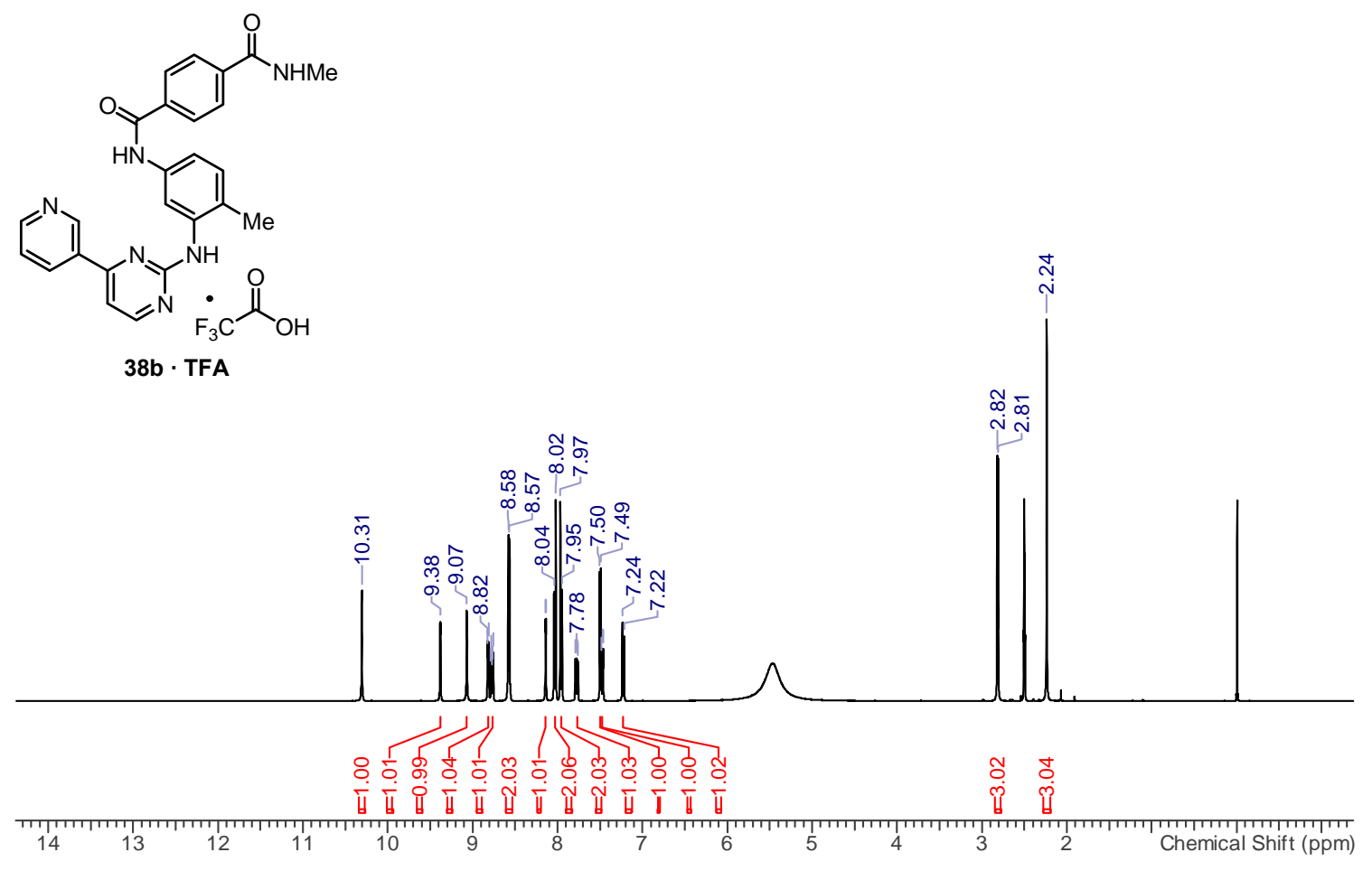

${ }^{13} \mathrm{C}-\mathrm{NMR}$
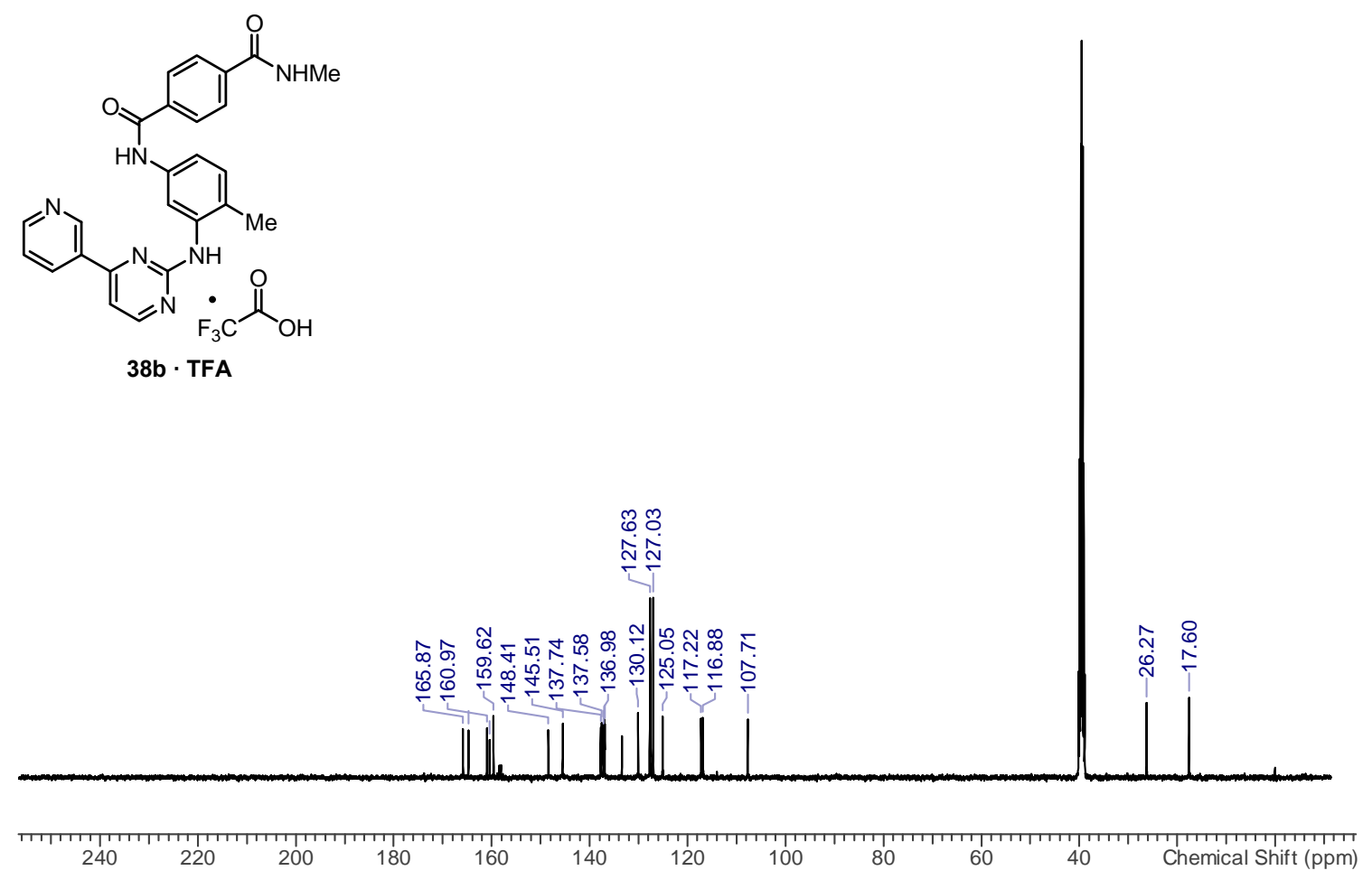
$N^{I}, N^{l}$-Dimethyl-N4-(4-methyl-3-\{[4-(pyridin-3-yl)pyrimidin-2-yl]amino\}phenyl)benzene-1,4dicarboxamide Trifluoroacetate salt (38c-TFA)

${ }^{1} \mathrm{H}-\mathrm{NMR}$<smiles>CNC(=O)c1ccc(C(=O)Nc2ccc(C)c(Nc3nccc(-c4cccnc4)n3)c2)cc1</smiles>
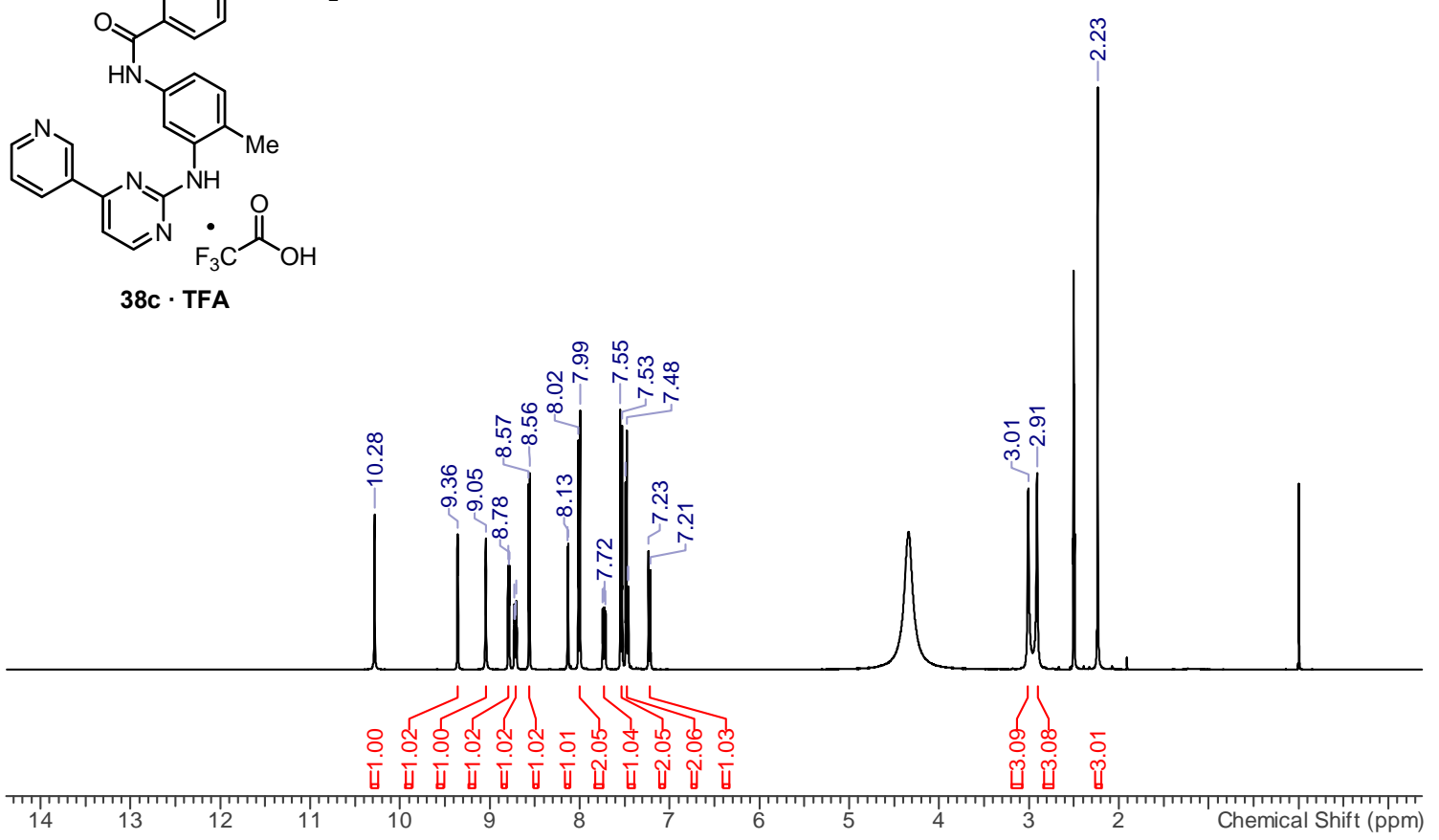

${ }^{13} \mathrm{C}-\mathrm{NMR}$<smiles>CNC(=O)c1ccc(C(=O)Nc2ccc(C)c(Nc3nccc(-c4cccnc4)n3)c2)cc1</smiles>

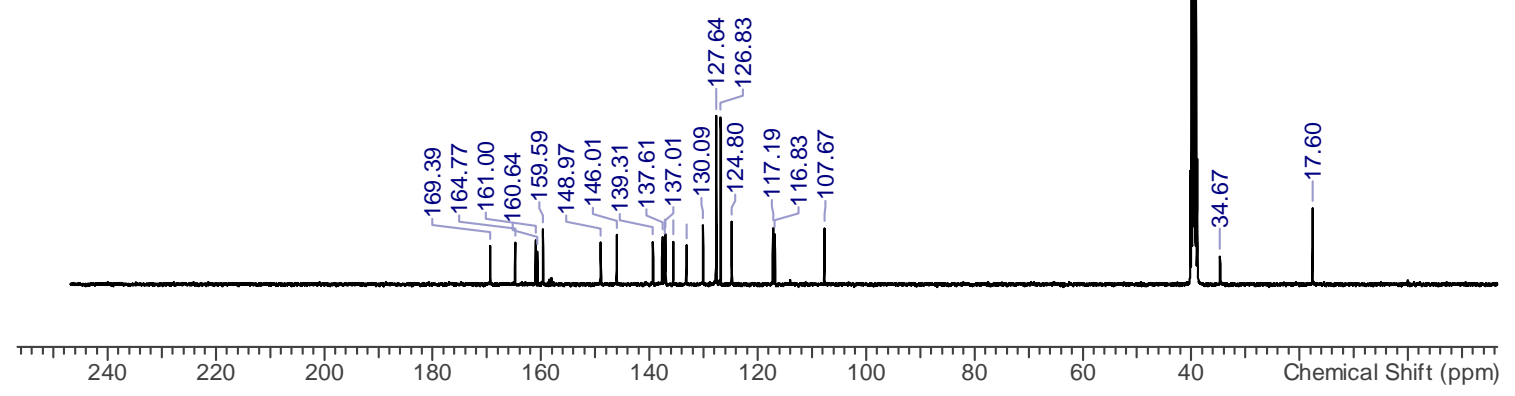




\section{4-Methanesulfinyl- $N$-(4-methyl-3-\{[4-(pyridin-3-yl)pyrimidin-2-yl]amino\}phenyl)benzamide}

Trifluoroacetate salt (39·TFA)

${ }^{1} \mathrm{H}-\mathrm{NMR}$<smiles>Cc1ccc(NC(=O)c2ccc(S(C)=O)cc2)c(Nc2nccc(-c3cccnc3)n2)c1</smiles>

$39 \cdot$ TFA

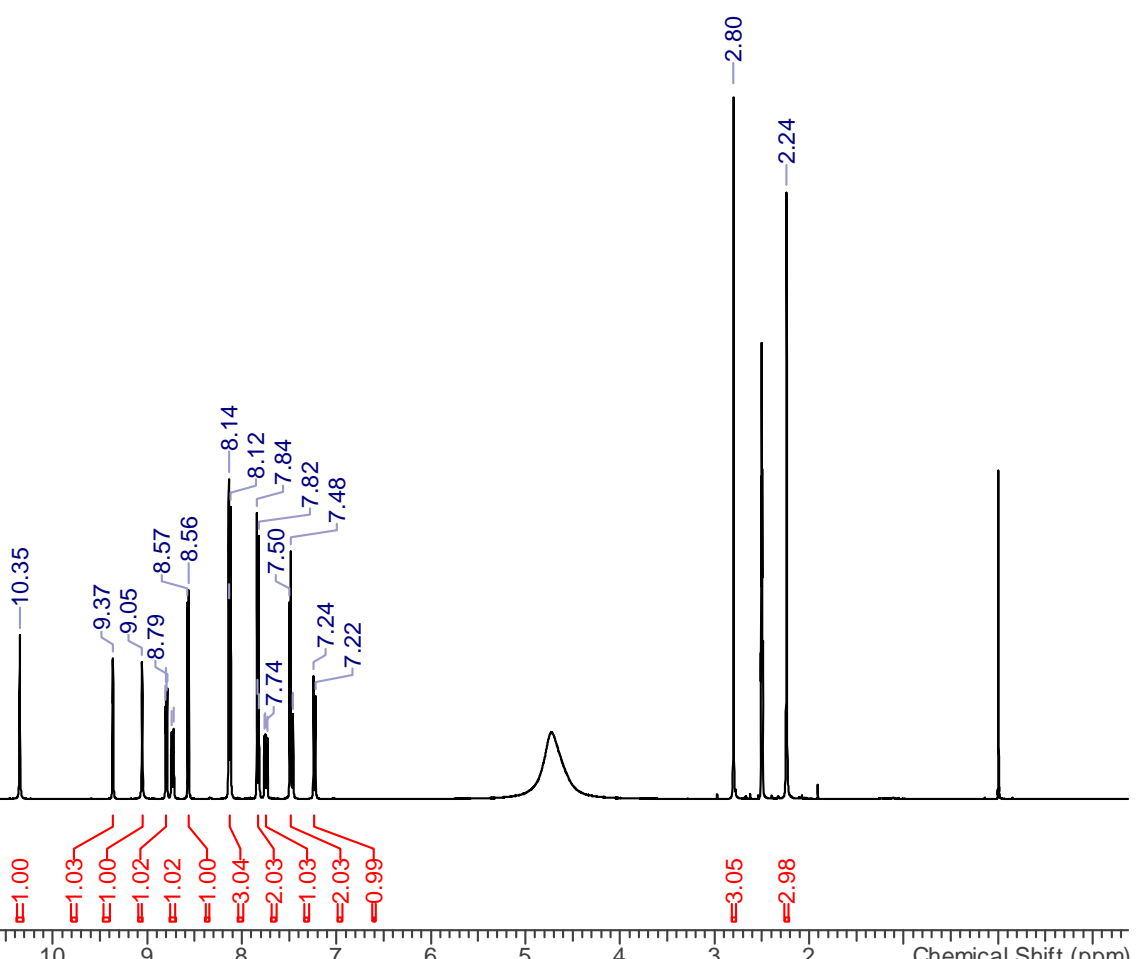

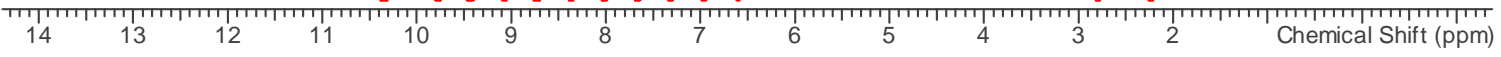

${ }^{13} \mathrm{C}-\mathrm{NMR}$

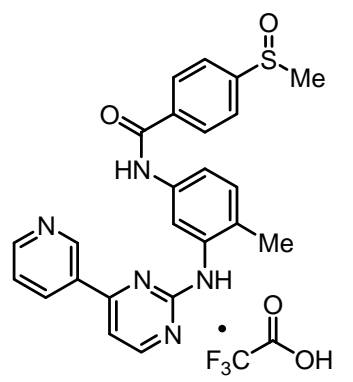

$39 \cdot$ TFA

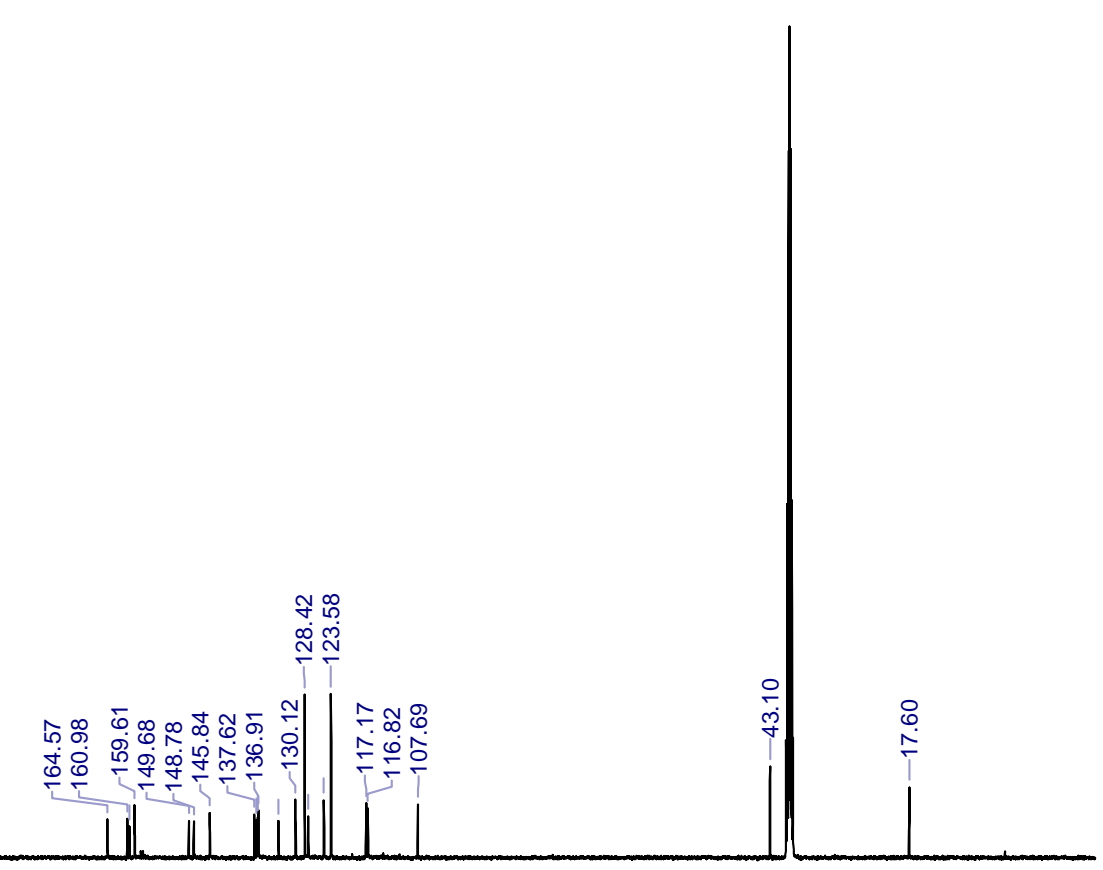

$\begin{array}{lllllllll}240 & 220 & 200 & 180 & 0\end{array}$




\section{4-Methanesulfonyl- $N$-(4-methyl-3-\{[4-(pyridin-3-yl)pyrimidin-2-yl]amino $\}$ phenyl)benzamide}

\section{Trifluoroacetate salt $(40 \cdot$ TFA)}

${ }^{1} \mathrm{H}-\mathrm{NMR}$<smiles>Cc1ccc(NC(=O)c2ccc(S(C)(=O)=O)cc2)c(Nc2nccc(-c3cccnc3)n2)c1</smiles>

$40 \cdot$ TFA

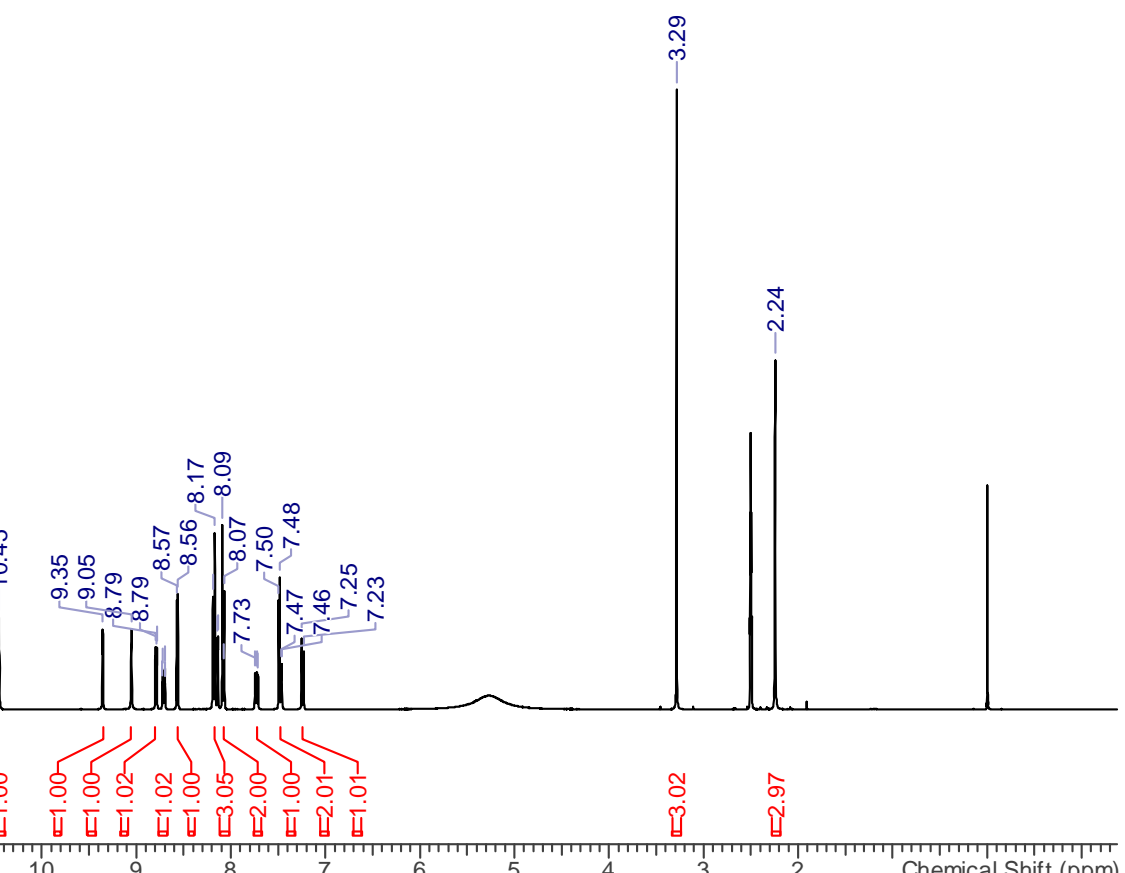

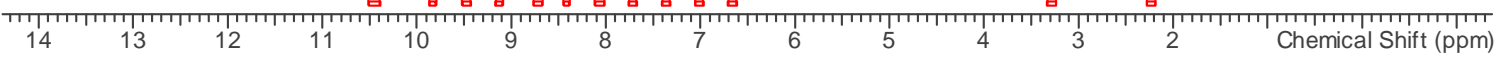

${ }^{13} \mathrm{C}-\mathrm{NMR}$<smiles>Cc1ccc(NC(=O)c2ccc(S(C)(=O)=O)cc2)cc1Nc1nccc(-c2cccnc2)n1</smiles>
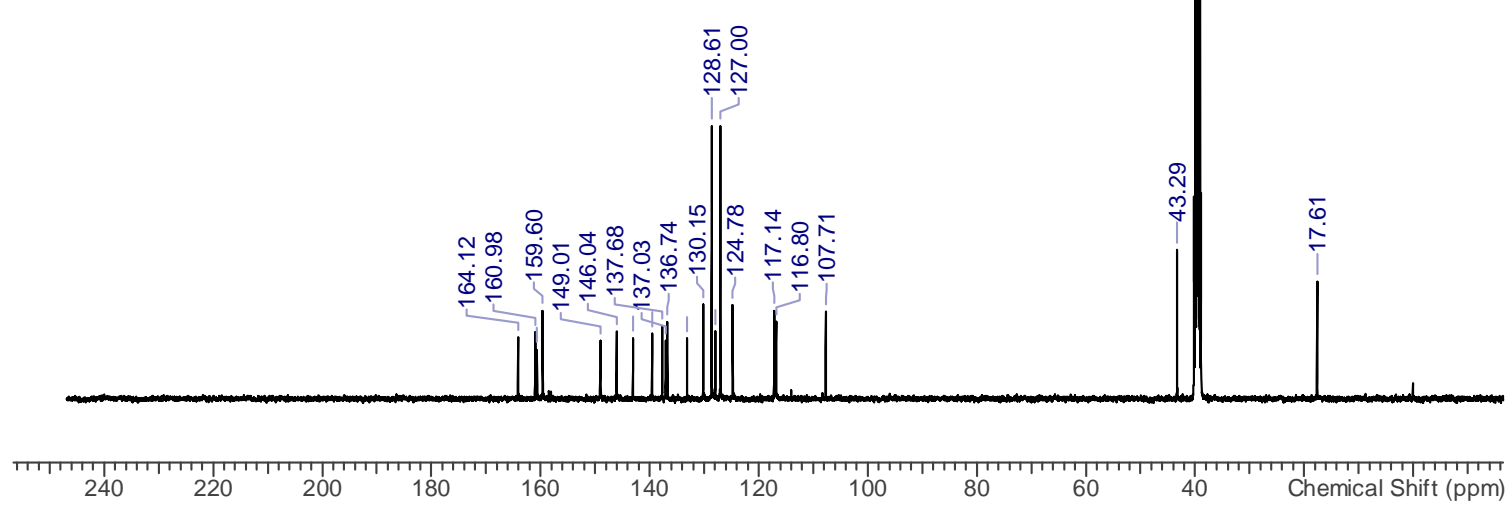
4-[Imino(methyl)oxo- $\lambda^{6}$-sulfanyl]- $N$-(4-methyl-3-\{[4-(pyridin-3-yl)pyrimidin-2-yl]amino\}phenyl)benzamide (41a)

${ }^{1} \mathrm{H}-\mathrm{NMR}$<smiles>Cc1ccc(NC(=O)c2ccc(S(N)(=O)=O)cc2)cc1Nc1nccc(-c2cccnc2)n1</smiles><smiles>C1CCCCC1</smiles> 


\section{4-[Methyl(methylimino)oxo- $\lambda^{6}$-sulfanyl]- $N$-(4-methyl-3-\{[4-(pyridine-3-yl)pyrimidin-2-yl]-}

amino\}phenyl)benzamide (41b)

${ }^{1} \mathrm{H}-\mathrm{NMR}$<smiles>Cc1ccc(NC(=O)c2ccc(S(C)(=O)=O)cc2)cc1Nc1nccc(-c2cccnc2)n1</smiles>

41b

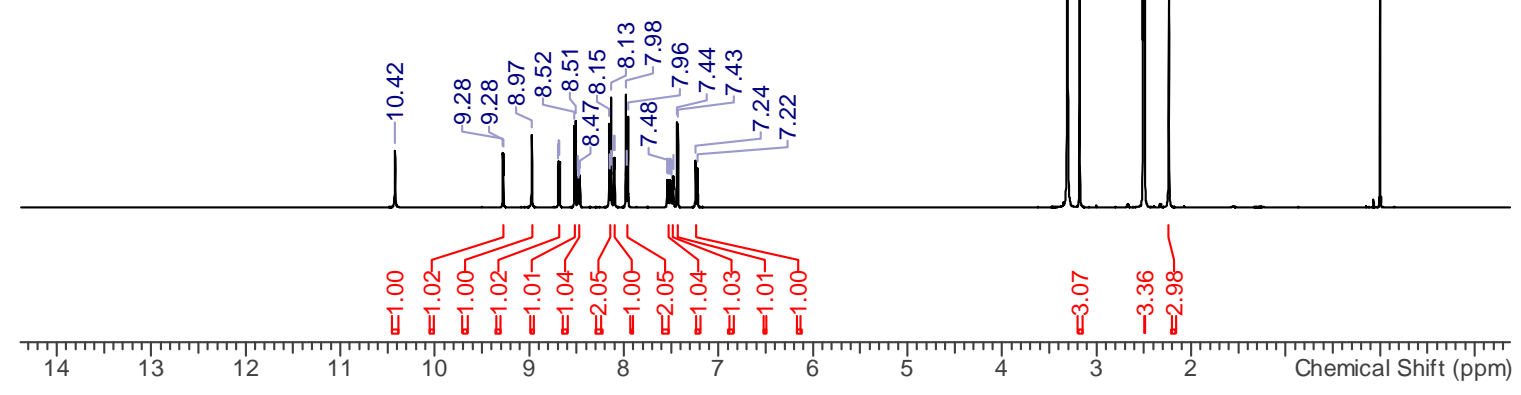

${ }^{13} \mathrm{C}-\mathrm{NMR}$<smiles>Cc1ccc(NC(=O)c2ccc(S(C)(=O)=O)cc2)cc1Nc1nccc(-c2cccnc2)n1</smiles>

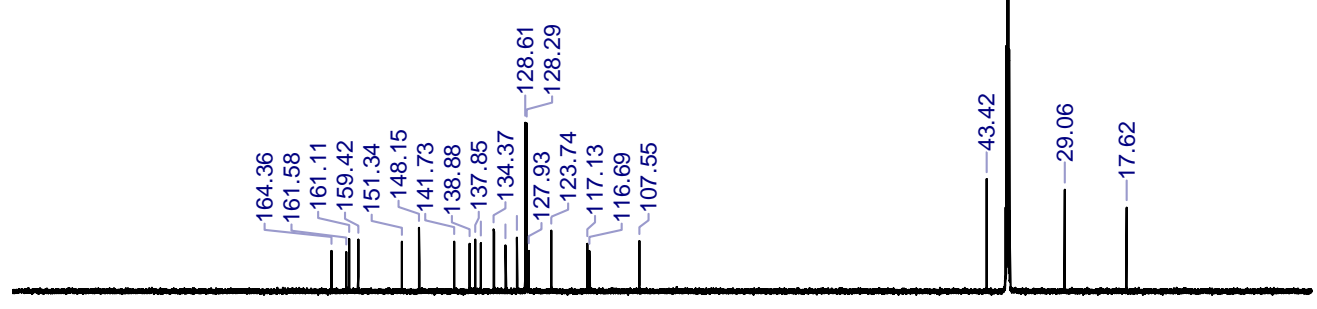

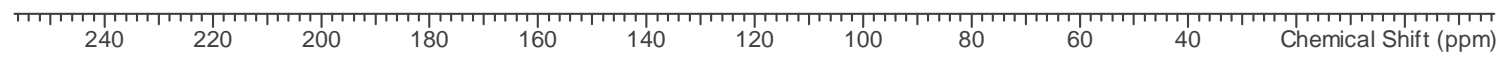




\section{$\mathrm{N}$-(4-Methyl-3-\{[4-(pyridine-3-yl)pyrimidin-2-yl]amino\}phenyl)-4-sulfamoylbenzamide}

\section{Trifluoroacetate salt $(42 \mathrm{a} \cdot \mathrm{TFA})$}

${ }^{1} \mathrm{H}-\mathrm{NMR}$

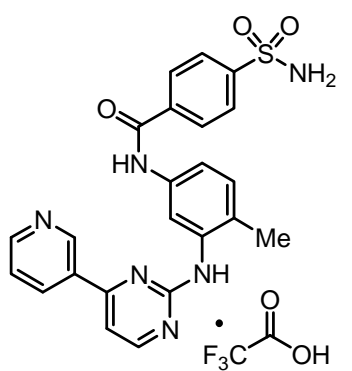

42a - TFA

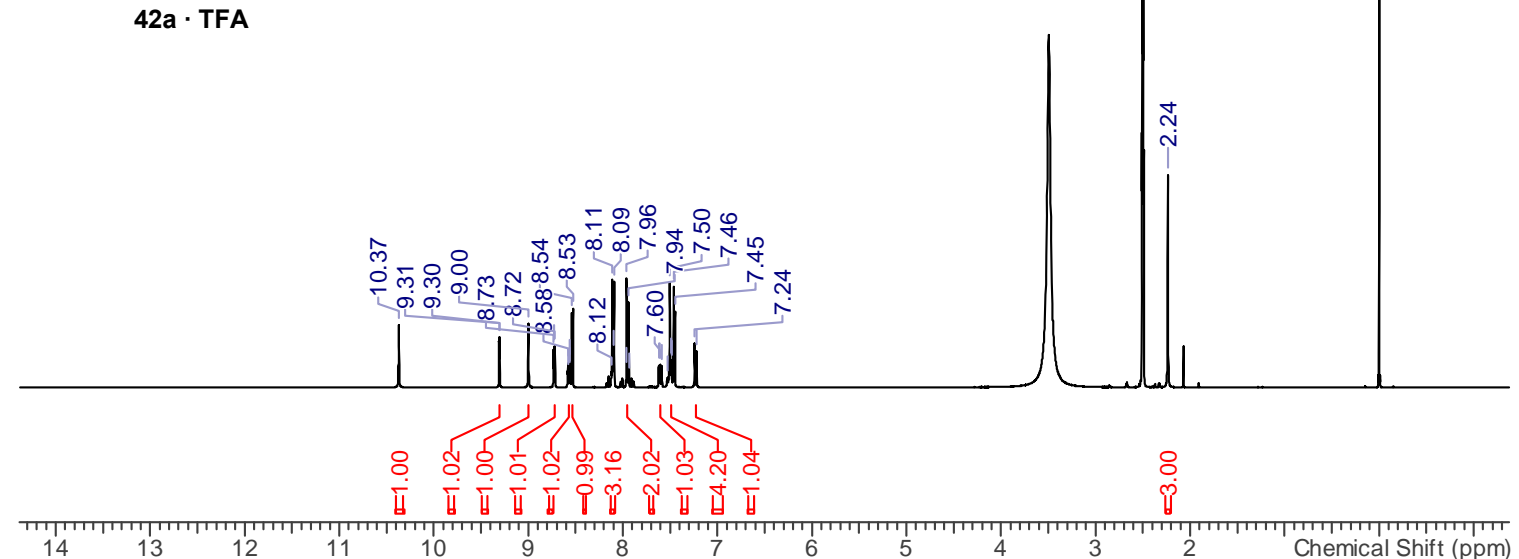

${ }^{13} \mathrm{C}-\mathrm{NMR}$

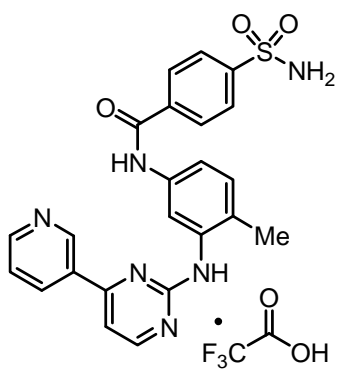

42a $\cdot$ TFA

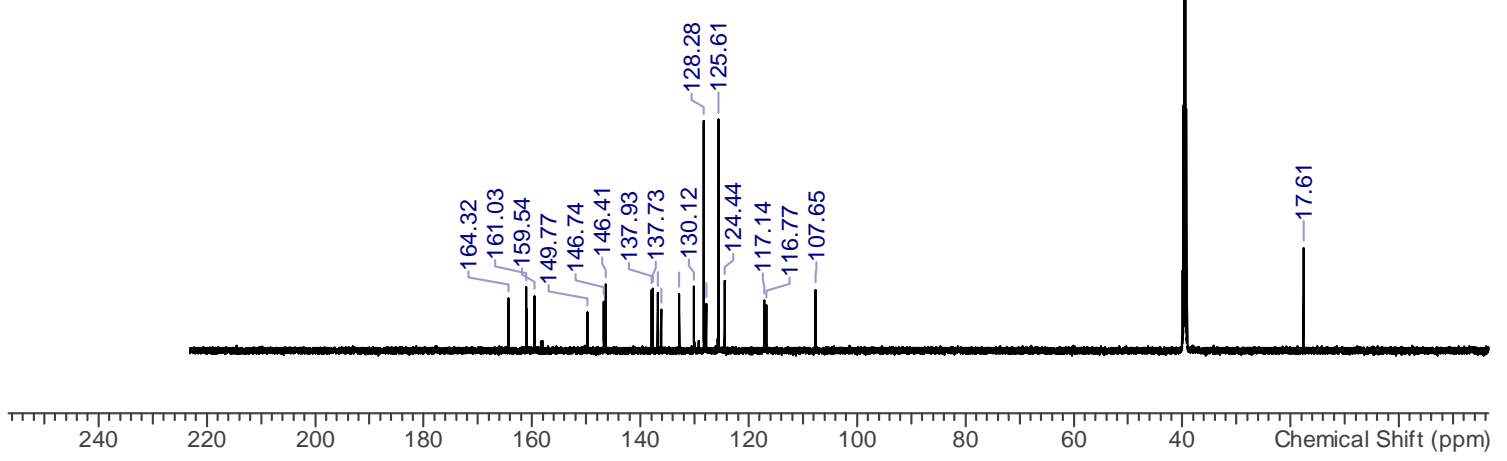




\section{$N$-(4-Methyl-3-\{[4-(pyridine-3-yl)pyrimidin-2-yl]amino\}phenyl)-4-(methylsulfamoyl)benzamide}

\section{Trifluoroacetate salt $(42 \mathrm{~b} \cdot \mathrm{TFA})$}

${ }^{1} \mathrm{H}-\mathrm{NMR}$
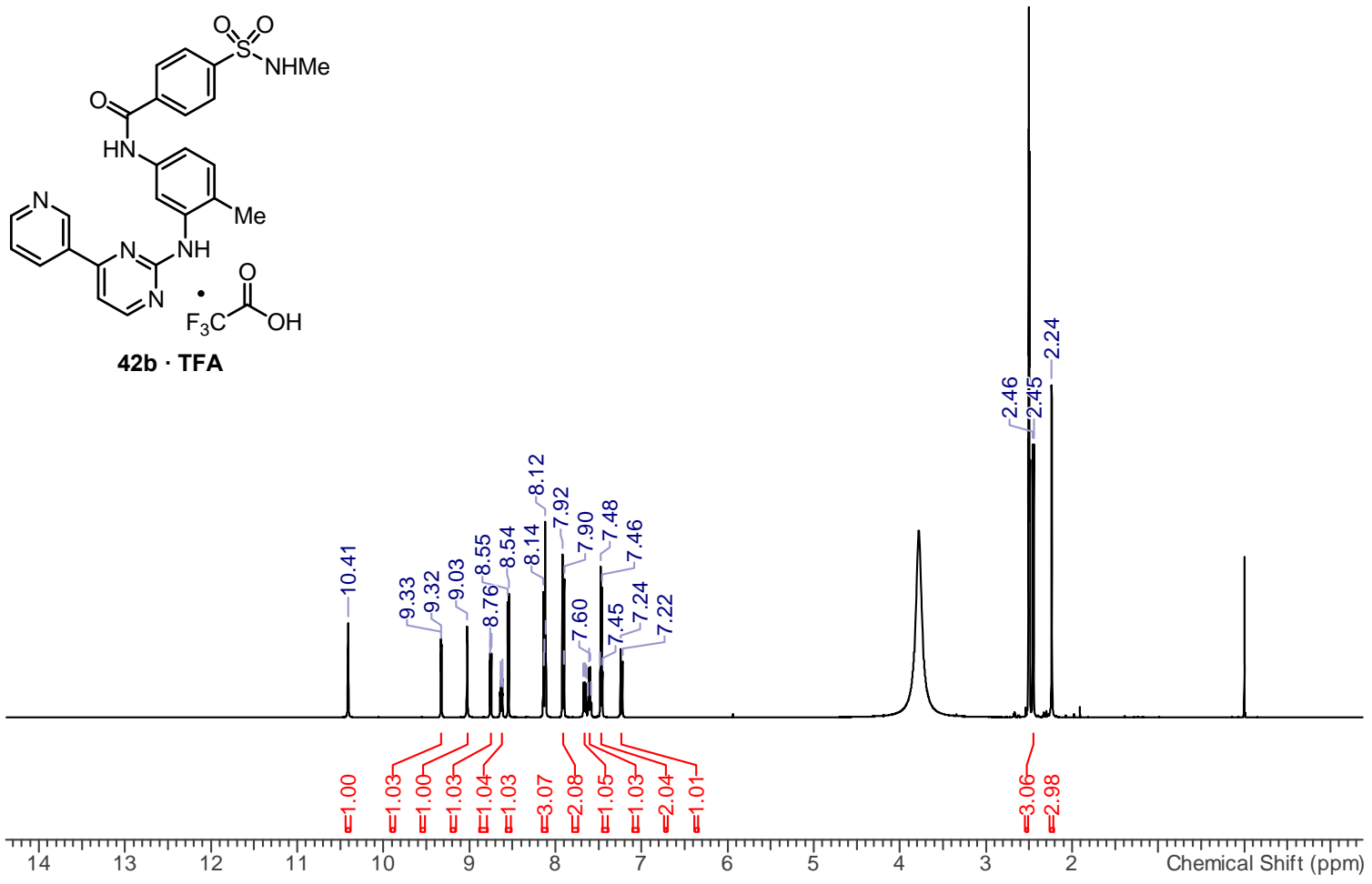

${ }^{13} \mathrm{C}-\mathrm{NMR}$

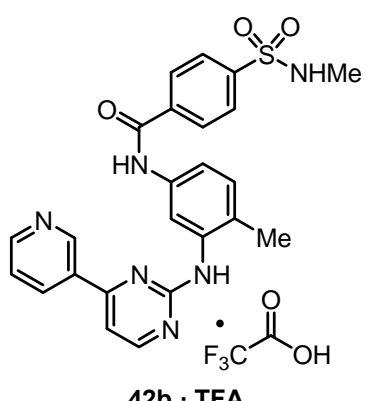

42b - TFA
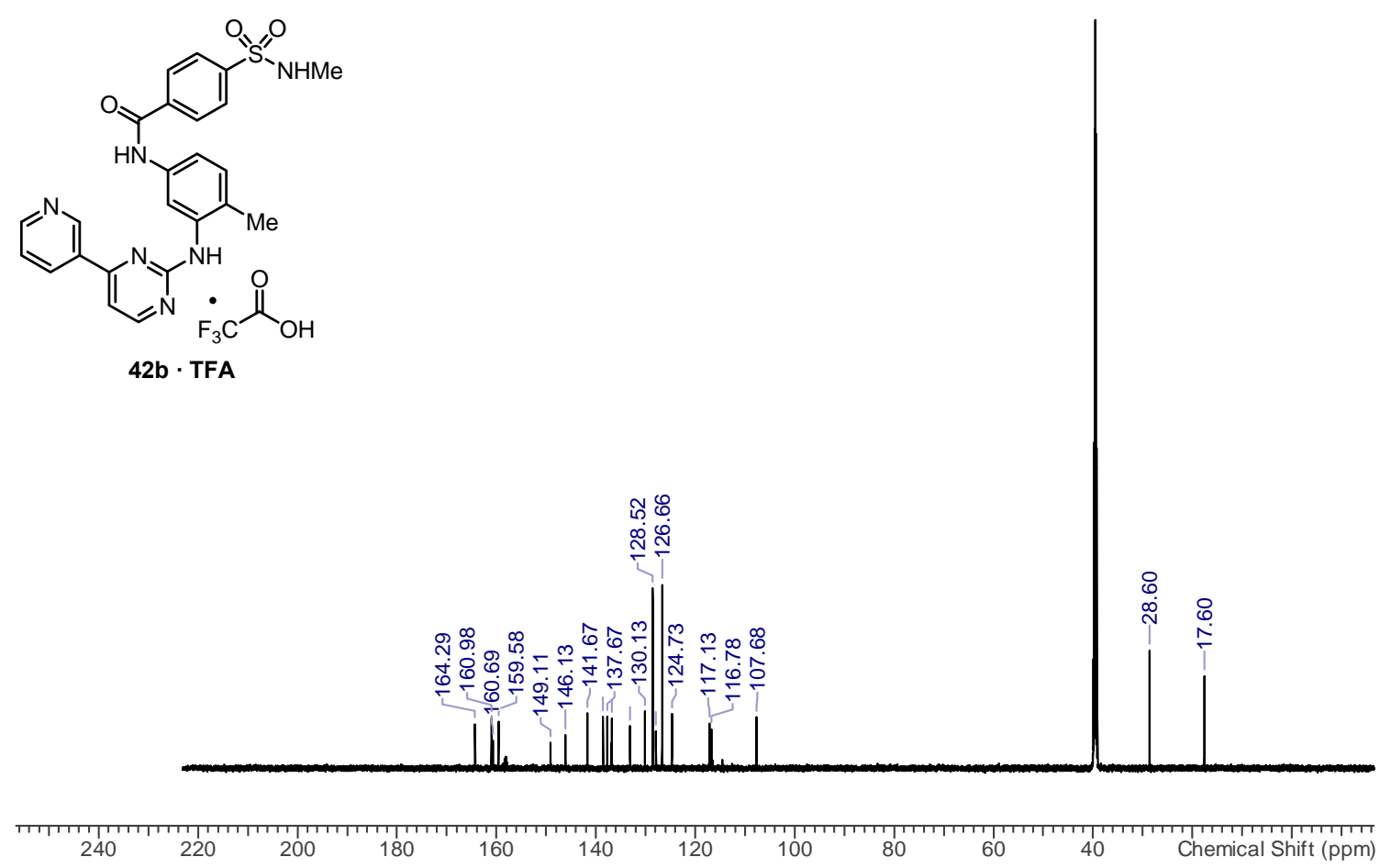
4-(Dimethylsulfamoyl)- $N$-(4-methyl-3-\{[4-(pyridine-3-yl)pyrimidin-2-yl]amino $\}$ phenyl)benzamide (42c)

${ }^{1} \mathrm{H}-\mathrm{NMR}$
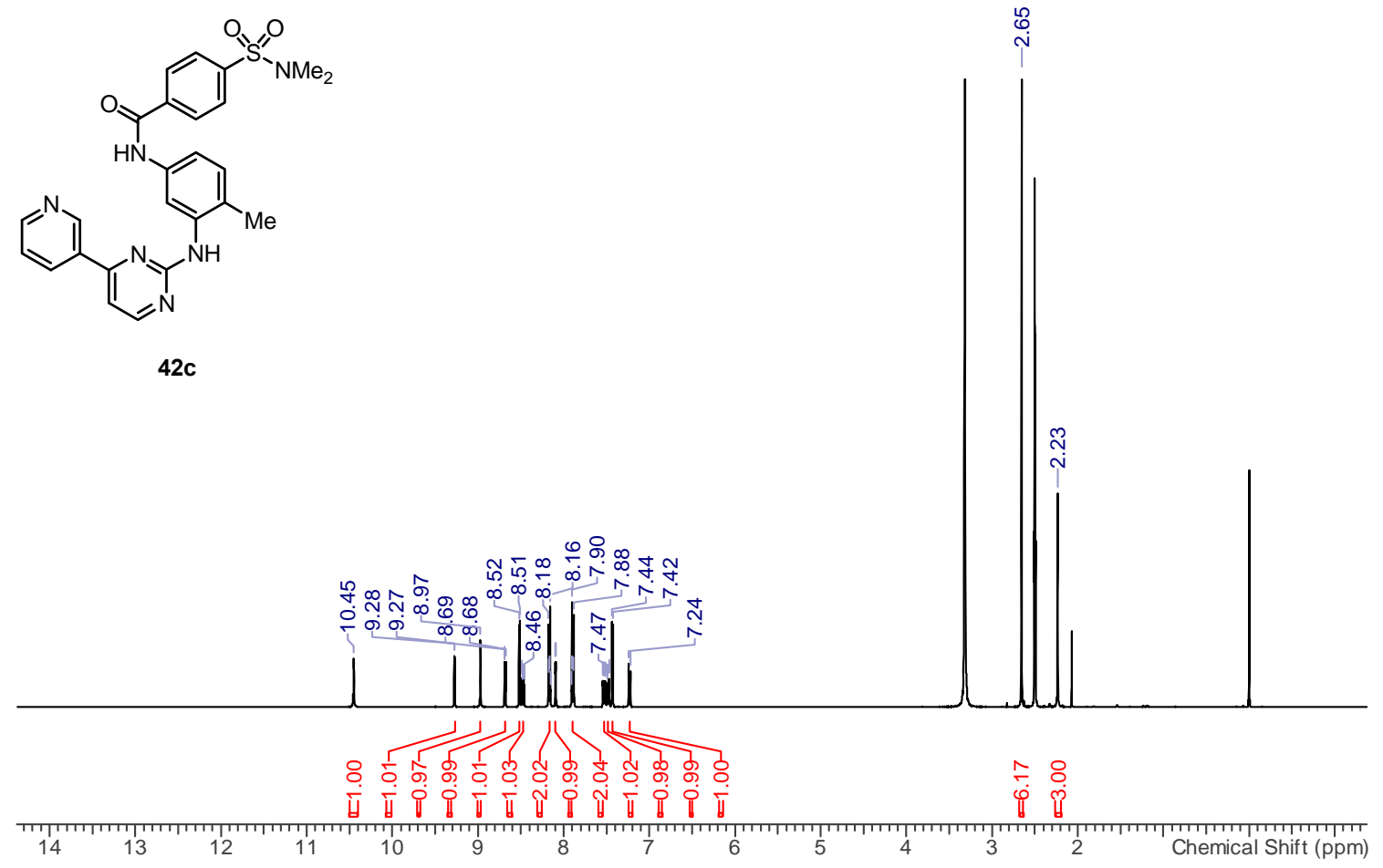

${ }^{13} \mathrm{C}-\mathrm{NMR}$<smiles>Cc1ccc(NC(=O)c2ccc(S(N)(=O)=O)cc2)cc1Nc1nccc(-c2cccnc2)n1</smiles>
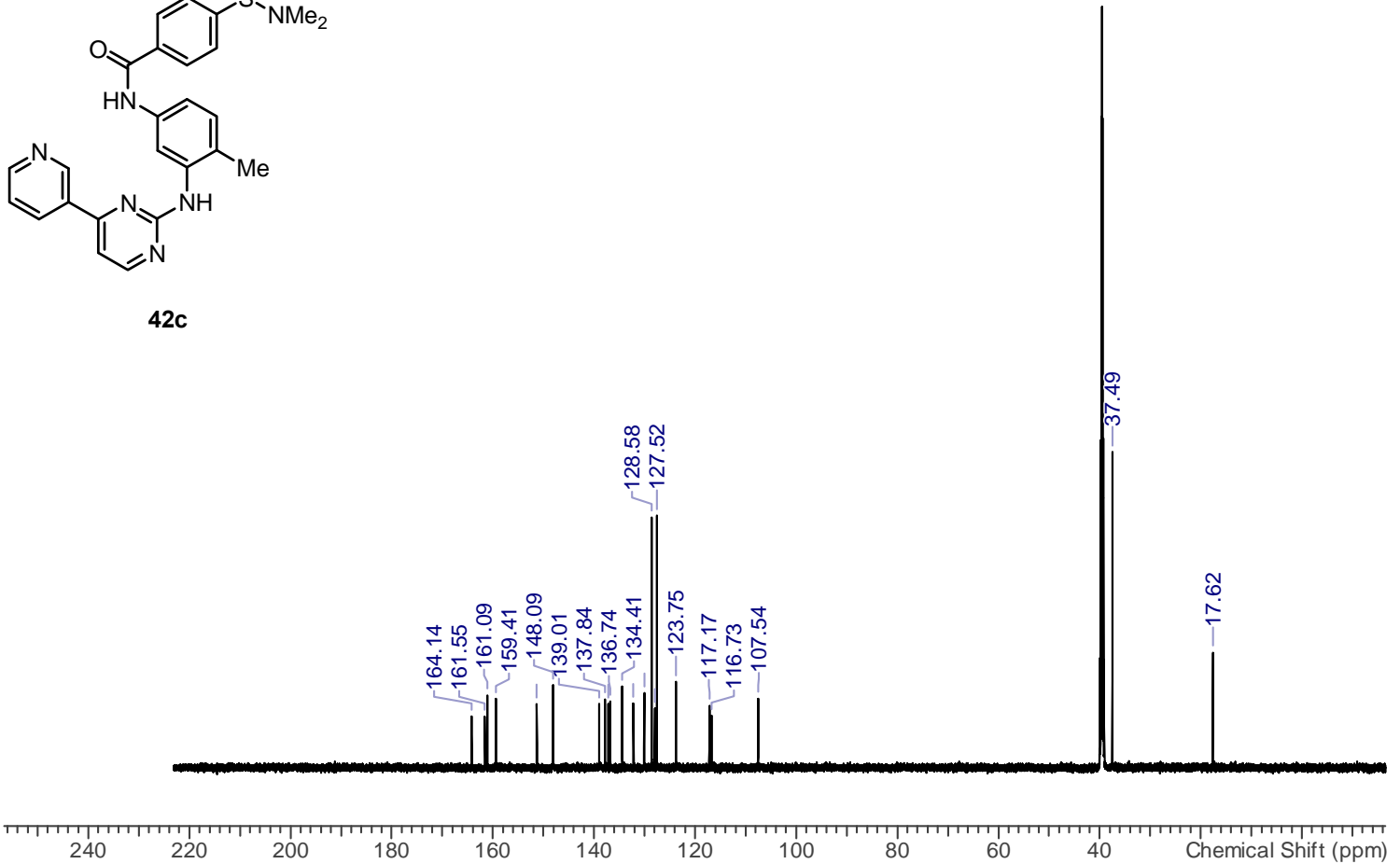
4-(Dimethylphosphoryl)- $N$-(4-methyl-3-\{[4-(pyridin-3-yl)pyrimidin-2-yl]amino\}phenyl)benzamide Trifluoroacetate salt $(43 \cdot$ TFA)

${ }^{1} \mathrm{H}-\mathrm{NMR}$<smiles>Cc1ccc(NC(=O)c2ccc(S(C)(=O)=O)cc2)c(Nc2nccc(-c3cccnc3)n2)c1</smiles>

$43 \cdot$ TFA

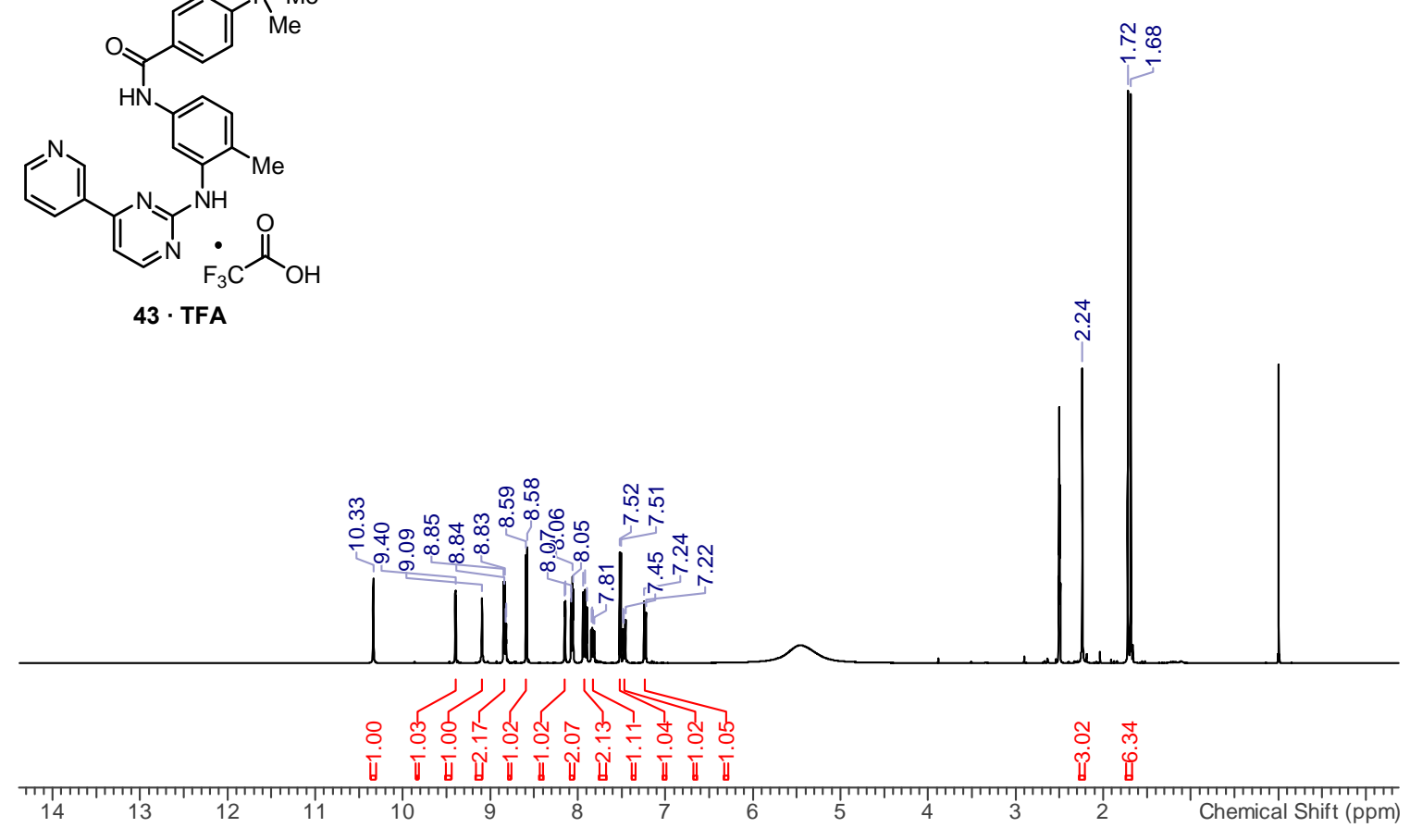

${ }^{13} \mathrm{C}-\mathrm{NMR}$<smiles>Cc1ccc(NC(=O)c2ccc(S(C)(=O)=O)cc2)c(Nc2nccc(-c3cccnc3)n2)c1</smiles>

$43 \cdot$ TFA 
${ }^{31}$ P-NMR<smiles>Cc1ccc(NC(=O)c2ccc(P(C)(C)=O)cc2)cc1Nc1nccc(-c2cccnc2)n1</smiles>

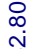

$\tilde{m}$

8

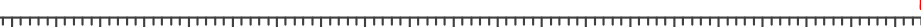

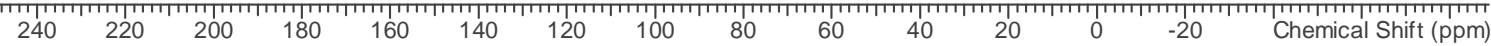

\section{4-(Dimethylphosphoryl)- $N$-(4-methyl-3-\{[4-(pyridin-3-yl)pyrimidin-2-yl]amino\}phenyl)-}

benzamide (43)

\section{${ }^{1} \mathrm{H}-\mathrm{NMR}$}

${ }^{1} \mathrm{H}$ NMR (400 MHz, DMSO-d) $\delta$ ppm 10.33 (s, $1 \mathrm{H}$ ) 9.28 (d. $J=2.2 \mathrm{~Hz}, 1 \mathrm{H}$ ) 8.97 (s, $\left.1 \mathrm{H}\right) 8.69$ (dd, $\left.J=4.8,1.5 \mathrm{~Hz}, 1 \mathrm{H}\right) 8.52$ (d. $\left.J=5.1 \mathrm{~Hz}, 1 \mathrm{H}\right) 8.48$ (ddd. $J=8.0,2.2,1.5 \mathrm{~Hz}, 1 \mathrm{H}) 8.11(\mathrm{~d}, J=2.2 \mathrm{~Hz}, 1 \mathrm{H}) 8.04-8.09(\mathrm{~m}, 2 \mathrm{H}) 7.89-7.96(\mathrm{~m}, 2 \mathrm{H}) 7.52(\mathrm{ddd}, J=8.0,4.8,0.7 \mathrm{~Hz}, 1 \mathrm{H}) 7.50(\mathrm{dd}, J=8.2,2.2 \mathrm{~Hz}, 1 \mathrm{H})$ 7.43 (d. $J=5.1 \mathrm{~Hz}, 1 \mathrm{H}) 7.23$ (dd. $J=8.2 .0 .5 \mathrm{~Hz}, 1 \mathrm{H}) 2.24$ (s. $3 \mathrm{H}) 1.70$ (d. $J=13.4 \mathrm{~Hz}, 6 \mathrm{H}$ )

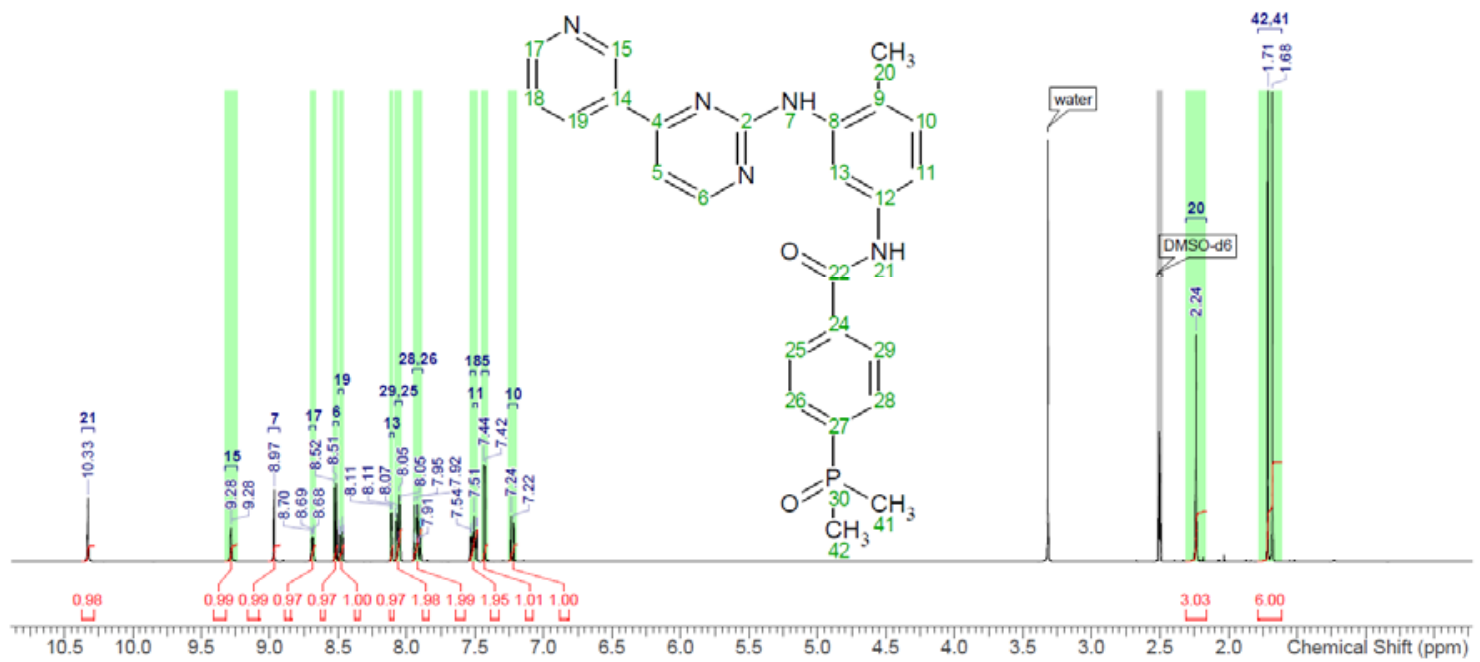




\section{${ }^{13} \mathrm{C}-\mathrm{NMR}$}

${ }^{13} \mathrm{C}$ NMR (101 MHz, DMSO-d $\left.d_{6}\right) \delta$ ppm 164.8 (s) 161.6 (s) 161.1 (s) 159.4 (s) 151.3 (s) 148.1 (s) 139.2 (d, $\left.J=93.4 \mathrm{~Hz}\right) 137.8$ (s) 137.5 (d, $\left.J=2.2 \mathrm{~Hz}\right) 136.9$ (s) 134.4 (s) 132.2 (s) 130.0 (s) 129.8 (d, $J=9.9 \mathrm{~Hz}) 127.8$ (s) 127.5 (d, $J=11.6 \mathrm{~Hz}) 123.7$ (s) 117.1 (s) 116.7 (s) 107.5 (s) 17.6 (s) 17.6 (d, $J=70.1 \mathrm{~Hz}$ )

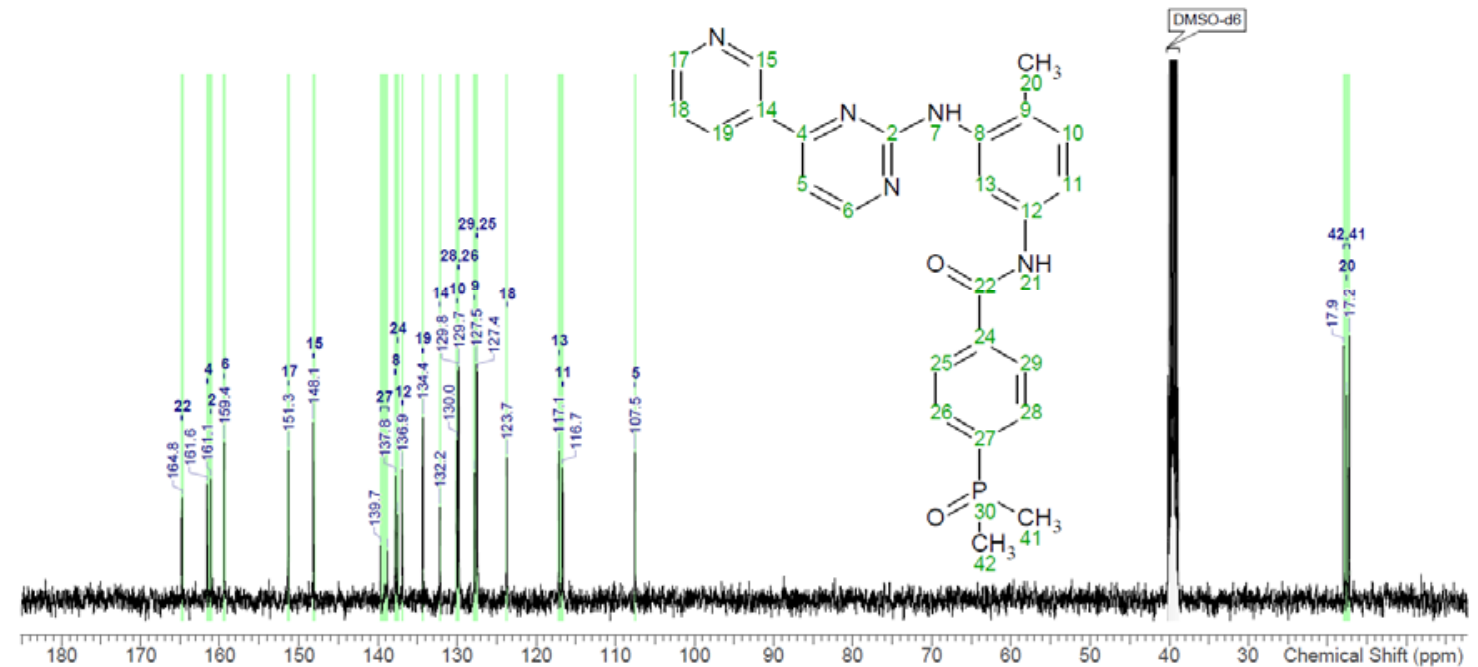

${ }^{31}$ P-NMR

${ }^{31} \mathrm{P}$ NMR $(162 \mathrm{MHz}$, DMSO-d $)$ o ppm 32.4 (s)<smiles></smiles>

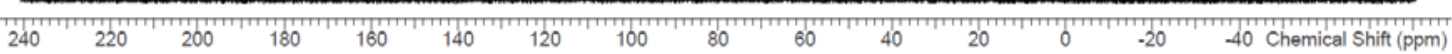


Ethyl Methyl(\{4-[(4-methyl-3-\{[4-(pyridin-3-yl)pyrimidin-2-yl]amino\}phenyl)carbamoyl]phenyl\})phosphinate Trifluoroacetate salt $(44 a \cdot$ TFA)

${ }^{1} \mathrm{H}-\mathrm{NMR}$<smiles>CCOP(=O)(c1ccc(C(=O)Nc2ccc(C)c(Nc3nccc(-c4cccnc4)n3)c2)cc1)c1ccc(C(F)(F)F)cn1</smiles>

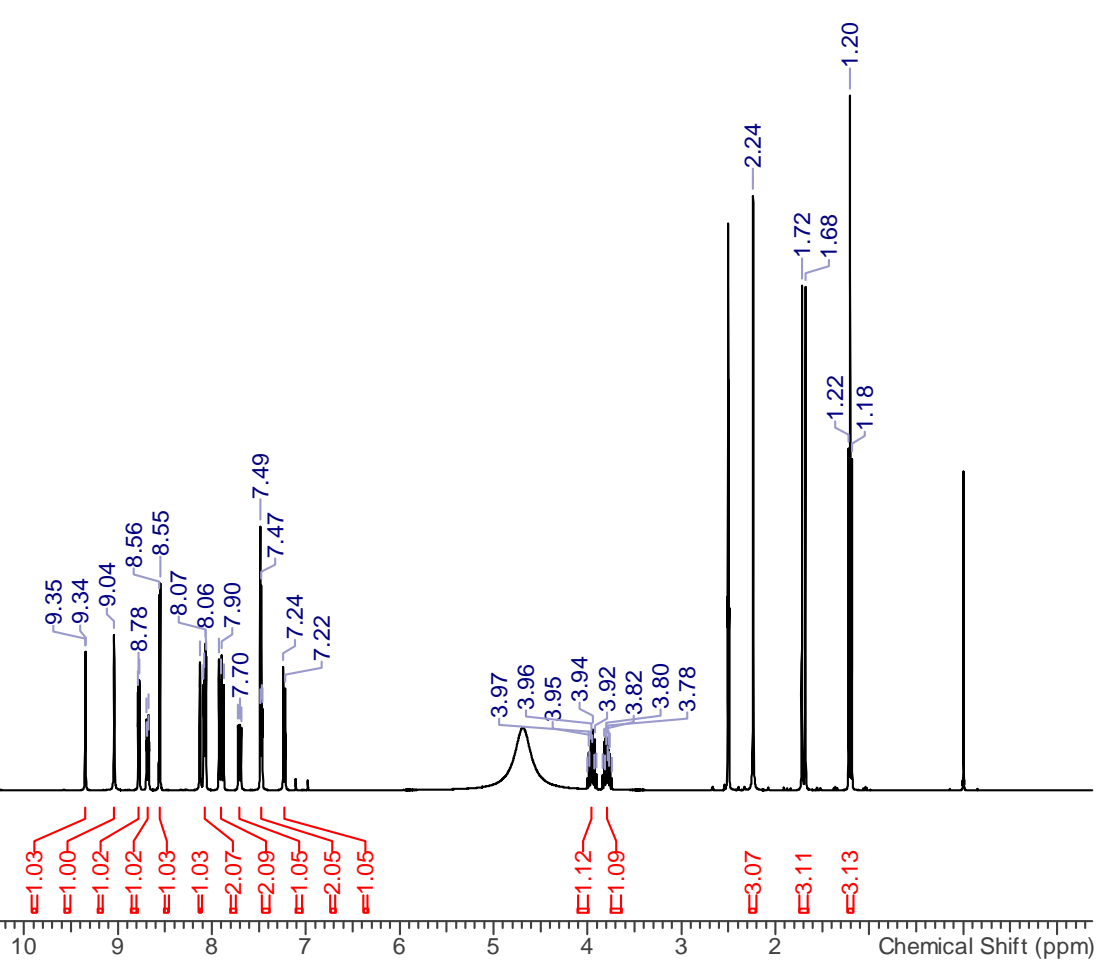

${ }^{13} \mathrm{C}-\mathrm{NMR}$<smiles>CCOP(=O)(c1ccc(C(=O)Nc2ccc(C)c(Nc3nccc(-c4cccnc4)n3)c2)cc1)c1ccnc(C(F)(F)C(F)(F)C(F)(F)C(=O)O)n1</smiles>
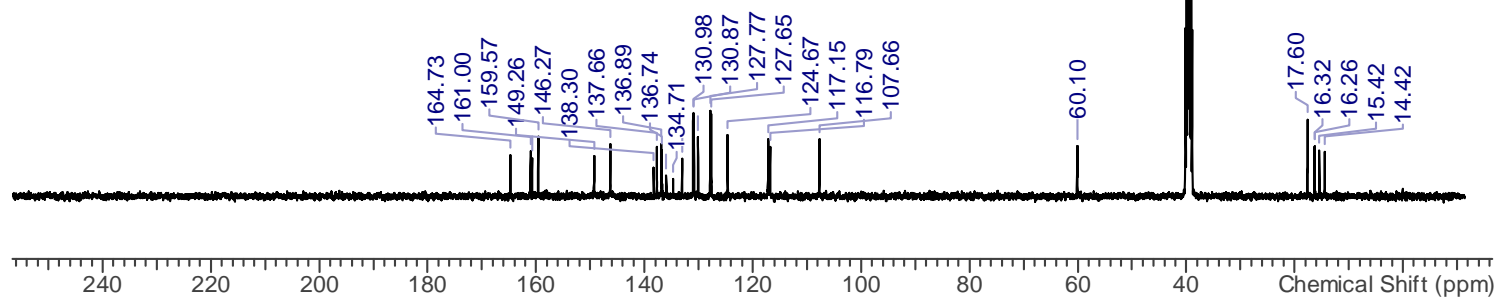


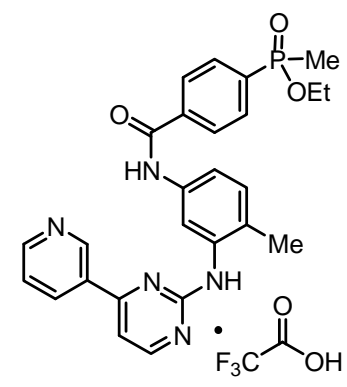

$44 a \cdot \operatorname{TFA}$

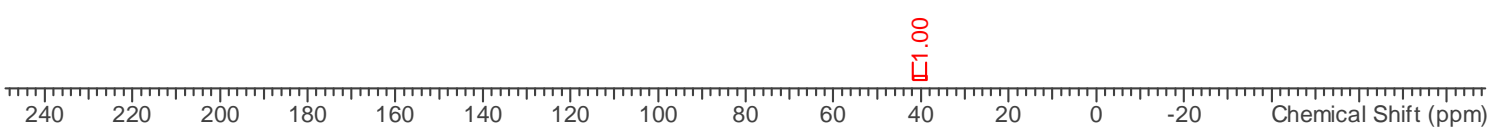

Methyl(\{4-[(4-methyl-3-\{[4-(pyridin-3-yl)pyrimidin-2-yl]amino\}phenyl)carbamoyl]phenyl\})phosphinic Acid Trifluoroacetate salt (44b·TFA)

${ }^{1} \mathrm{H}-\mathrm{NMR}$<smiles>Cc1ccc(NC(=O)c2ccc(P(=O)(O)O)cc2)cc1Nc1nccc(-c2cccnc2)n1</smiles>

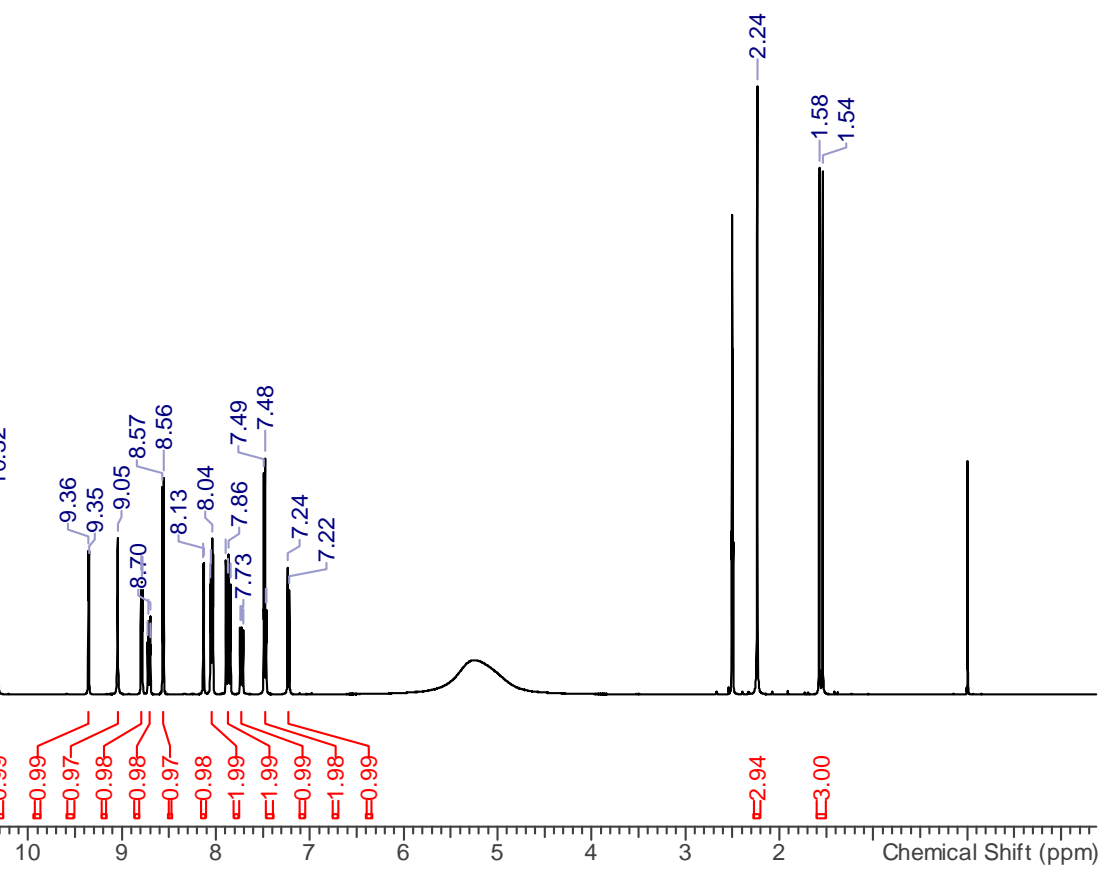

$\begin{array}{lllllll}14 & 13 & 12 & 11 & 10 & 9 & 8\end{array}$


${ }^{13} \mathrm{C}-\mathrm{NMR}$<smiles>Cc1ccc(NC(=O)c2ccc(P(C)(C)=O)cc2)c(Nc2nccc(-c3cccnc3)n2)c1</smiles>

44b - TFA
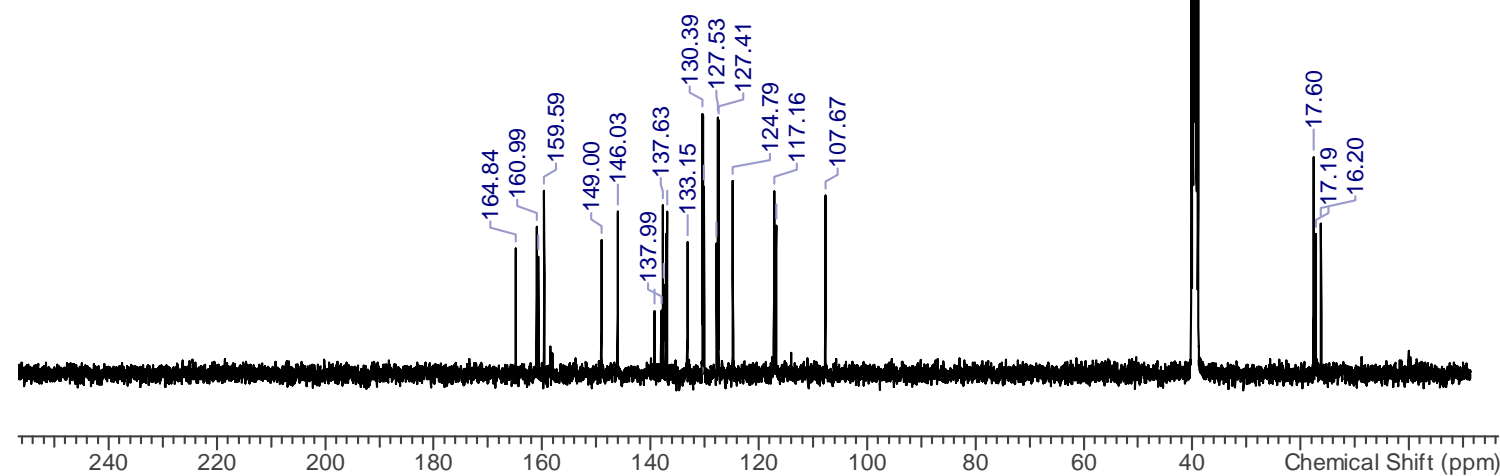

${ }^{31} \mathrm{P}-\mathrm{NMR}$<smiles>Cc1ccc(NC(=O)c2ccc(P(=O)(O)O)cc2)cc1Nc1nccc(-c2cccnc2)n1</smiles>

$\infty$

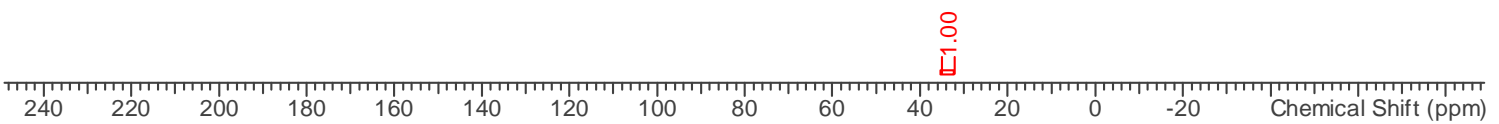


Methyl(\{4-[(4-methyl-3-\{[4-(pyridin-3-yl)pyrimidin-2-yl]amino\}phenyl)carbamoyl]phenyl\})phosphinic Acid (44b)

${ }^{1} \mathrm{H}-\mathrm{NMR}$

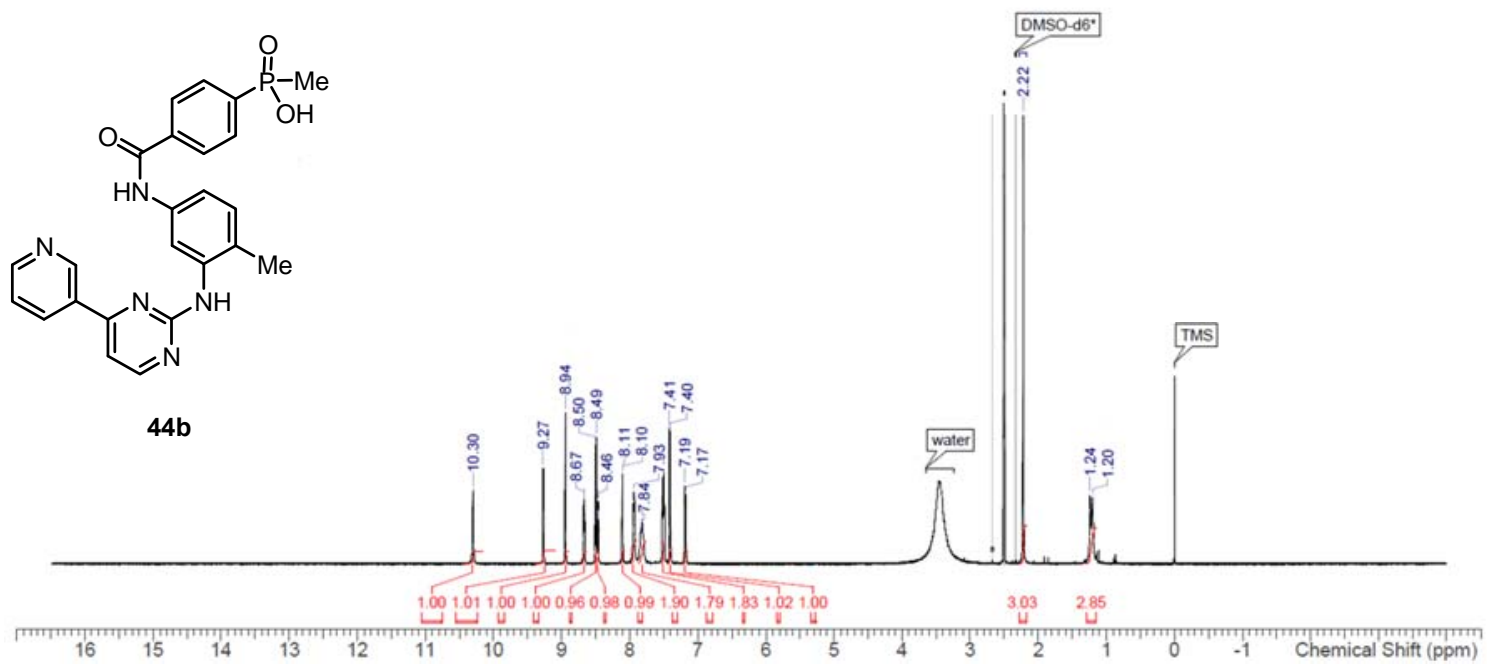

${ }^{13} \mathrm{C}-\mathrm{NMR}$

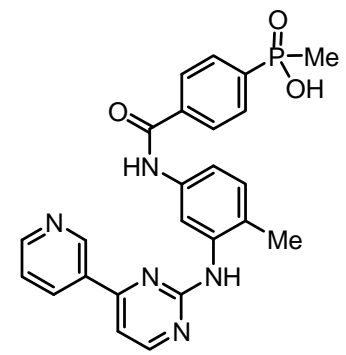

44b

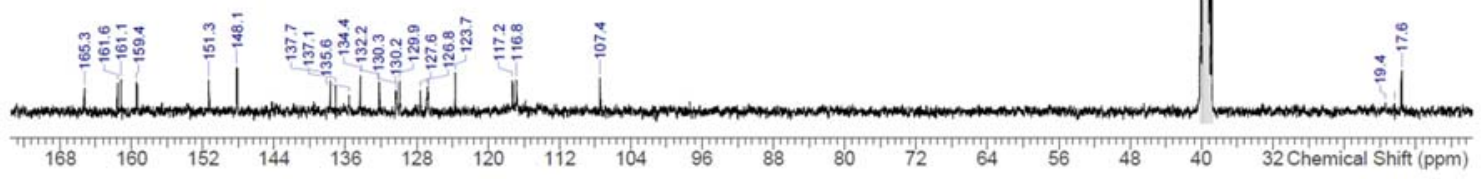


${ }^{31} \mathrm{P}-\mathrm{NMR}$<smiles>Cc1ccc(NC(=O)c2ccc(S(=O)(=O)O)cc2)cc1Nc1nccc(-c2cccnc2)n1</smiles>

44b

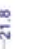

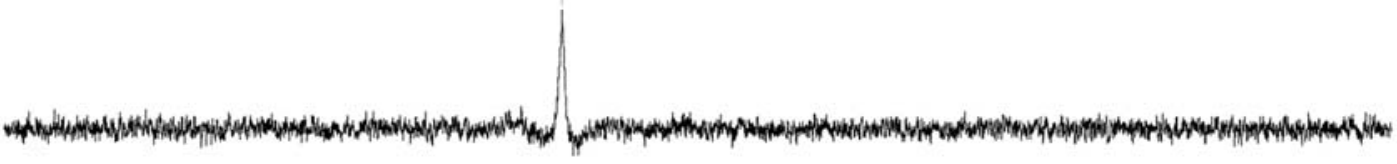

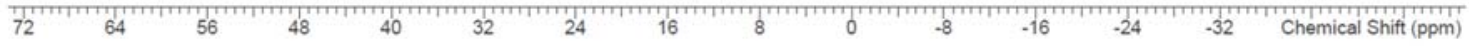

Diethyl \{4-[(4-Methyl-3-\{[4-(pyridin-3-yl)pyrimidin-2-yl]amino\}phenyl)carbamoyl]phenyl\}phosphonate Trifluoroacetate salt $(45 \mathrm{a} \cdot \mathrm{TFA})$

${ }^{1} \mathrm{H}-\mathrm{NMR}$<smiles>CCOP(=O)(OCC)c1ccc(C(=O)Nc2ccc(C)c(Nc3nccc(-c4cccnc4)n3)c2)cc1</smiles>

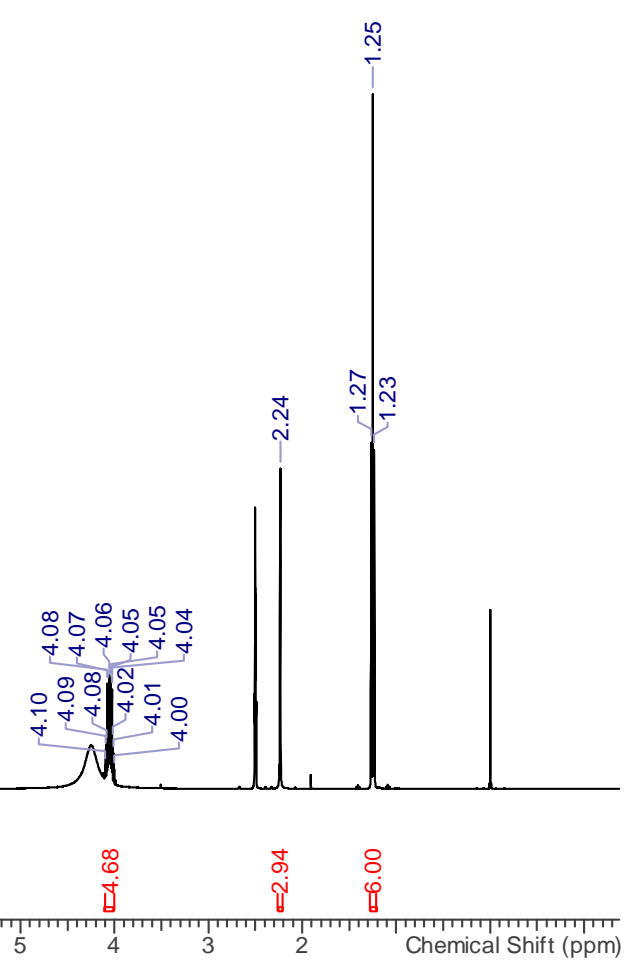


${ }^{13} \mathrm{C}-\mathrm{NMR}$<smiles>CCOP(=O)(OCC)c1ccc(C(=O)Nc2ccc(Nc3nccc(-c4cccnn4)n3)c(Nc3c[n+](C(F)(F)F)ccn3)c2)cc1</smiles>

45a - TFA

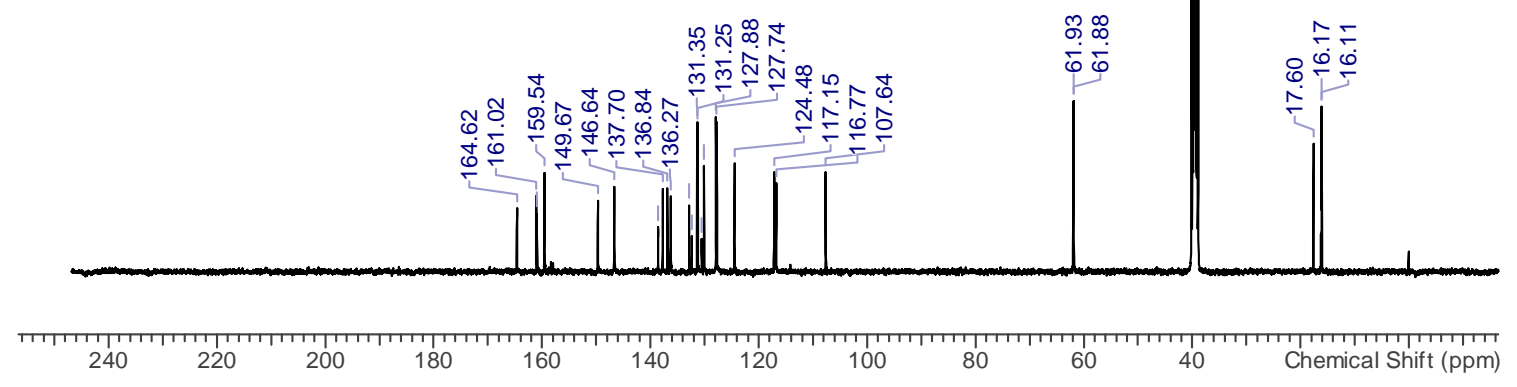

${ }^{31} \mathrm{P}-\mathrm{NMR}$

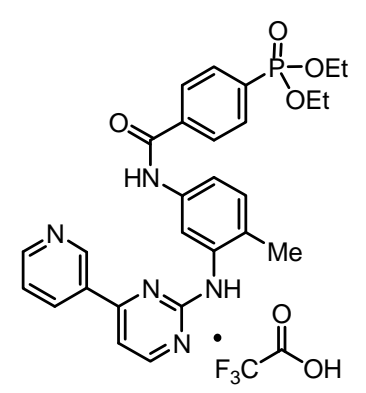

45a - TFA

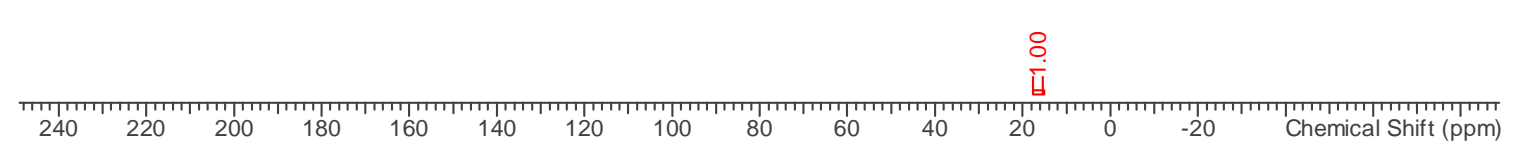




\section{Diethyl \{4-[(4-Methyl-3-\{[4-(pyridin-3-yl)pyrimidin-2-yl]amino\}phenyl)carbamoyl]phenyl\}-}

phosphonate (45a)

\section{${ }^{1} \mathrm{H}-\mathrm{NMR}$}

${ }^{1} \mathrm{H}$ NMR $\left.(400 \mathrm{MHz}, \text { DMSO-d })_{6}\right) \delta$ ppm $10.38(\mathrm{~s}, 1 \mathrm{H}) 9.29$ (d, $\left.J=1.8 \mathrm{~Hz}, 1 \mathrm{H}\right) 8.97$ (s, $\left.1 \mathrm{H}\right) 8.69$ (dd, $\left.J=4.8,1.6 \mathrm{~Hz}, 1 \mathrm{H}\right) 8.52$ (d, $\left.J=5.2 \mathrm{~Hz}, 1 \mathrm{H}\right) 8.48$ (ddd, $J=8.0,2.3,1.7 \mathrm{~Hz}, 1 \mathrm{H}) 8.12(\mathrm{~d}, J=2.2 \mathrm{~Hz}, 1 \mathrm{H}) 8.06-8.11(\mathrm{~m}, 2 \mathrm{H}) 7.83-7.91(\mathrm{~m}, 2 \mathrm{H}) 7.53$ (ddd, $J=8.0,4.8,0.8 \mathrm{~Hz}, 1 \mathrm{H}) 7.50$ (dd, $J=8.5,2.2 \mathrm{~Hz}, 1 \mathrm{H})$

7.43 (d. $J=5.2 \mathrm{~Hz} .1 \mathrm{H}) 7.23$ (d. $J=8.5 \mathrm{~Hz} .1 \mathrm{H}) 4.08$ (ddq. $J=10.3 .8 .2 .7 .1 .7 .1 .7 .1 \mathrm{~Hz} .2 \mathrm{H}$ ) 4.04 (ddq. $J=10.3 .8 .4 .7 .1 .7 .1 .7 .1 \mathrm{~Hz}, 2 \mathrm{H}$ ) 2.25 (s. $3 \mathrm{H}$ ) 1.26 (t, $J=7.1 \mathrm{~Hz}, 6 \mathrm{H}$ )

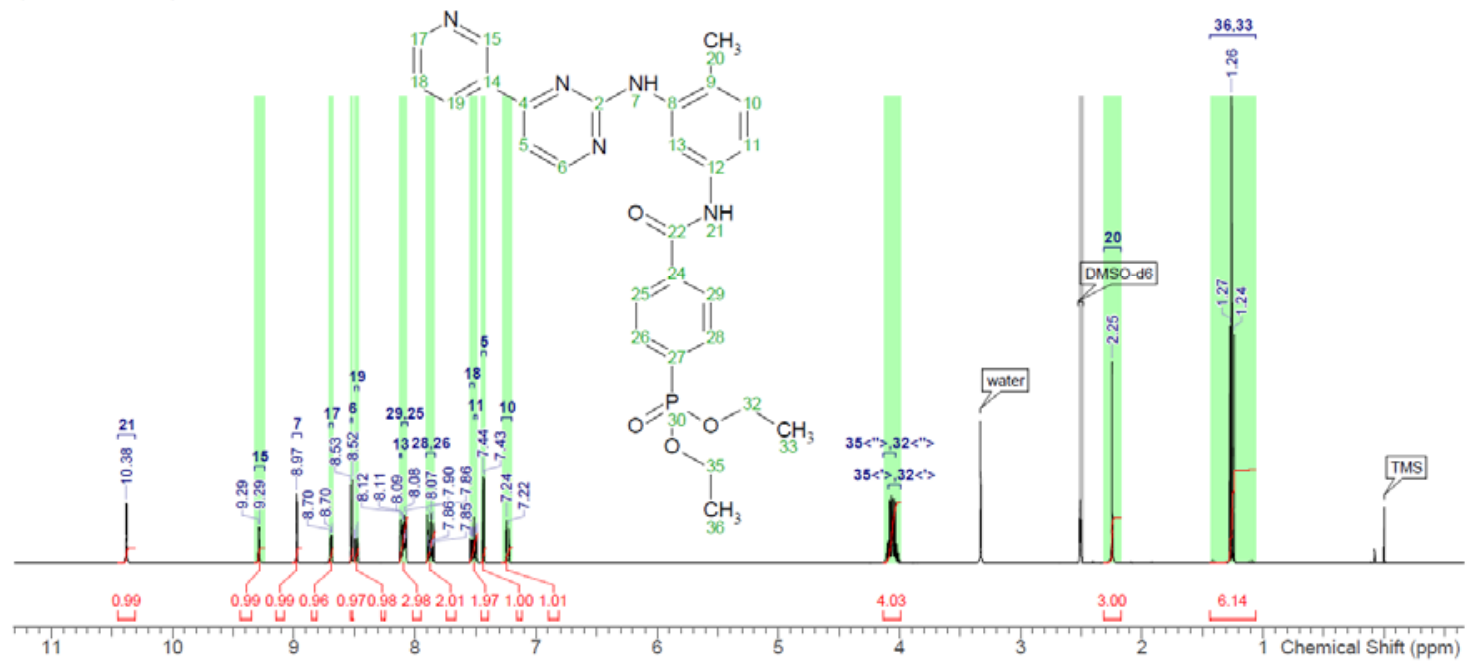

${ }^{13} \mathrm{C}-\mathrm{NMR}$

${ }^{13} \mathrm{C} \mathrm{NMR}\left(101 \mathrm{MHz}, D M S O-d_{\text {}}\right) \delta$ ppm 164.6 (s) 161.6 (s) 161.1 (s) 159.4 (s) 151.3 (s) 148.1 (s) 138.6 (d, $\left.J=3.0 \mathrm{~Hz}\right) 137.8$ (s) 136.8 (s) 134.4 (s) 132.2 (s) 131.3 (d. $J=9.9 \mathrm{~Hz}) 131.4$ (d. $J=185.4 \mathrm{~Hz}) 130.1$ (s) 127.9 (s) 127.8 (d. $J=14.8 \mathrm{~Hz}) 123.7$ (s) 117.1 (s) 116.7 (s) 107.5 (s) 61.9 (d. $J=5.2 \mathrm{~Hz}) 17.6$ (s) 16.1 (d. $J=5.6 \mathrm{~Hz})$

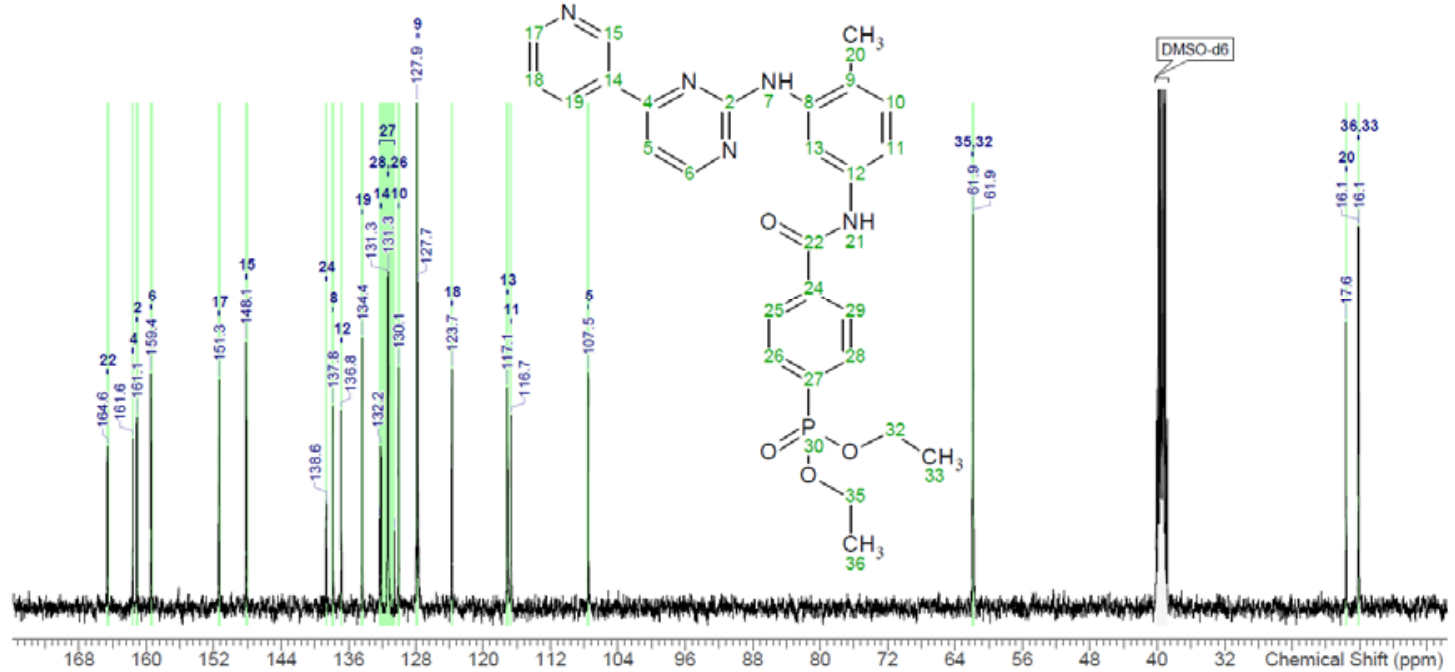


${ }^{31}$ P-NMR

${ }^{31} \mathrm{P} \mathrm{NMR}\left(162 \mathrm{MHz}, \mathrm{DMSO}-d_{6}\right) \delta \mathrm{ppm} 16.7$ (s)

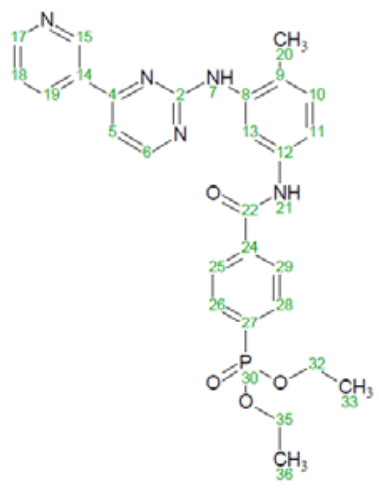

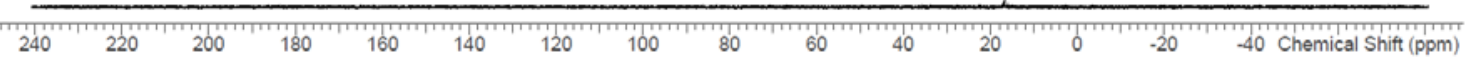

Ethoxy\{4-[(4-methyl-3-\{[4-(pyridin-3-yl)pyrimidin-2-yl]amino\}phenyl)carbamoyl]phenyl\}phosphinic Acid Trifluoroacetate salt (45b·TFA)

${ }^{1} \mathrm{H}-\mathrm{NMR}$<smiles>CCOP(=O)(O)c1ccc(C(=O)Nc2ccc(C)c(Nc3nccc(-c4cccnc4)n3)c2)cc1</smiles>

45b - TFA

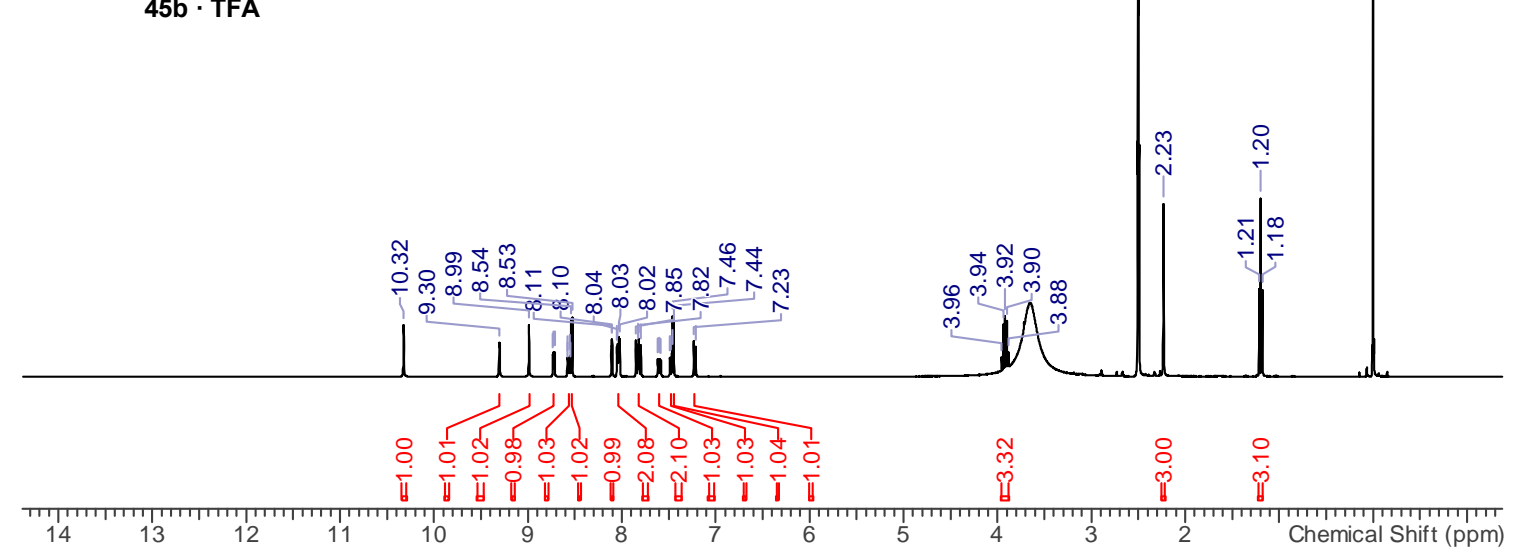


${ }^{13} \mathrm{C}-\mathrm{NMR}$<smiles>CCOP(=O)(O)c1ccc(C(=O)Nc2ccc(C)c(Nc3nccc(-c4cccnc4)n3)c2)cc1</smiles>

45b - TFA
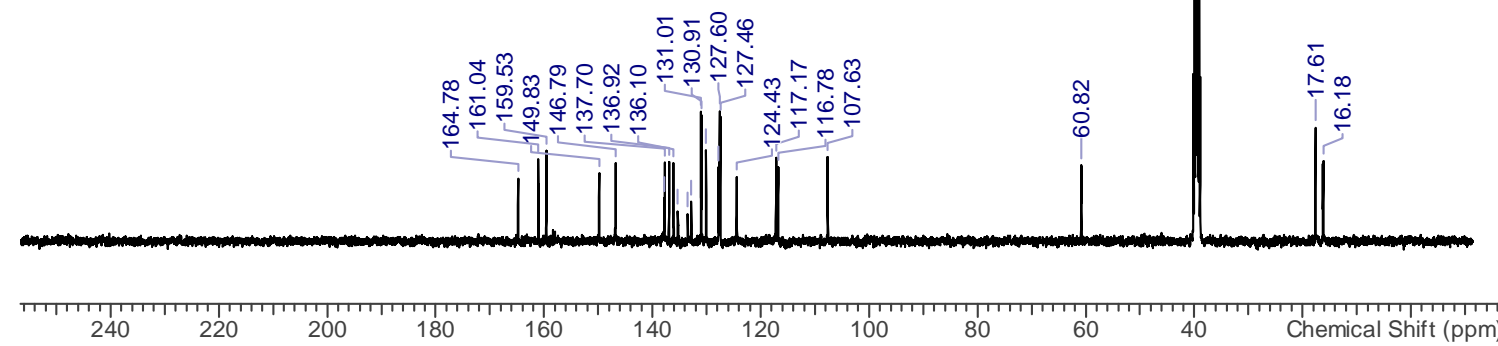

${ }^{31} \mathrm{P}-\mathrm{NMR}$<smiles>CCOP(=O)(O)c1ccc(C(=O)Nc2ccc(C)c(Nc3nccc(-c4cccnc4)n3)c2)cc1</smiles>

45b - TFA

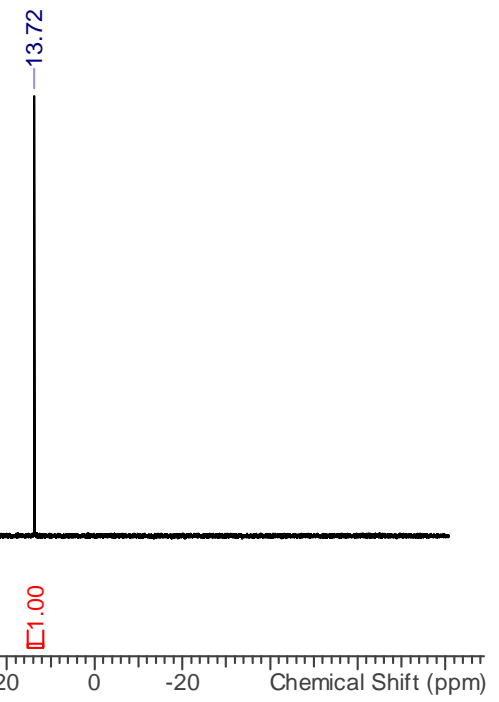


Ethoxy\{4-[(4-methyl-3-\{[4-(pyridin-3-yl)pyrimidin-2-yl]amino\}phenyl)carbamoyl]phenyl\}phosphinic Acid (45b)

${ }^{1} \mathrm{H}-\mathrm{NMR}$<smiles>CCOP(=O)(O)c1ccc(C(=O)Nc2ccc(C)c(Nc3nccc(-c4cccnc4)n3)c2)cc1</smiles>

$45 b$

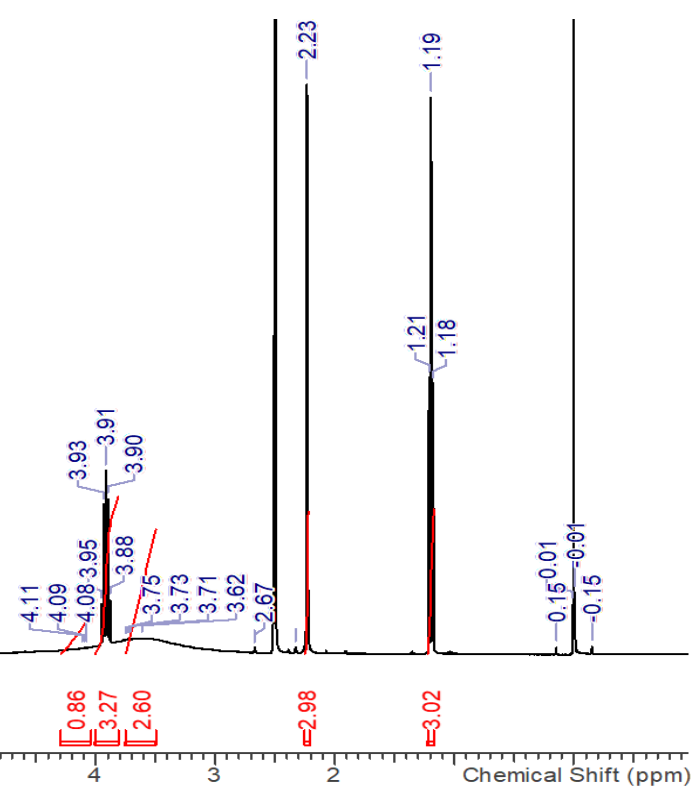

${ }^{13} \mathrm{C}-\mathrm{NMR}$<smiles>CCOP(=O)(O)c1ccc(C(=O)Nc2ccc(C)c(Nc3nccc(-c4cccnc4)n3)c2)cc1</smiles>

$45 b$

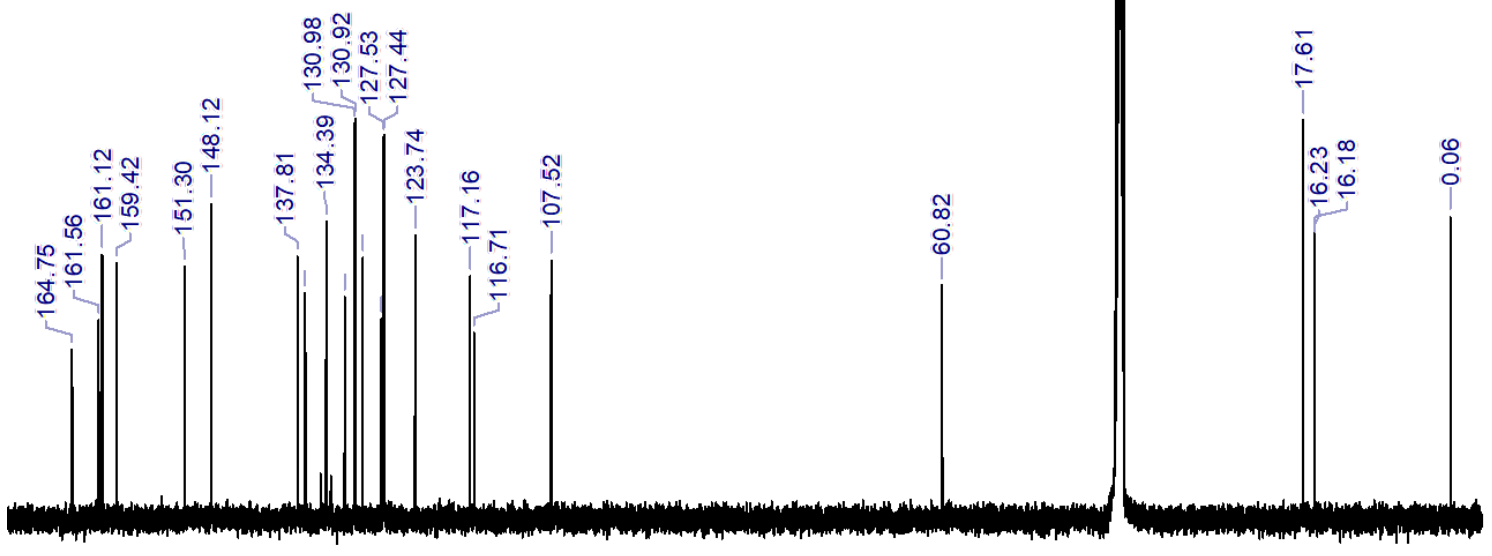

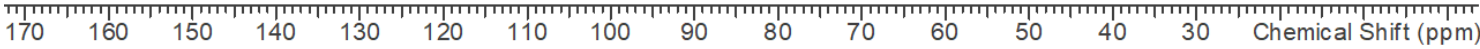


${ }^{31} \mathrm{P}-\mathrm{NMR}$<smiles>CCOP(=O)(O)c1ccc(C(=O)Nc2ccc(C)c(Nc3nccc(-c4cccnc4)n3)c2)cc1</smiles>

$45 b$

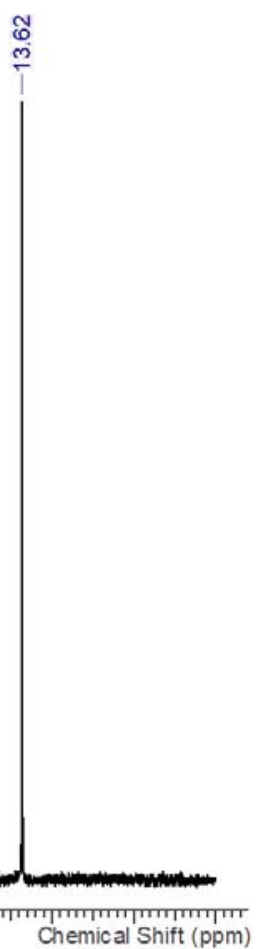

\section{\{4-[(4-Methyl-3-\{[4-(pyridin-3-yl)pyrimidin-2-yl]amino\}phenyl)carbamoyl]phenyl\}phosphonic} Acid (45c)

${ }^{1} \mathrm{H}-\mathrm{NMR}$<smiles>Cc1ccc(NC(=O)c2ccc(P(=O)(O)O)cc2)cc1Nc1nccc(-c2cccnc2)n1</smiles>

$45 \mathrm{c}$

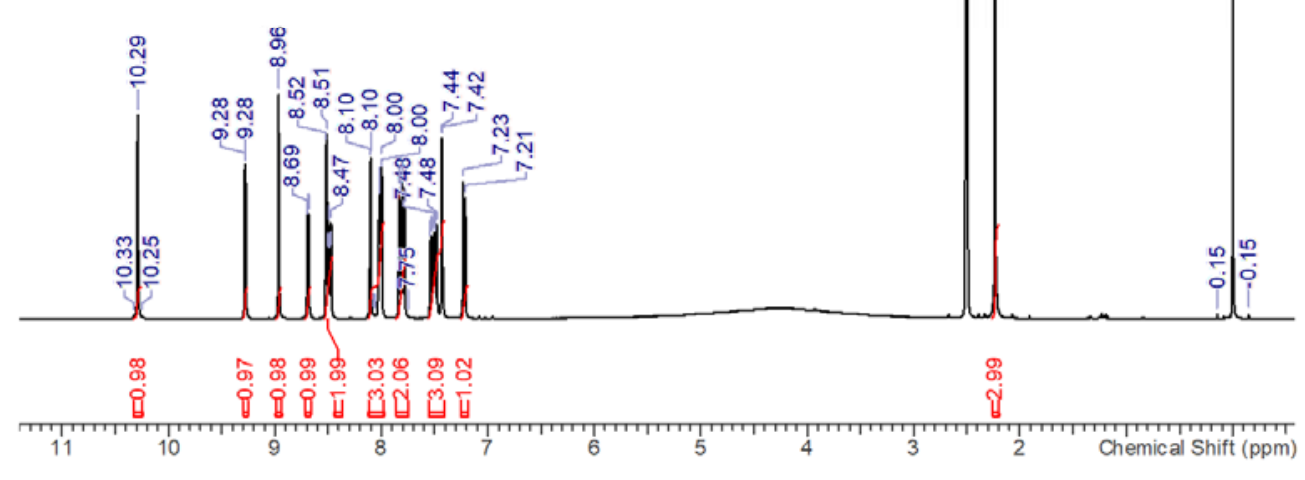


${ }^{13} \mathrm{C}-\mathrm{NMR}$<smiles>Cc1ccc(NC(=O)c2ccc(P(=O)(O)O)cc2)cc1Nc1nccc(-c2cccnc2)n1</smiles>

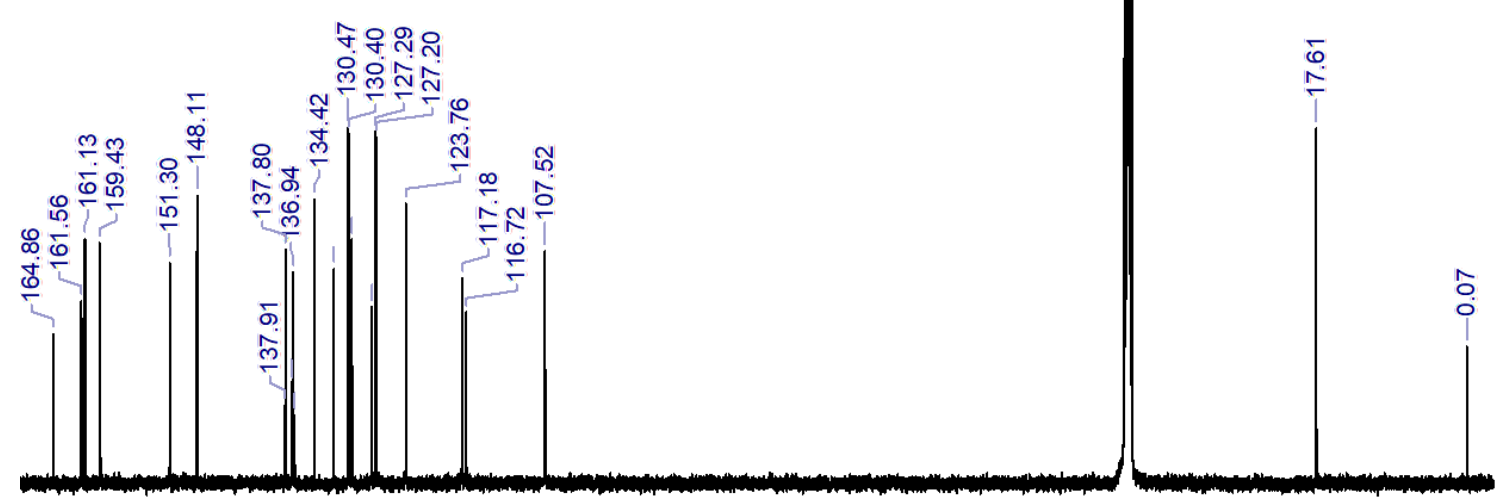

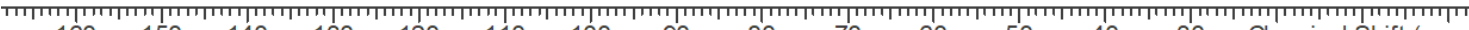

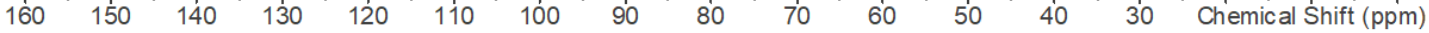

${ }^{31} \mathrm{P}-\mathrm{NMR}$<smiles>Cc1ccc(NC(=O)c2ccc(P(=O)(O)O)cc2)cc1Nc1nccc(-c2cccnc2)n1</smiles>

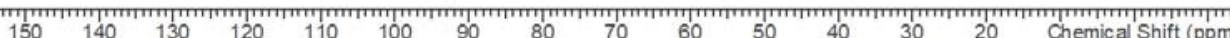




\section{1-Methyl-1,4i5-azaphosphinan-4-one (47b)}

${ }^{1} \mathrm{H}-\mathrm{NMR}$<smiles>CN1CC[AsH2]P1</smiles>

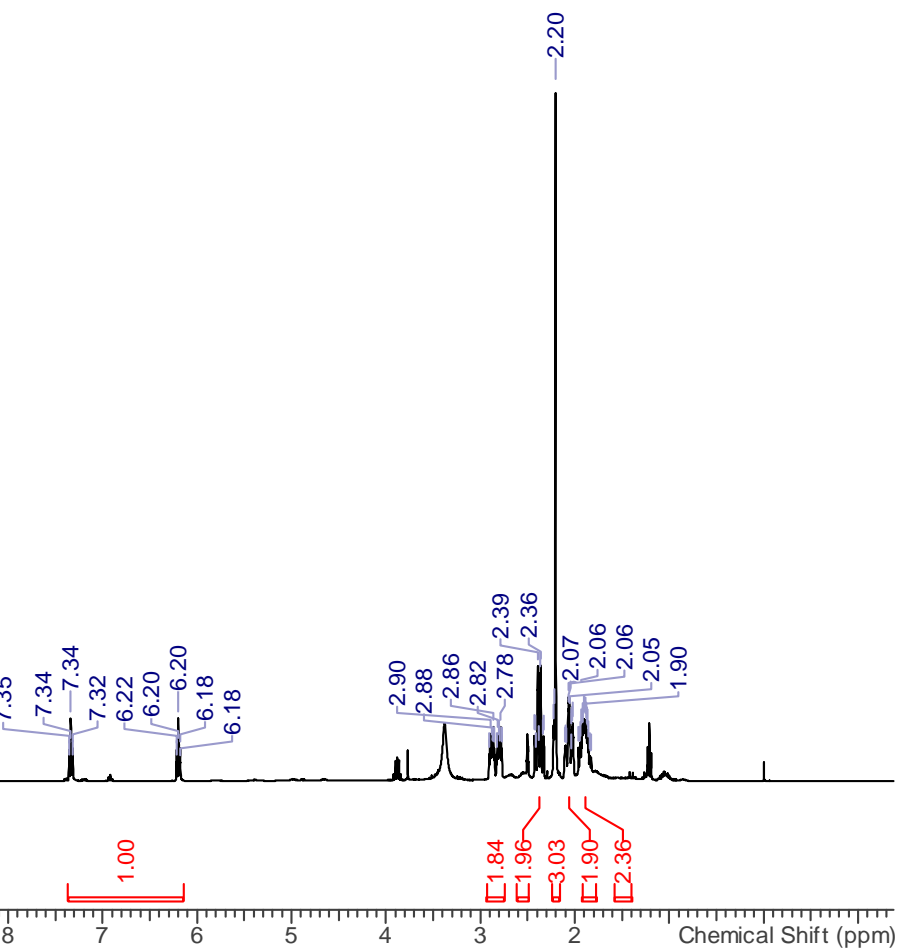

${ }^{13} \mathrm{C}-\mathrm{NMR}$

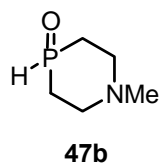

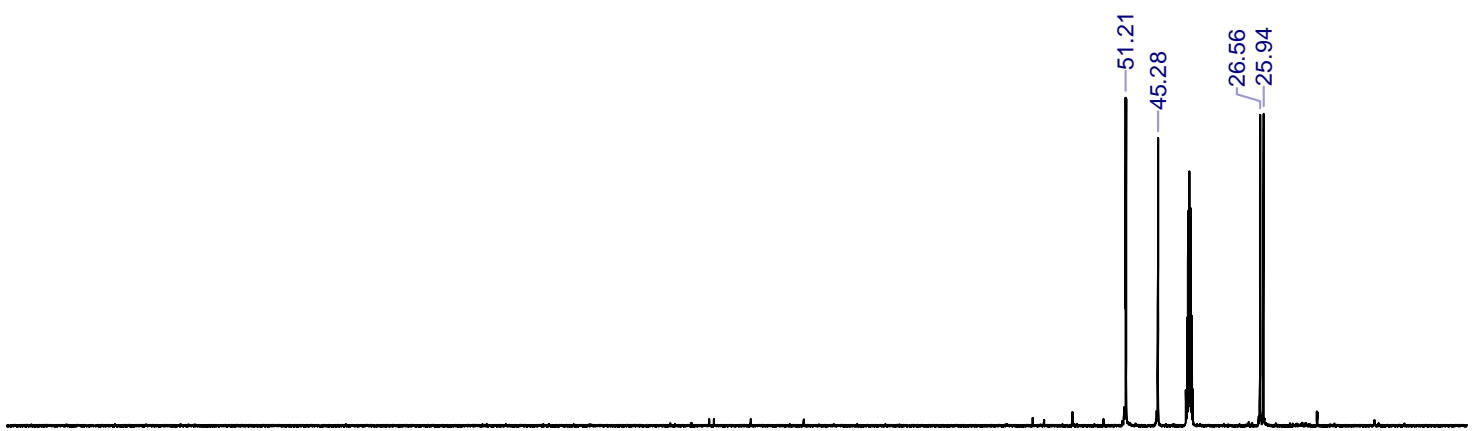

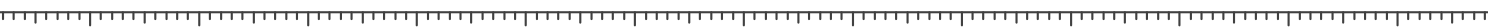

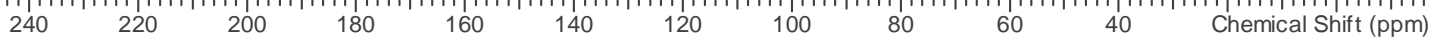


${ }^{31}$ P-NMR<smiles>CN1CC[Pb](=O)CC1</smiles>

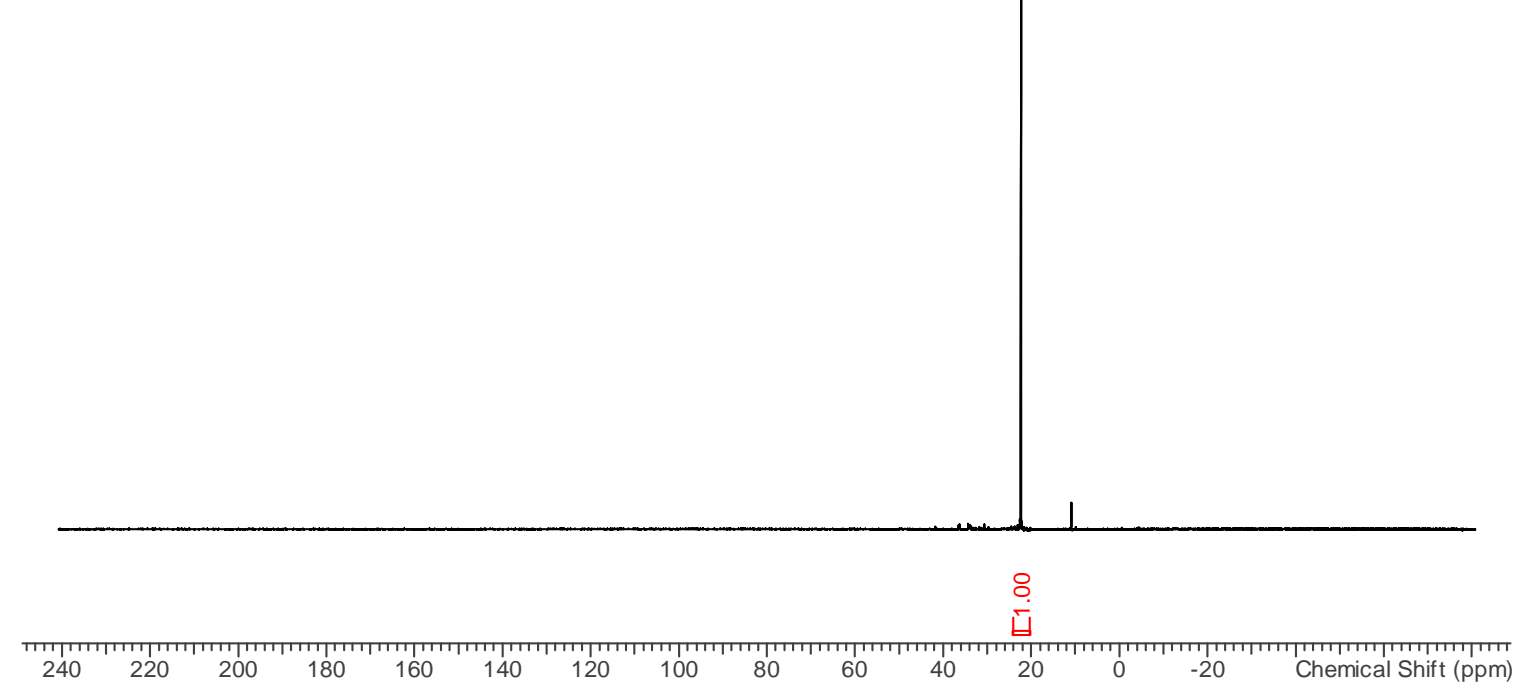

\section{1-Benzyl-4-[4-(trifluoromethyl)phenyl]-1,4 $\lambda^{5}$-azaphosphinan-4-one (48)}

${ }^{1} \mathrm{H}-\mathrm{NMR}$
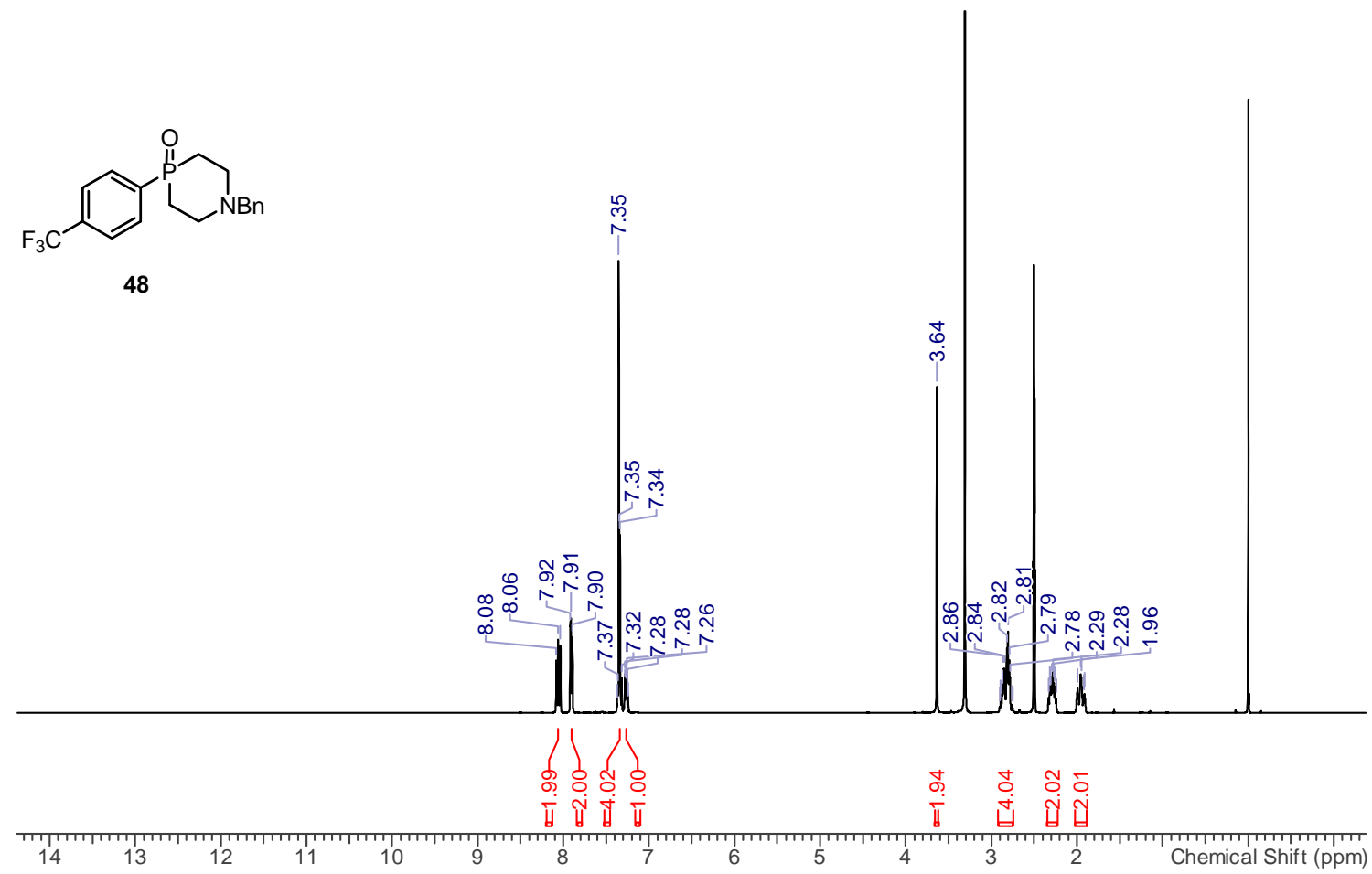
Tert-butyl 2-Oxo-2-[4-(trifluoromethyl)phenyl]-1,3,6,2 $2 \lambda^{5}$-dioxazaphosphocan-6-carboxylate (50)

${ }^{1}$ H-NMR

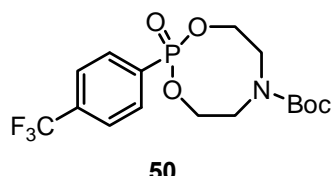

50
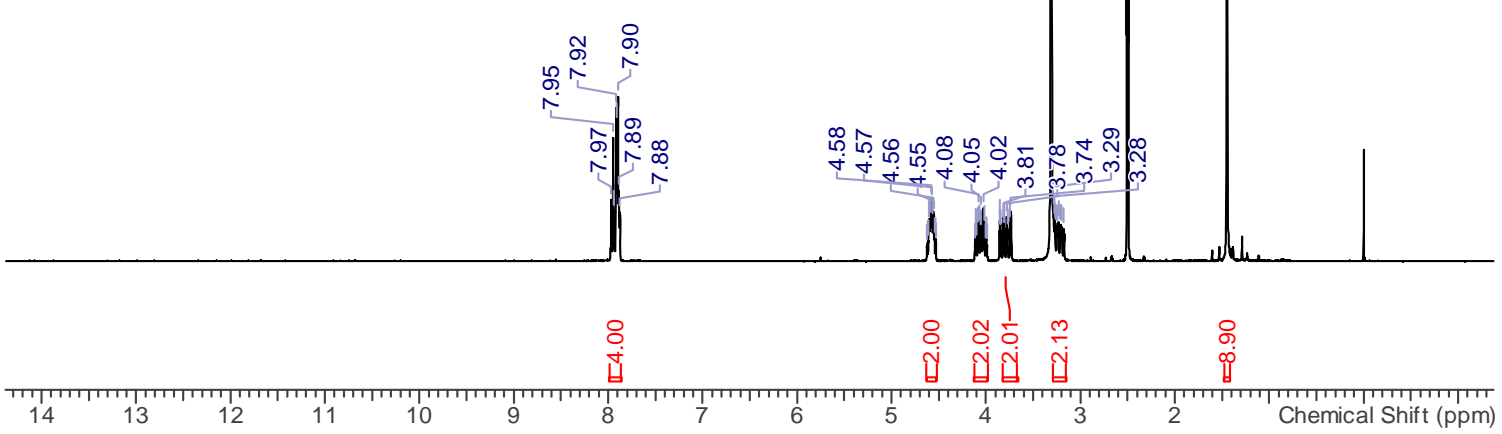

${ }^{13} \mathrm{C}-\mathrm{NMR}$<smiles>CC(C)(C)OC(=O)N1CCOP(=O)(c2ccc(C(F)(F)F)cc2)OCC1</smiles>

50

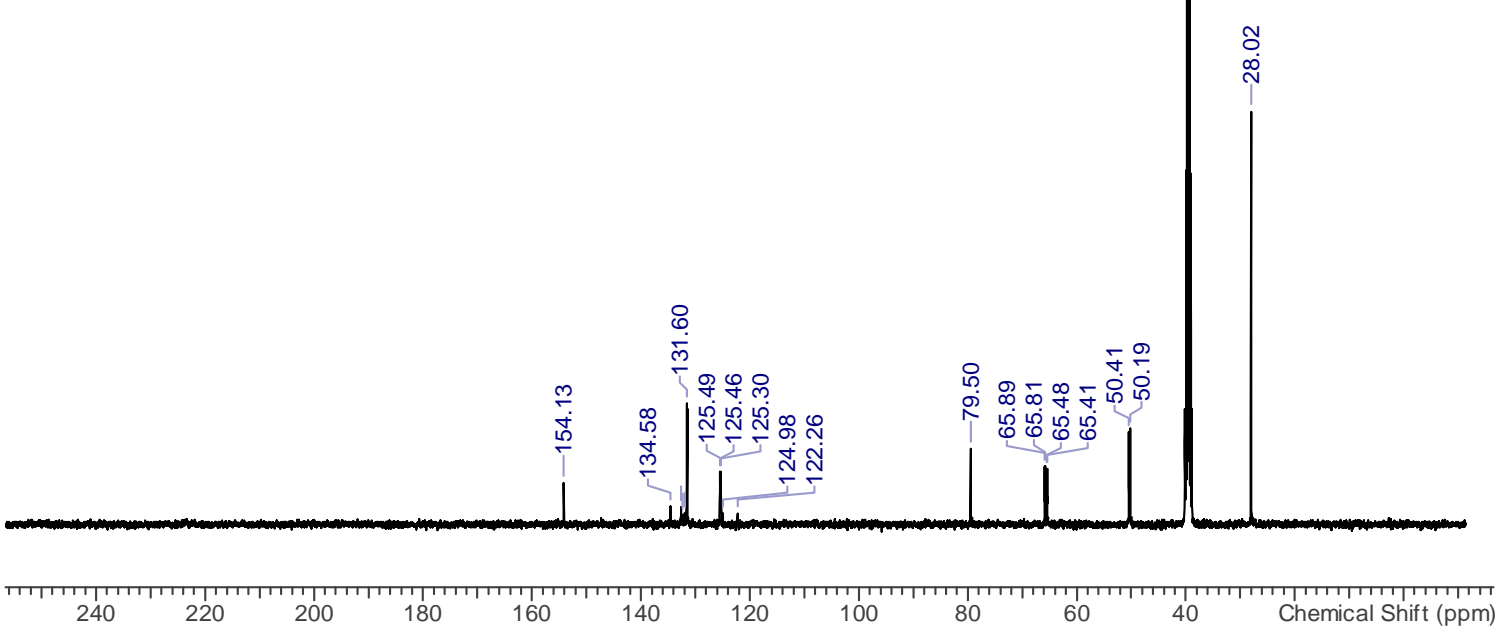


${ }^{31} \mathrm{P}-\mathrm{NMR}$

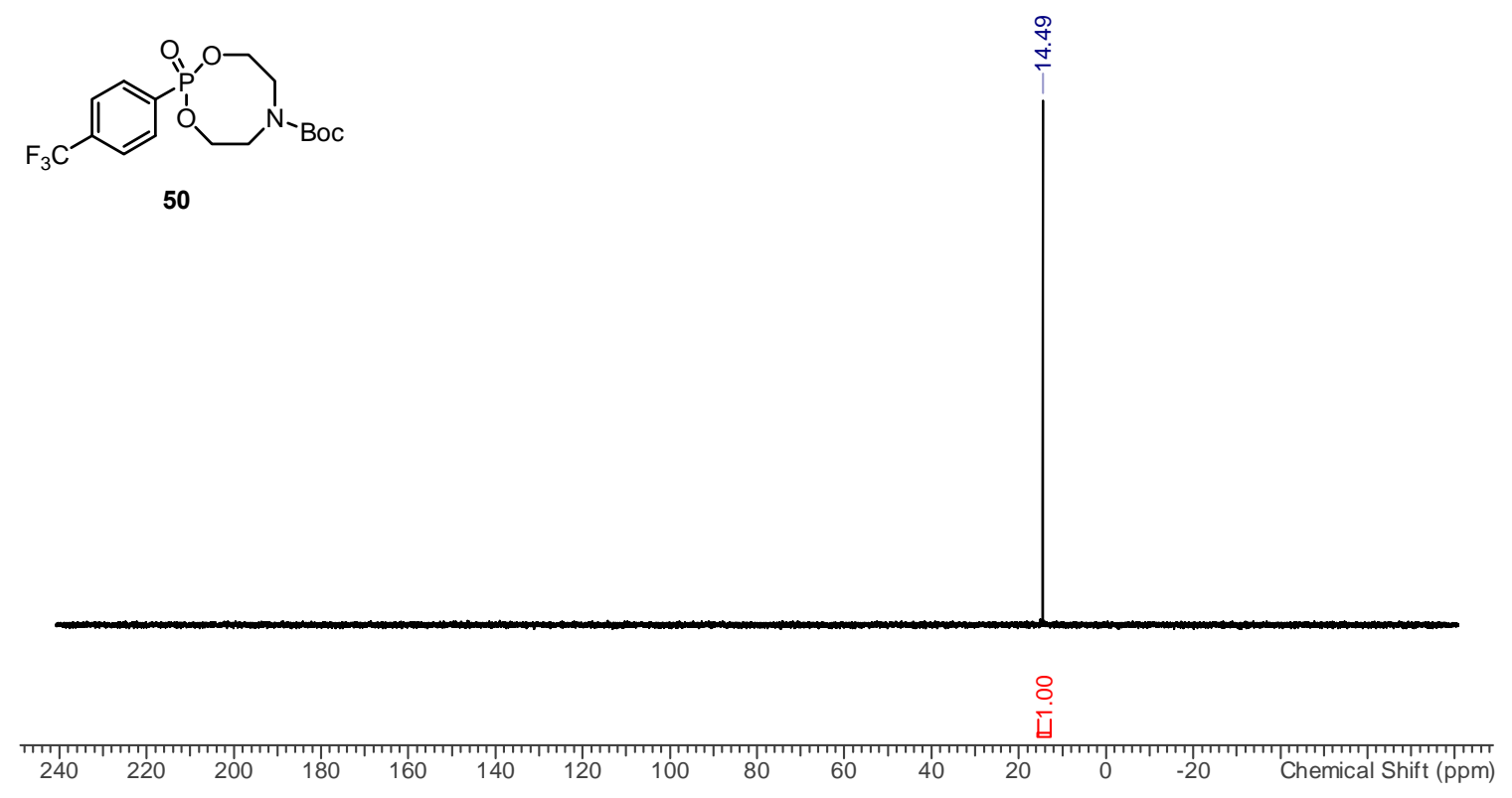

